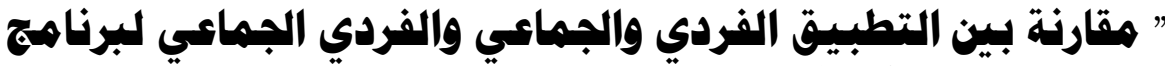

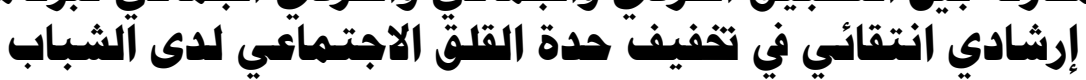 الجأمعي بألمهاكة العربية السعودية الاجتية
}

د/ أحمل محمل عبل الحميل

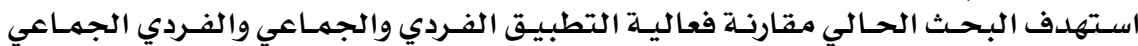

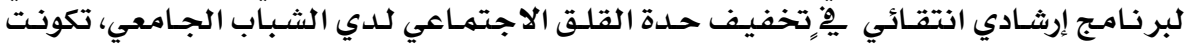

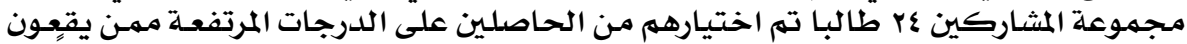

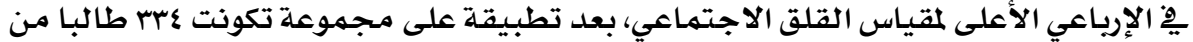

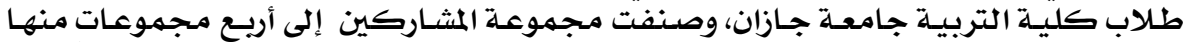

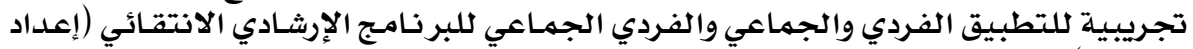

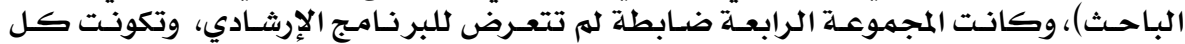

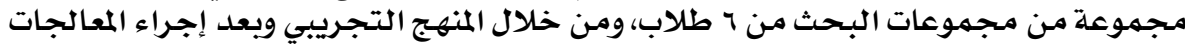

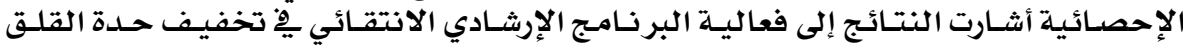

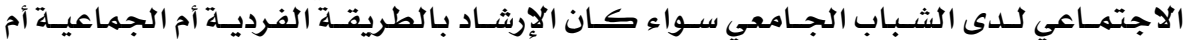

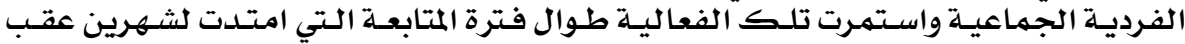

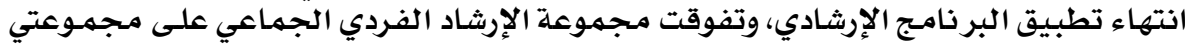

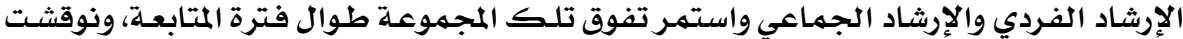

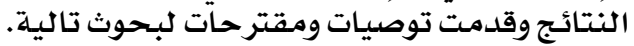

الكلمات المفتاحية: الإرثماد الفردي ـ الإرثماد الجماعي ـ القلق الاجتماعي ـ برنامـج إرثمادي

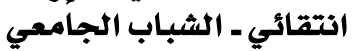

A Comparison of the Application of Individual or Group or Individual Group Eclectic Counselling Program to Alleviate Social Anxiety Among University Youth in Saudi Arabia

\section{Dr. Ahmed Mohamed Abdel-Hamid}

\section{Abstract:}

The current research aimed to compare the application of individual or group or individual group eclectic counselling program to alleviate social anxiety among university youth, formed group of participants 24 students were selected from those with high grades who fall in Alarbai top of the scale of social anxiety, after its application to formed 334 student groups students from the Faculty of Education, Jazan University and classified group of participants into four groups, including experimental individual, group and individual group eclectic counselling program (prepared by the researcher), and the control group was the fourth officer was not exposed indicative Program, and formed each of the research groups of 6 students, and through Experimental method, after conducting statistical treatments results showed the effectiveness of the individual or group or individual group eclectic counselling program to alleviate social anxiety among university students, and continued those efficiency throughout the follow-up

\section{V9}

\section{دراسات عربية في التزبية وعلم النفس (ASEP)}




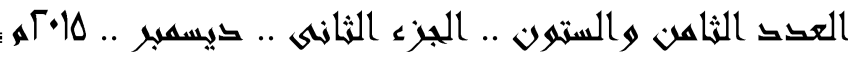

period, which lasted for two months after the end of the application of the counseling program, and Individual group counseling set outperformed the two sets of individual counseling set and group counseling set and continued superiority of the group throughout the follow-up period, and the results were discussed and made recommendations and suggestions for the next research

\section{Key words: individual counseling - group counseling - social anxiety- eclectic counselling program - university youth}

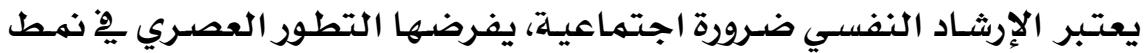

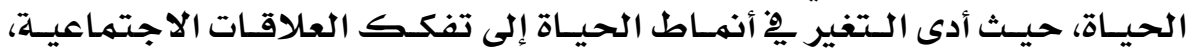

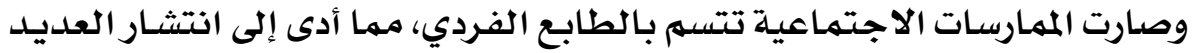

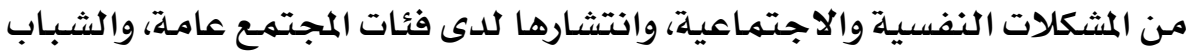
الجامعي بصفة خاصلة.

وتسعى خلدمات الإرشاد النفسي إلى مساعدة الإنسـان باعتبـاره فرداً، ومواطناً،

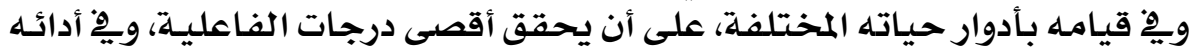

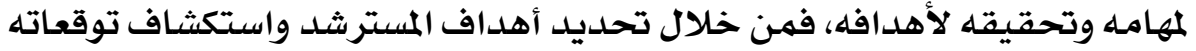

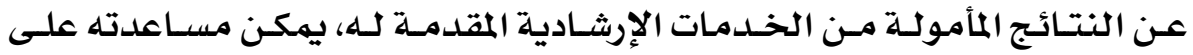

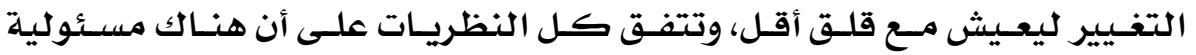

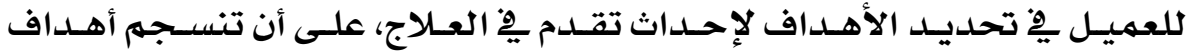

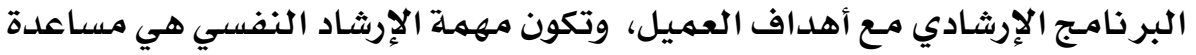

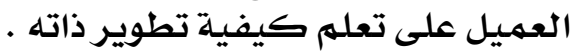

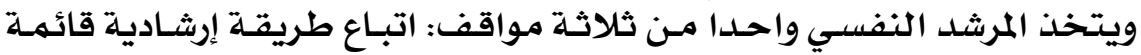

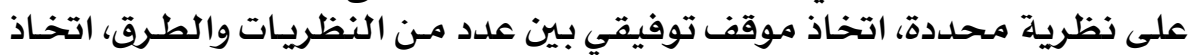

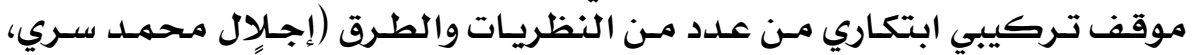

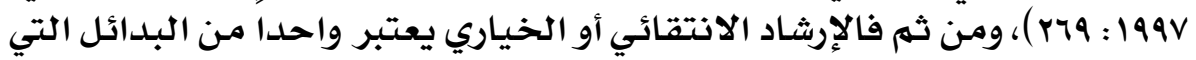

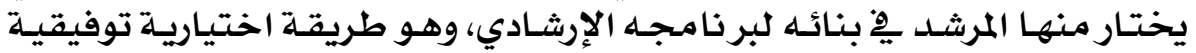

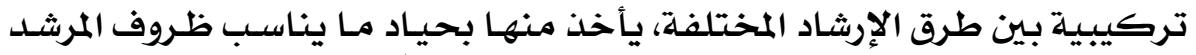

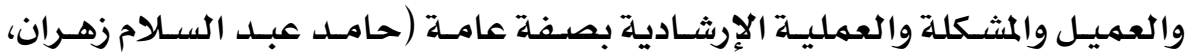

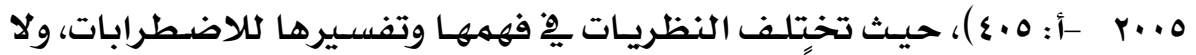

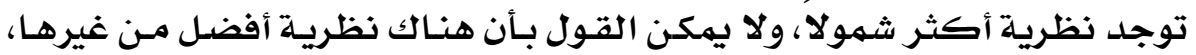

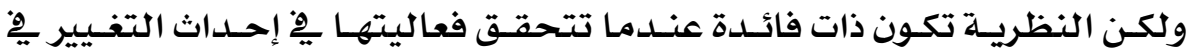

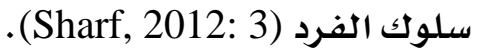

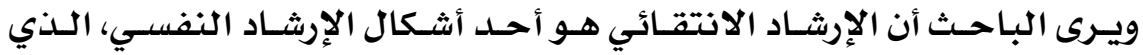

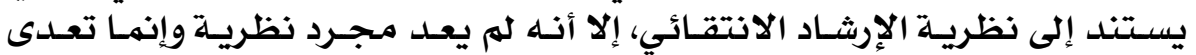

\section{$\Lambda$}




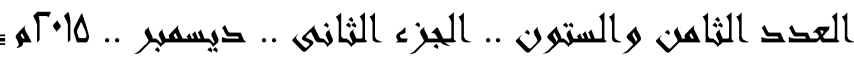

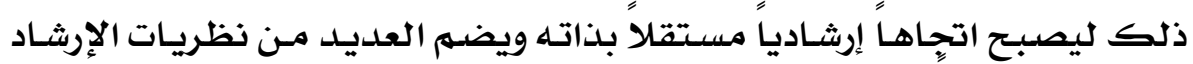

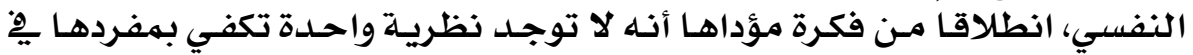

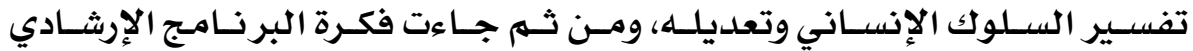

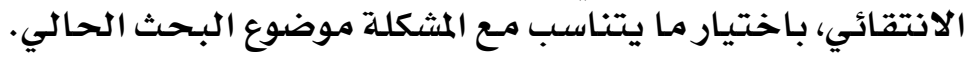

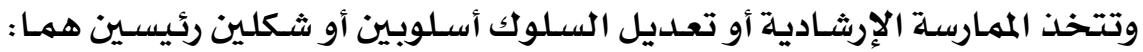

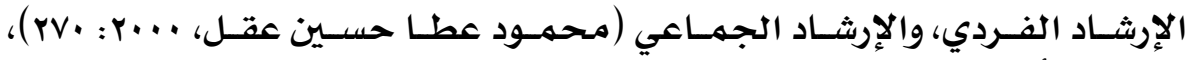

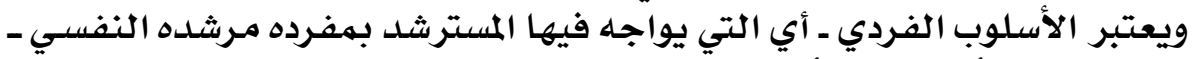

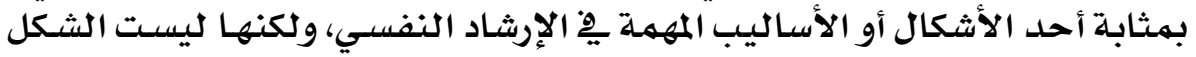

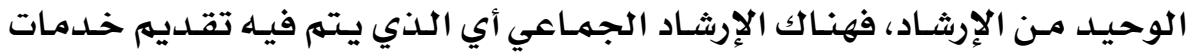

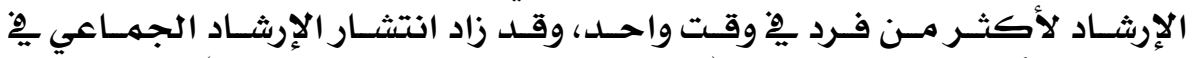

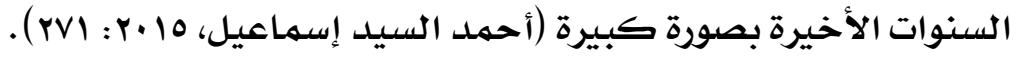

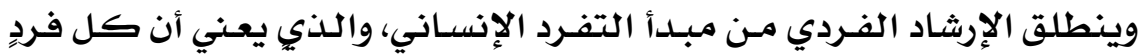

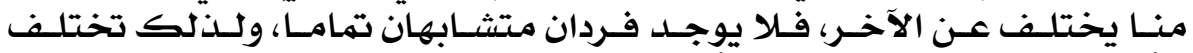

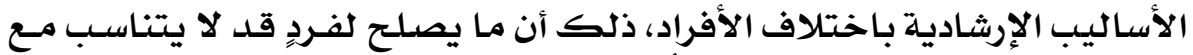

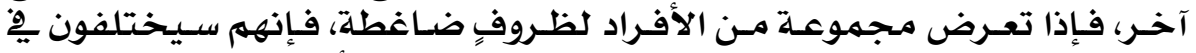

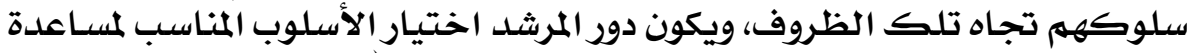

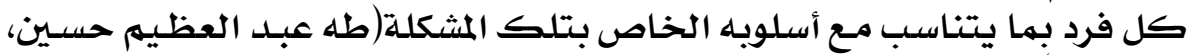

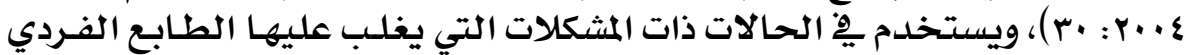

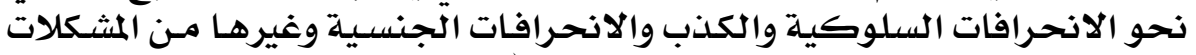

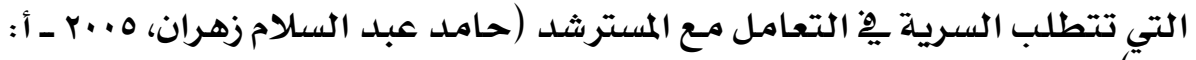
التي

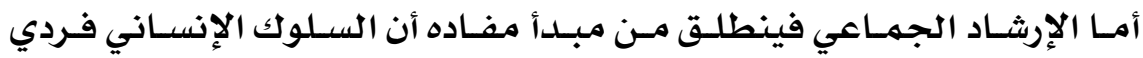

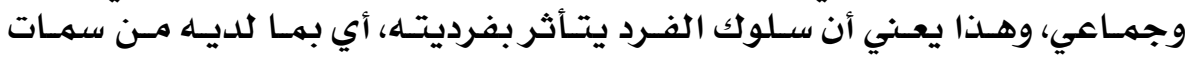

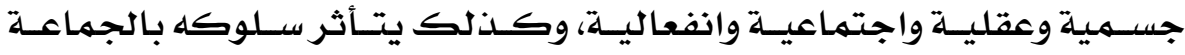

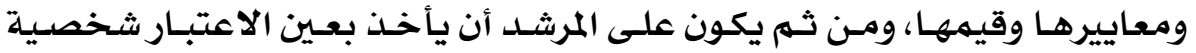

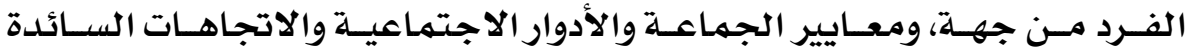

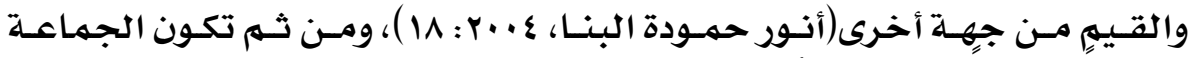

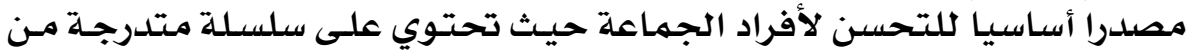

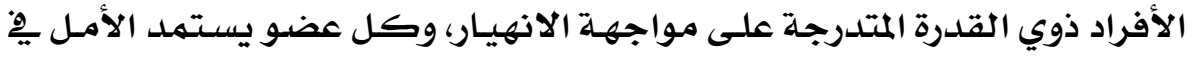

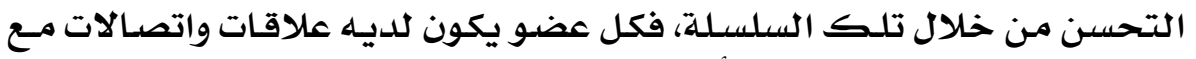

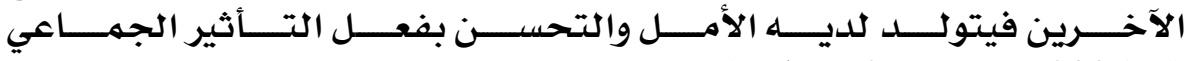
(Yalom \& Leszcz , 2005: 5)

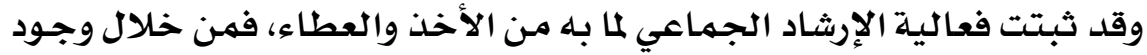

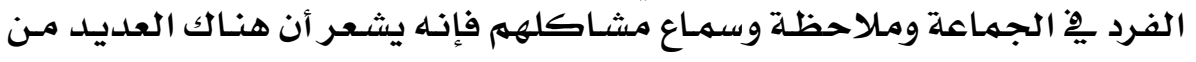

\section{$\Lambda 1$}




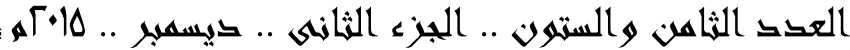

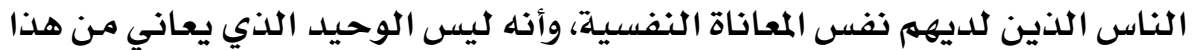

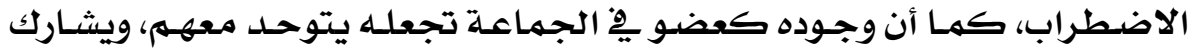

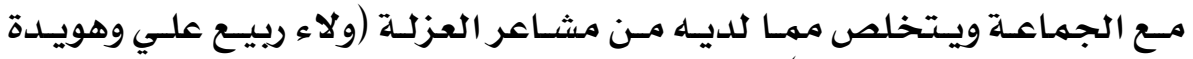

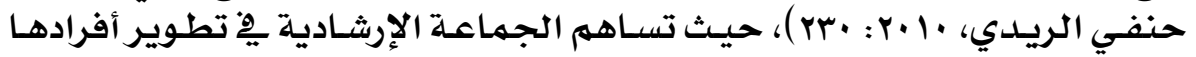

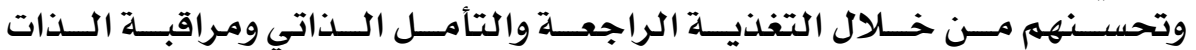

(Yalom \& Leszcz, 2005:48)

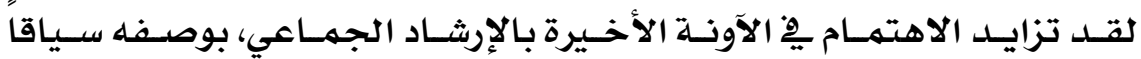

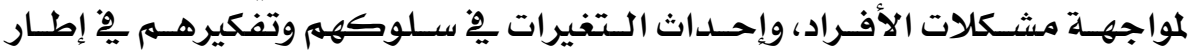

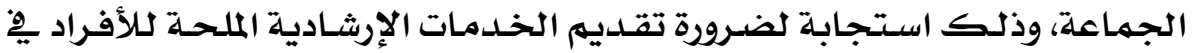

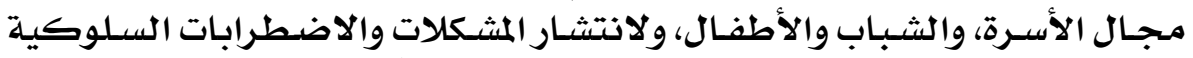

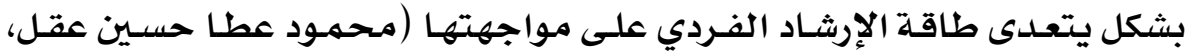

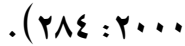

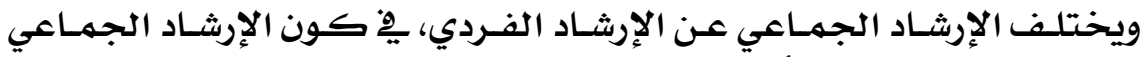

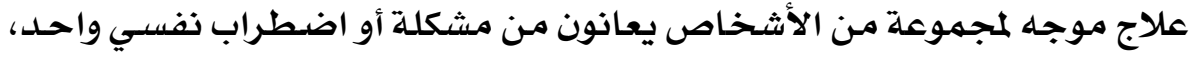

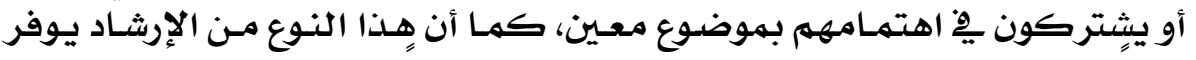

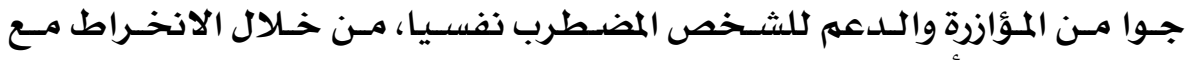

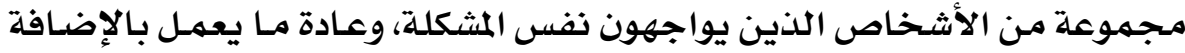

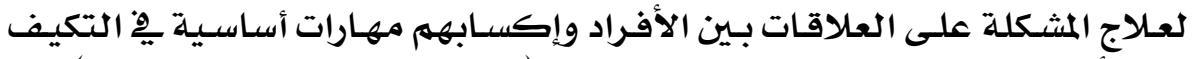

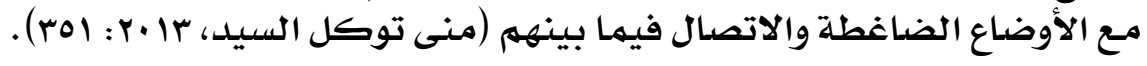

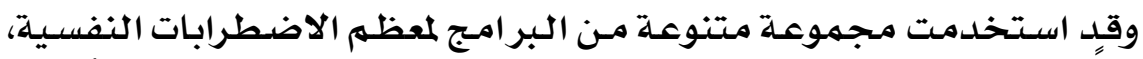

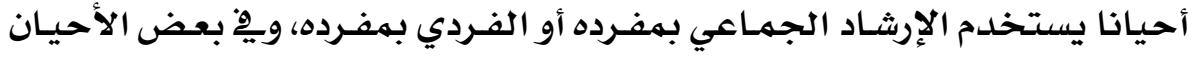

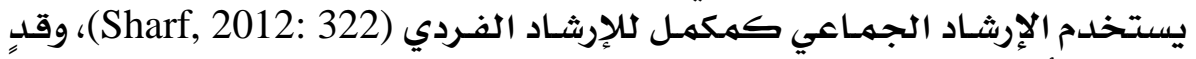

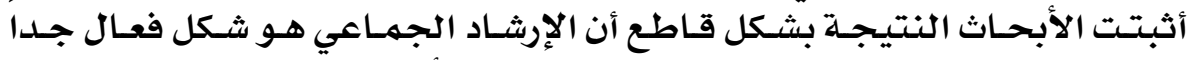

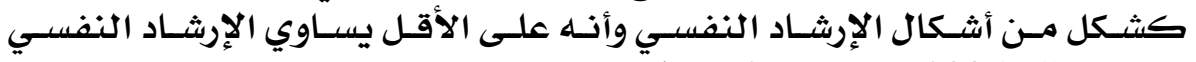

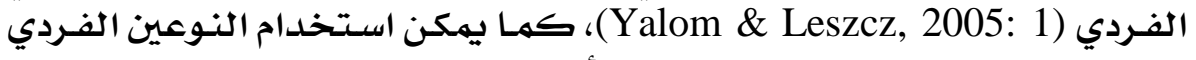

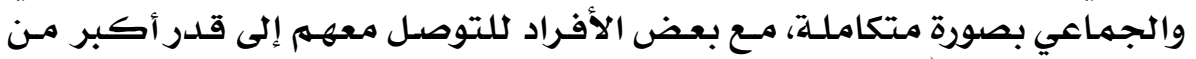

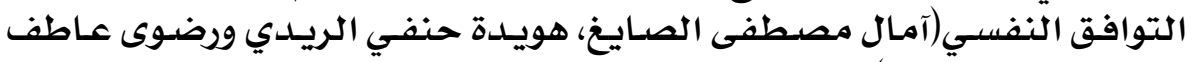

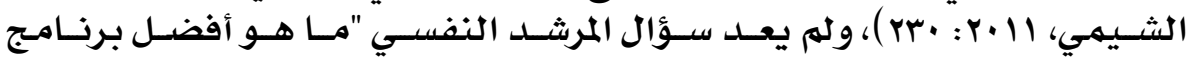

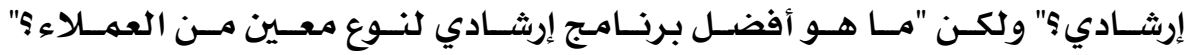
.(Sharf, 2012: 12)

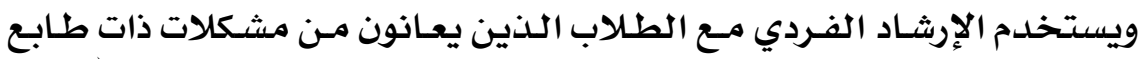

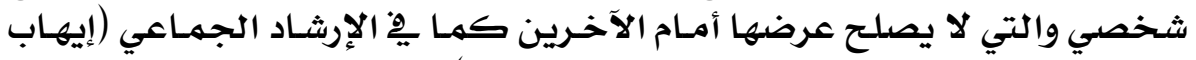

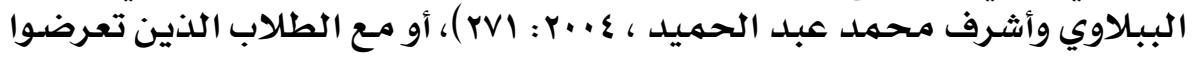

\section{$\Lambda Y$}




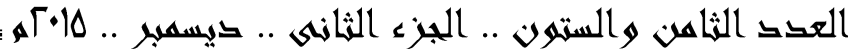

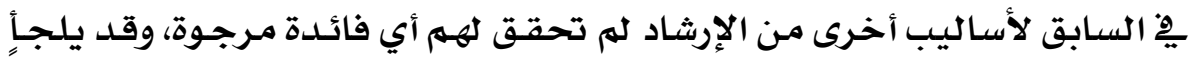

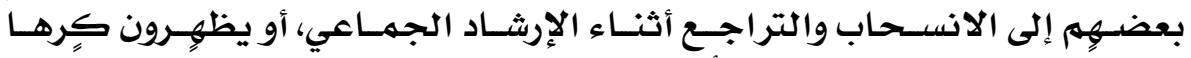

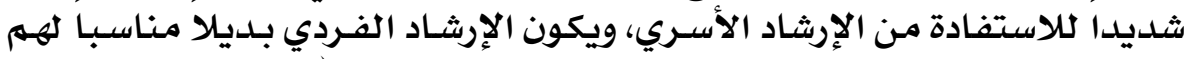

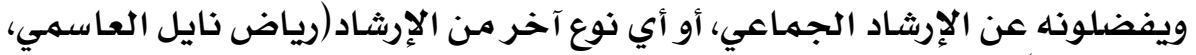
170: r 170)

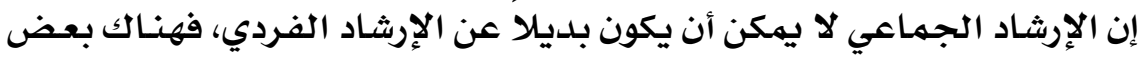

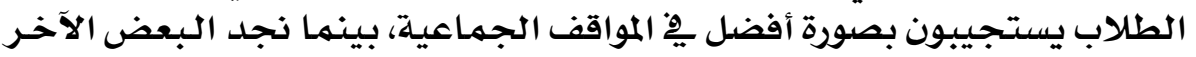

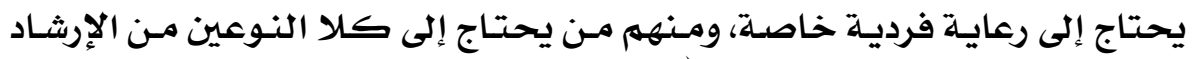

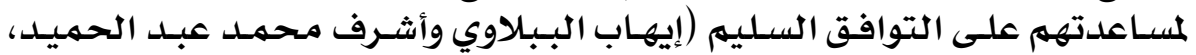

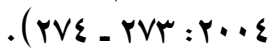

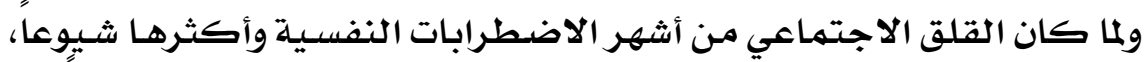

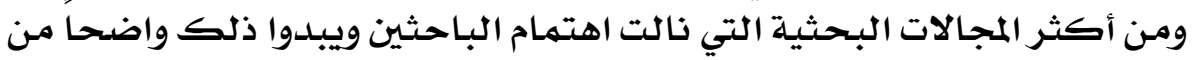

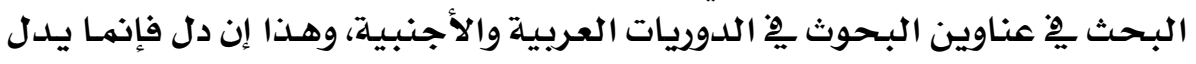

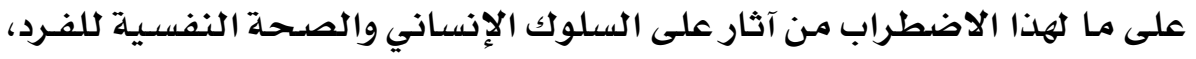

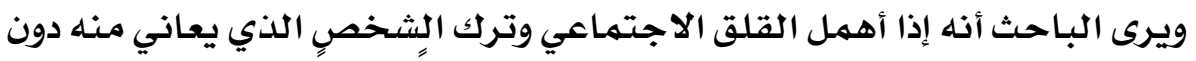

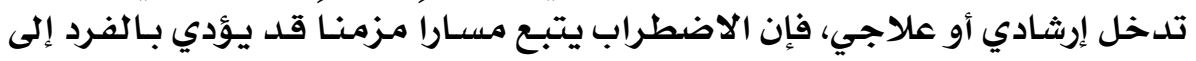

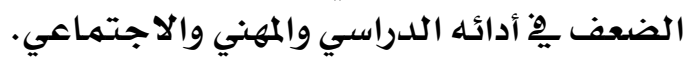

ويشير(Huang, Li, Li, Luo, Wang, Zhang, Gan \& Ji, 2013: 594) إلى واتي

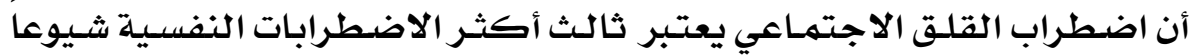

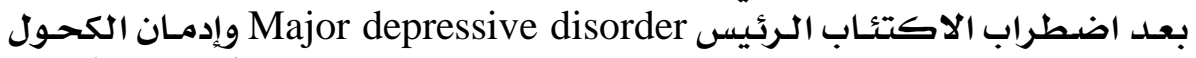
Alcohol dependence

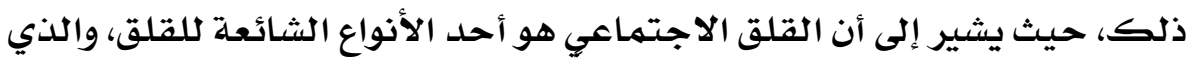

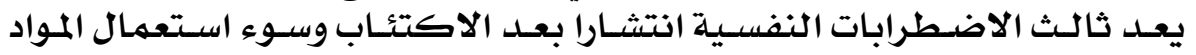

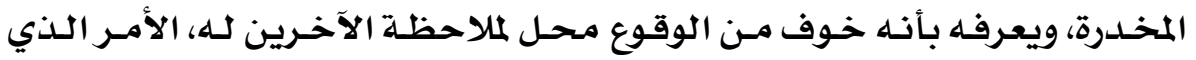

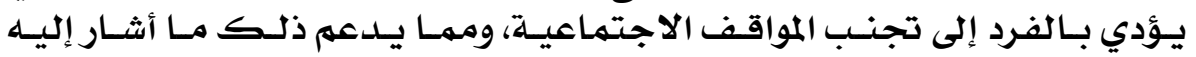
(Castella, Goldin, Jazaieri, Ziv, Heimberg , \& Gross, 2014: 139)

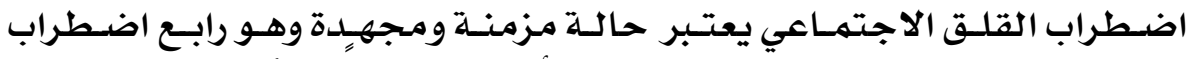

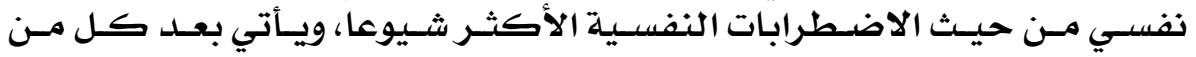

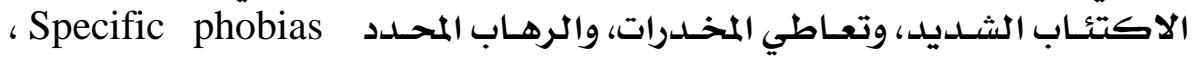

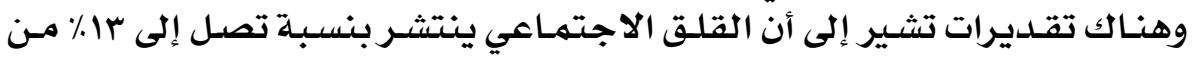

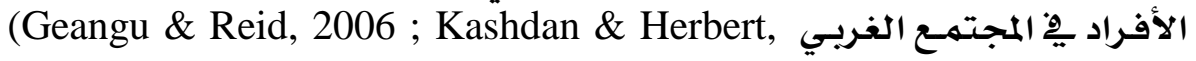

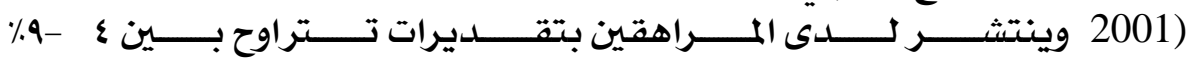

(Fisher, Masia_Warne, \& Klein, 2004: 241)

\section{$\Lambda \mathrm{r}$}




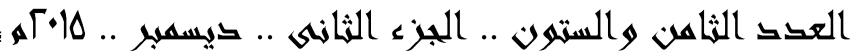

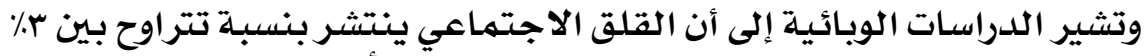

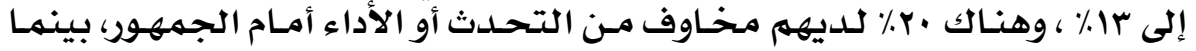

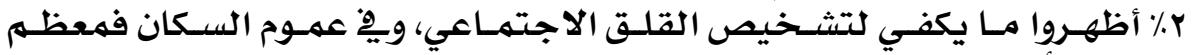

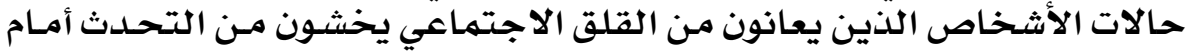

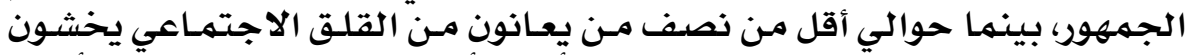

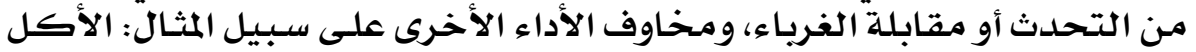

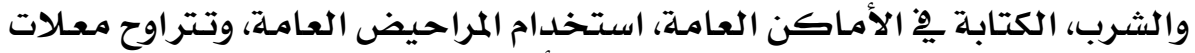

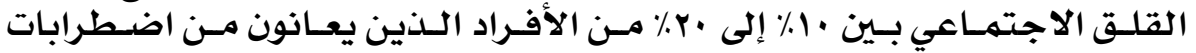
القلق (APA, 1994: 414)

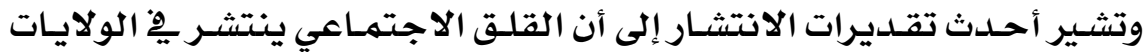

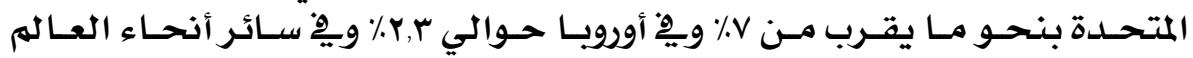

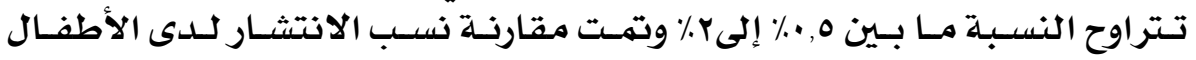

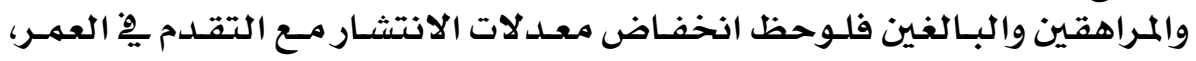

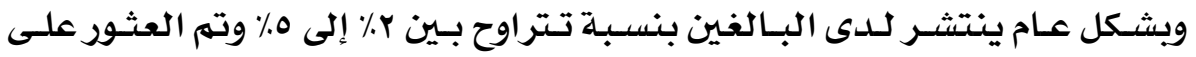

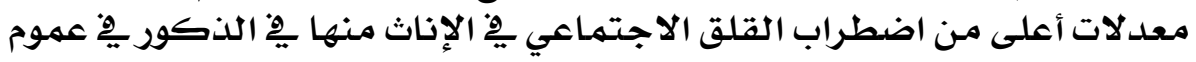

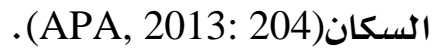

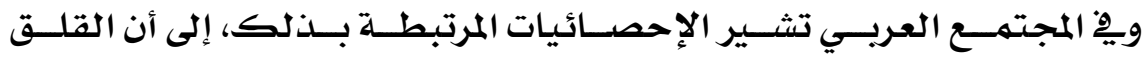

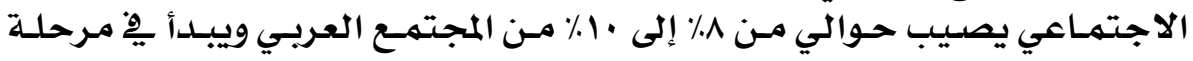

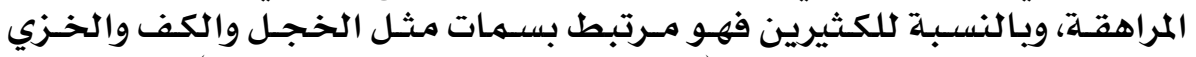

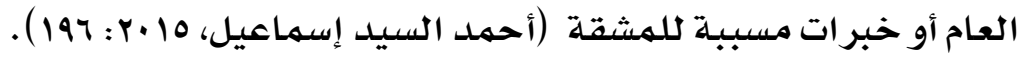

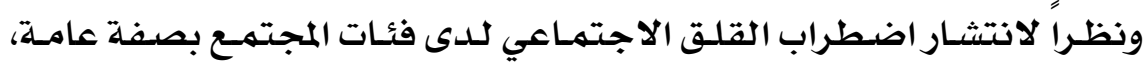

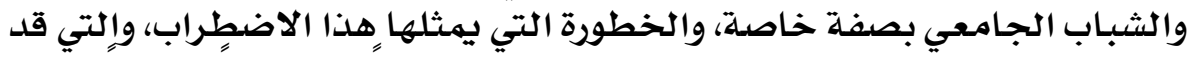

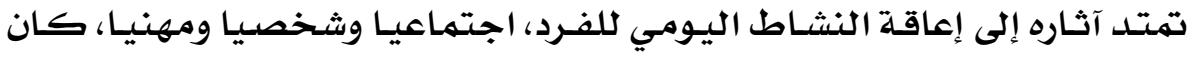

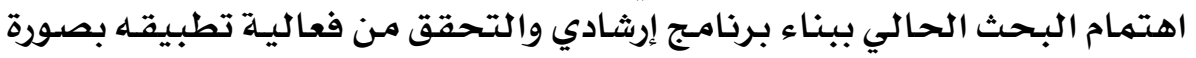

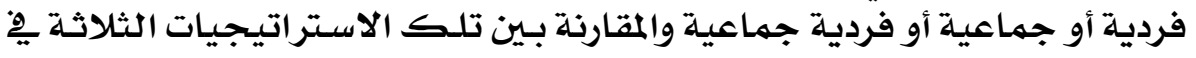

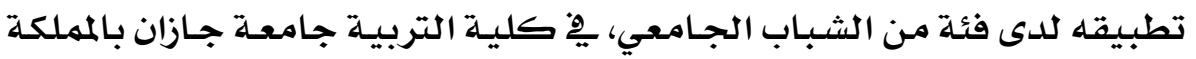

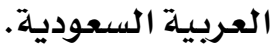

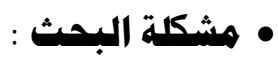

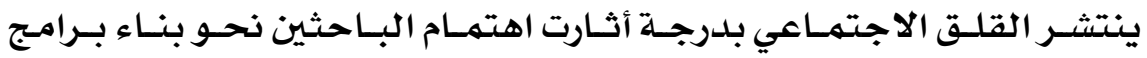

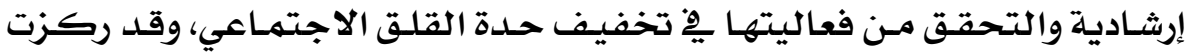

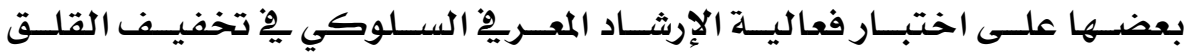

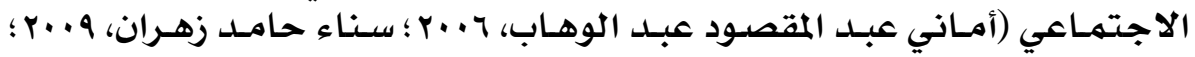

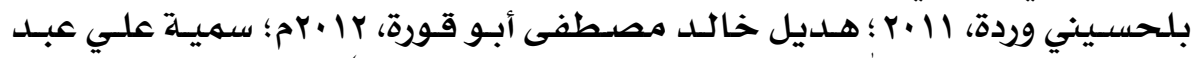

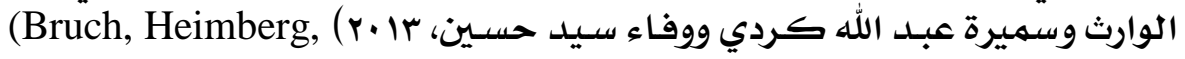

\section{$\Lambda \varepsilon$}




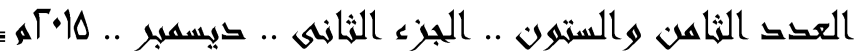

\& Hope, 1991; Baggen \& Kraaimaat, 2000; Wersebe, Sijbrandij \&

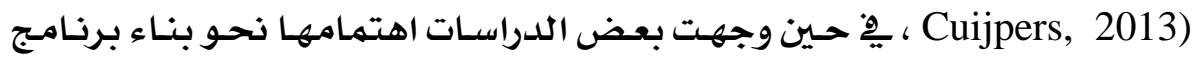

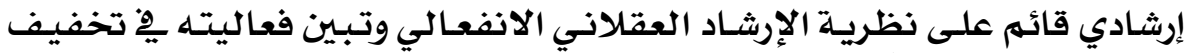

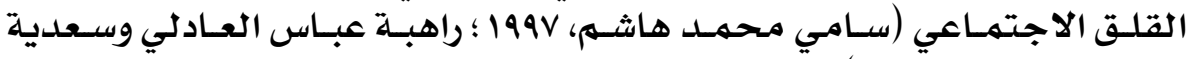

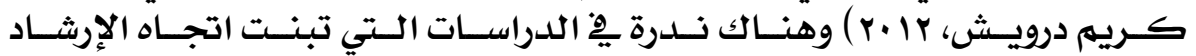

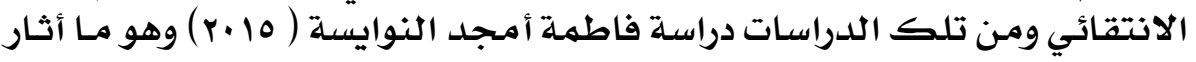

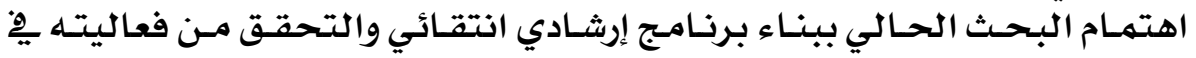

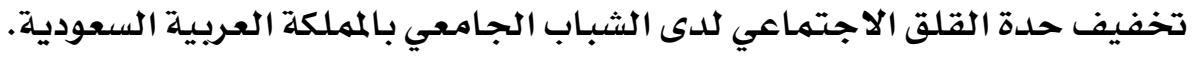

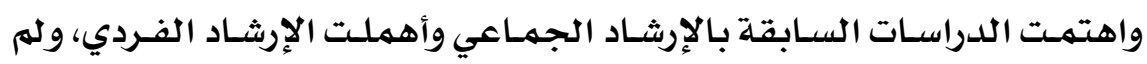

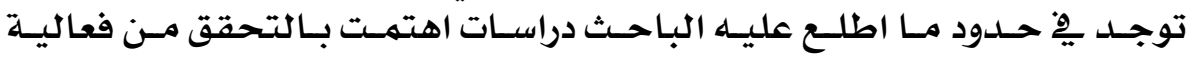

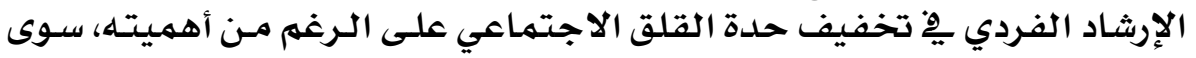

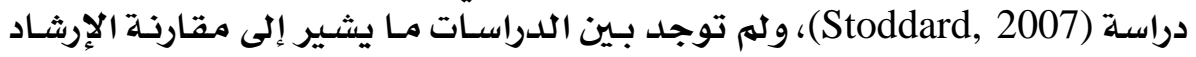

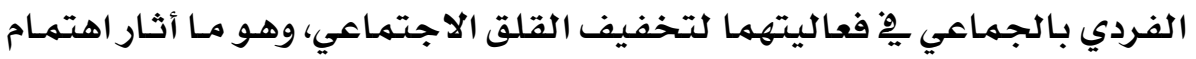

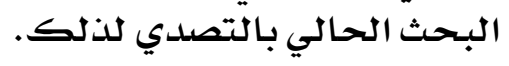

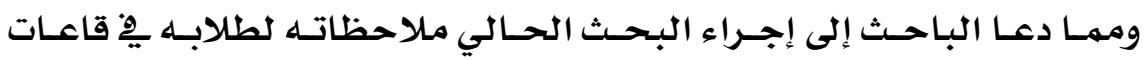

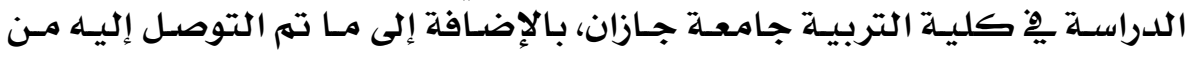

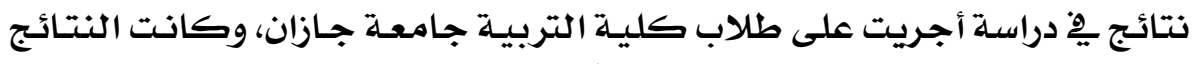

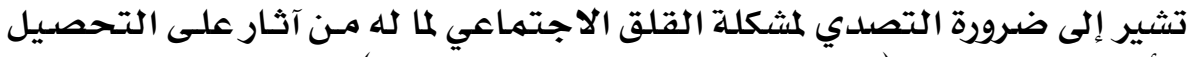

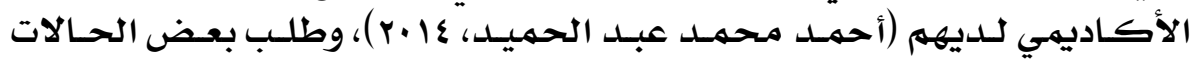

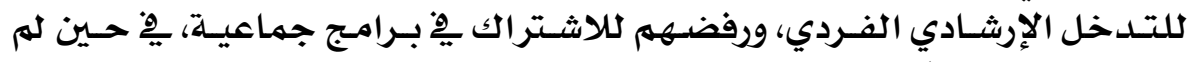

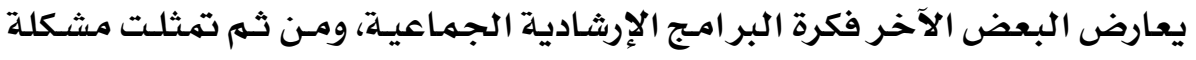

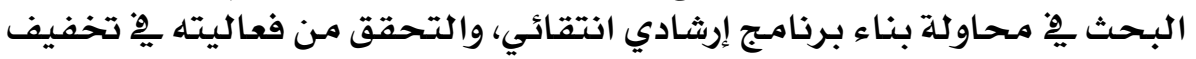

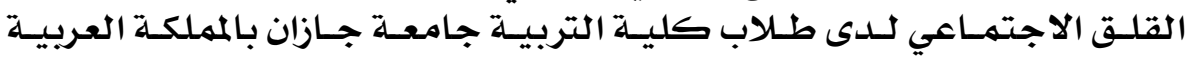

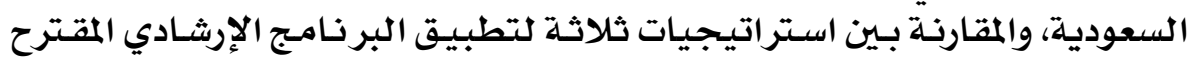

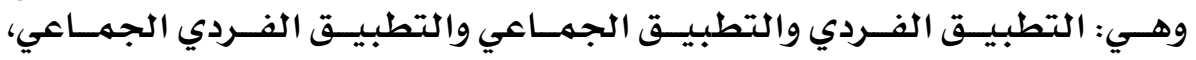

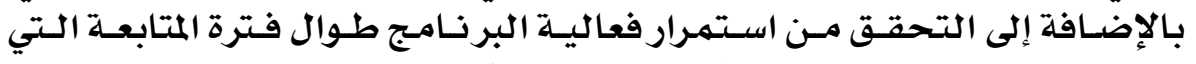

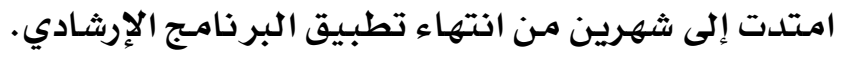

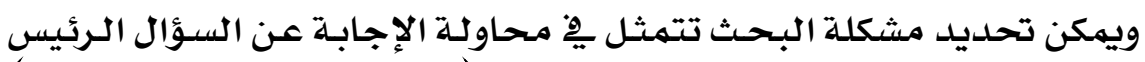

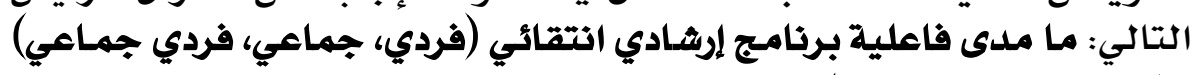

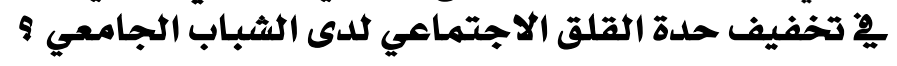

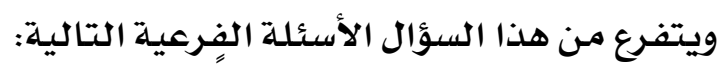

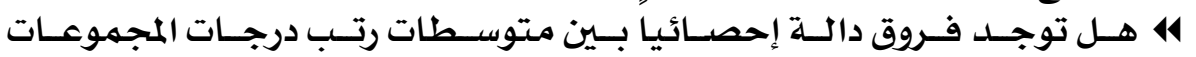

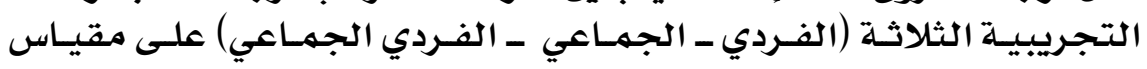

\section{$\Lambda \odot$}




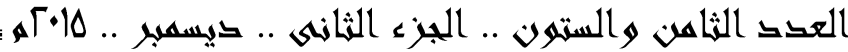

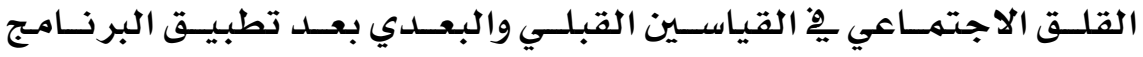
الإرشادي؟

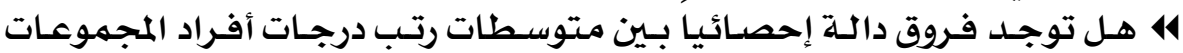

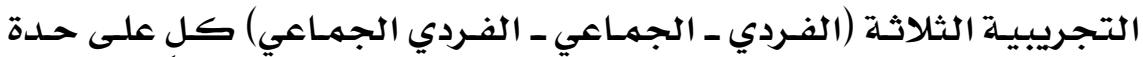

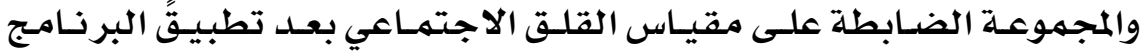
الإرشادي؟

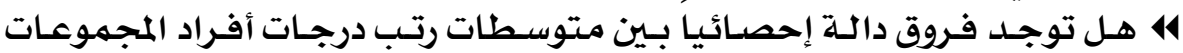

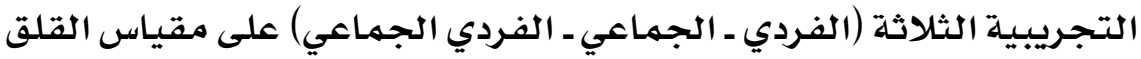

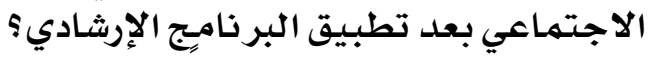

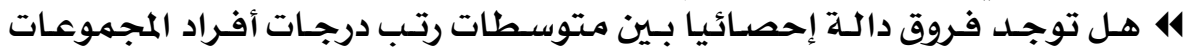

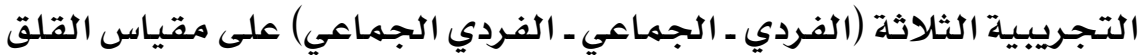

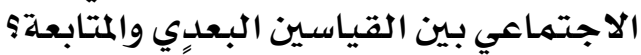

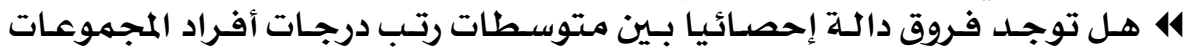

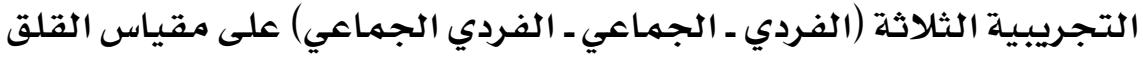

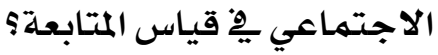

$$
\begin{aligned}
& \text { • أهداف البحث : }
\end{aligned}
$$

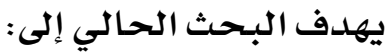

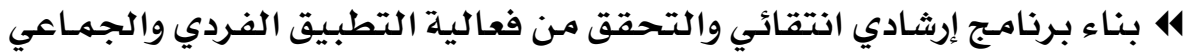

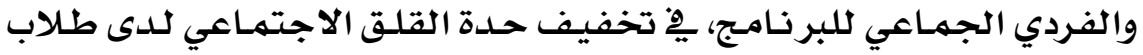

$$
\text { كلية التربية جامعامية جازان البرنان. }
$$

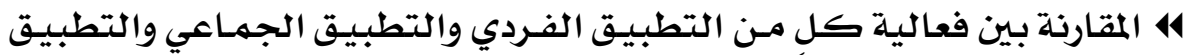

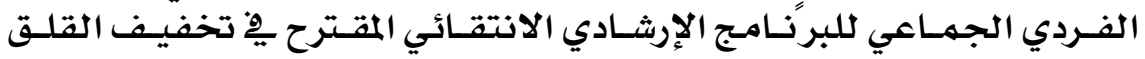

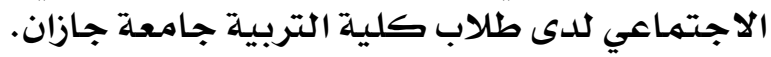

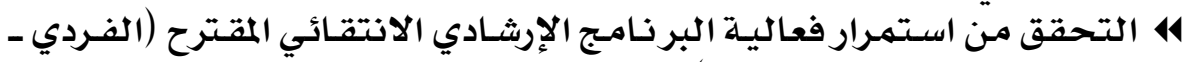

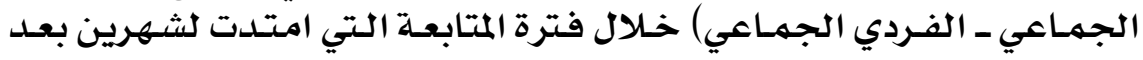

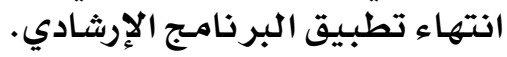

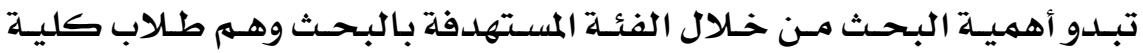

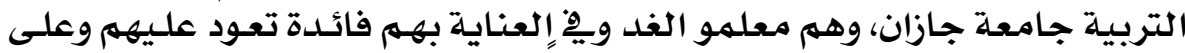

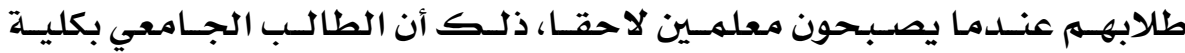

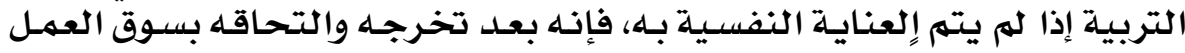

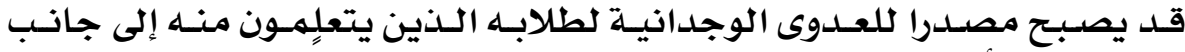

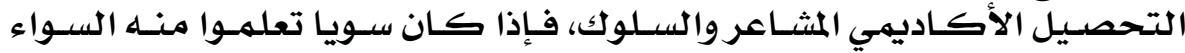

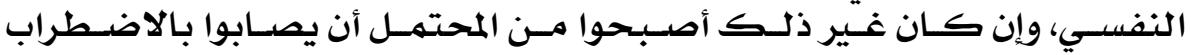

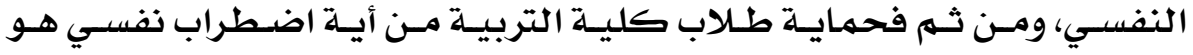

\section{$\Lambda 7$}




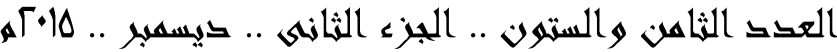

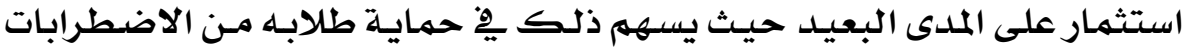
النفسية فيما بعلد الملدى البت

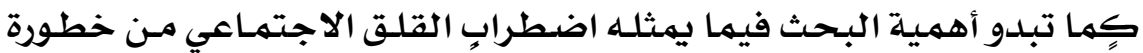

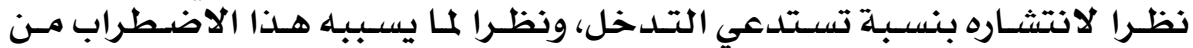

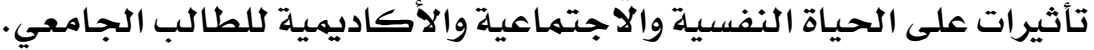

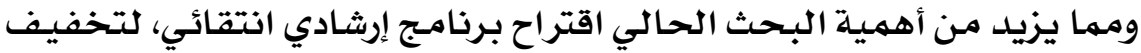

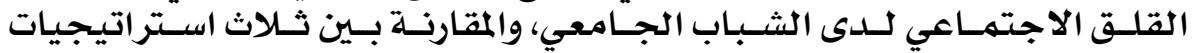

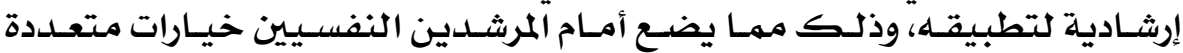

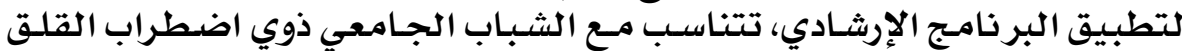

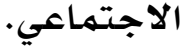

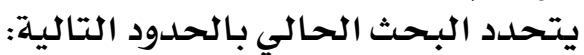

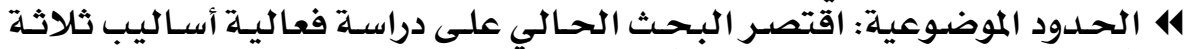

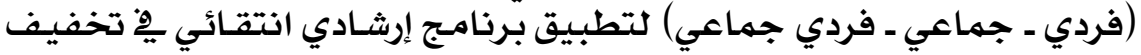

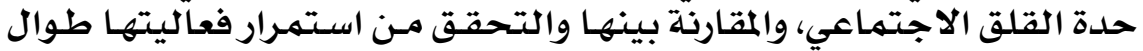

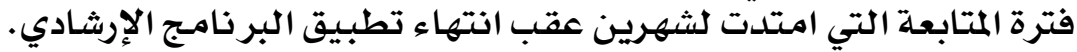

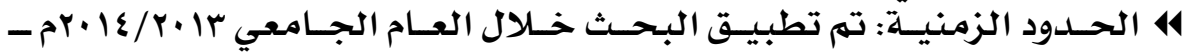

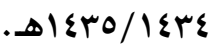

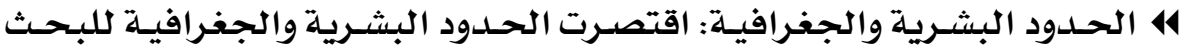

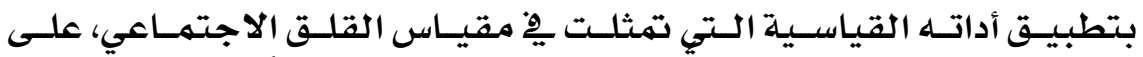

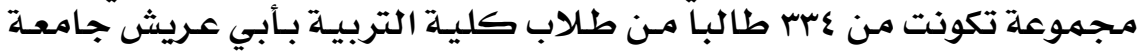

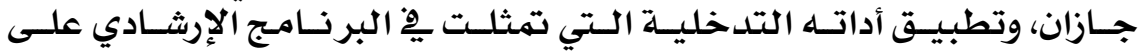

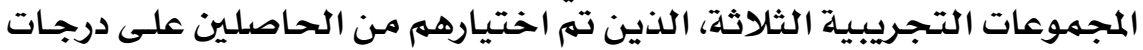

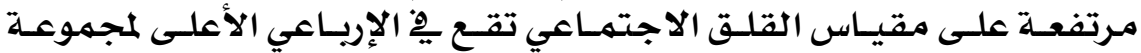

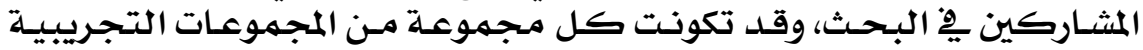

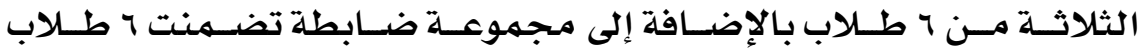

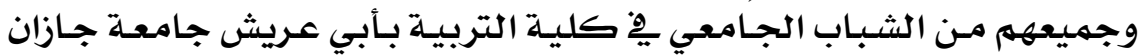

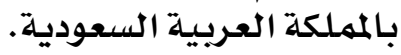

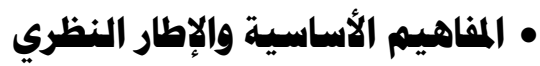

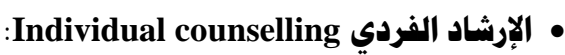

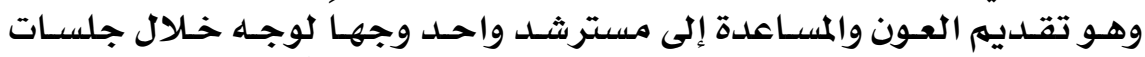

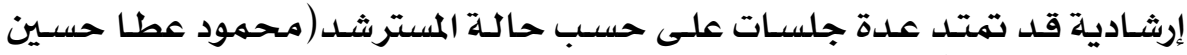

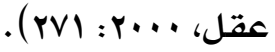

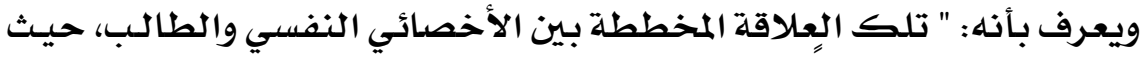

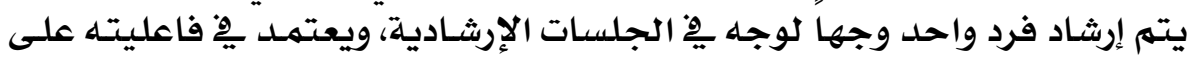

\section{$\Lambda \mathrm{V}$}




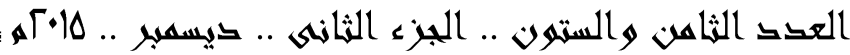

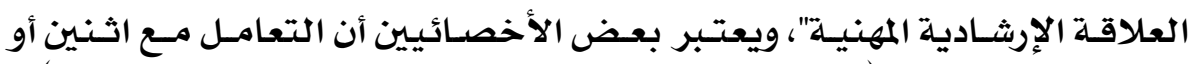

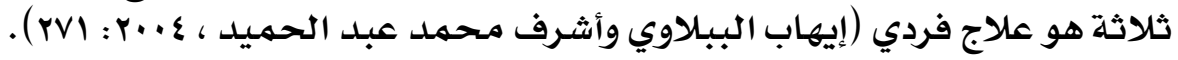

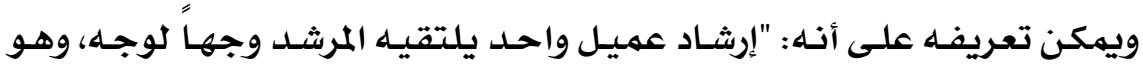

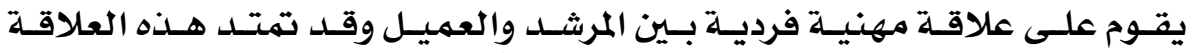

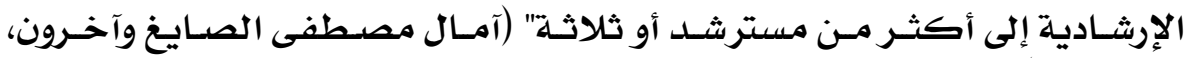
. r r r

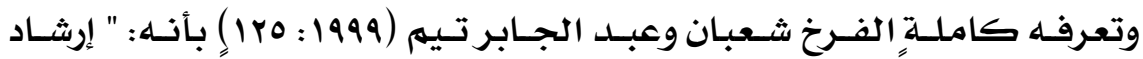

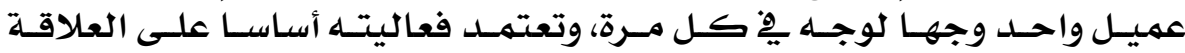

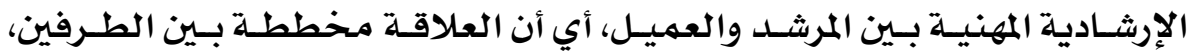

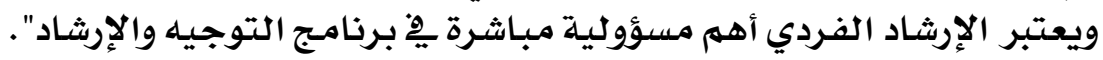

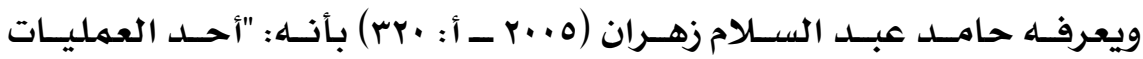

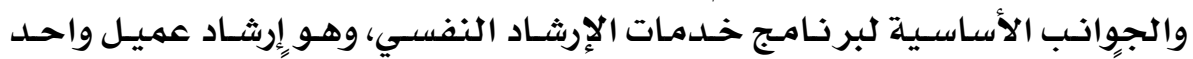

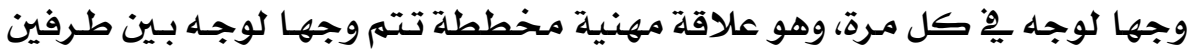

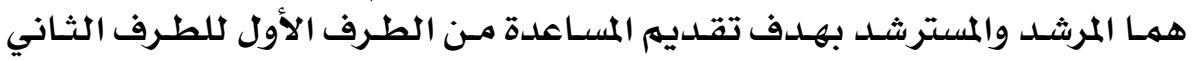

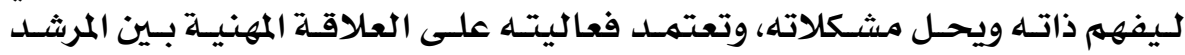
والعميل".

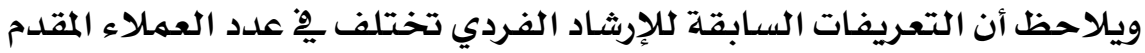

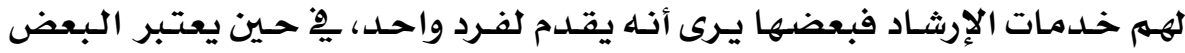

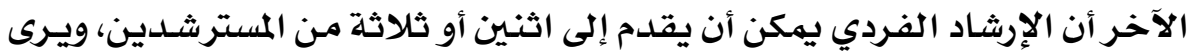

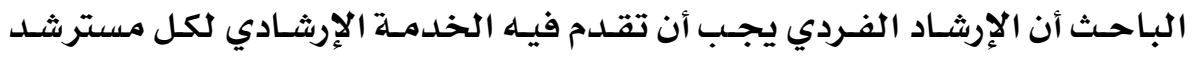

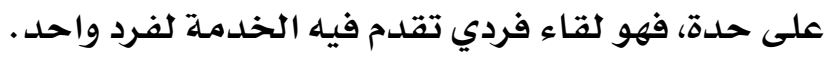

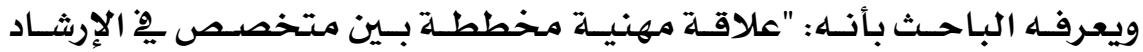

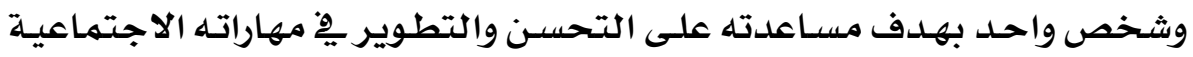
والشخصيـة".

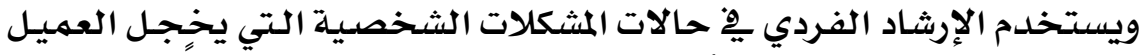

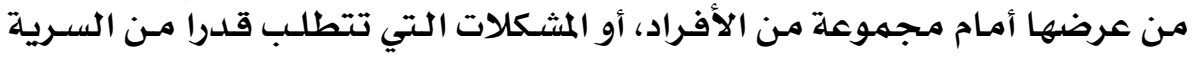

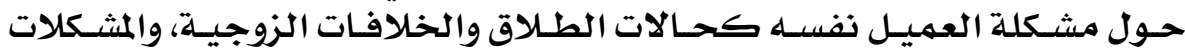

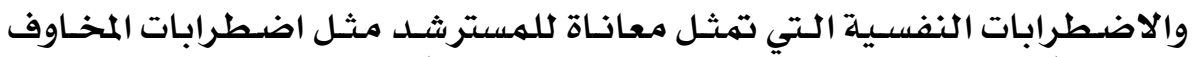

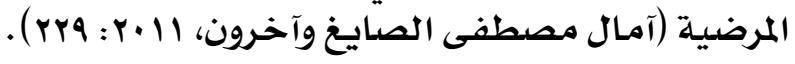

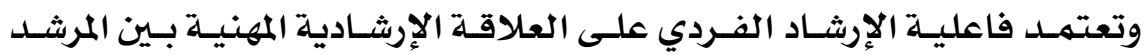

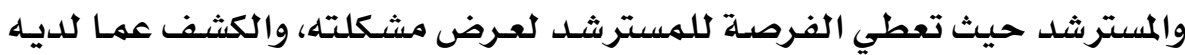

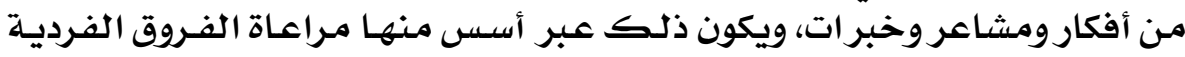

\section{$\Lambda \Lambda$}




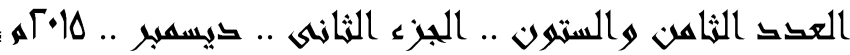

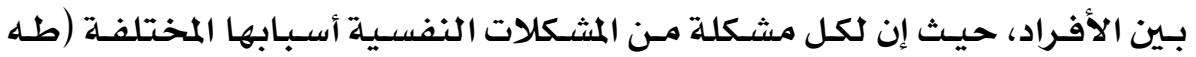

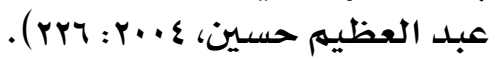

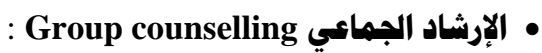

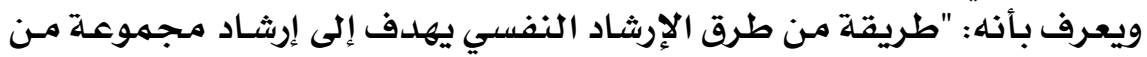

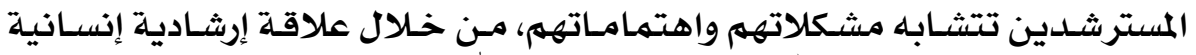

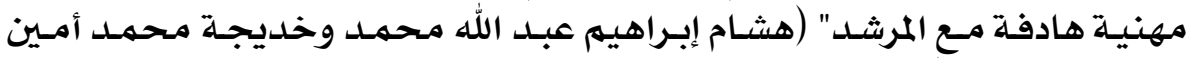

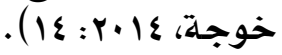

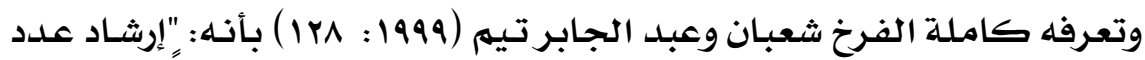

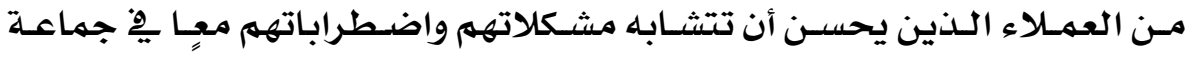

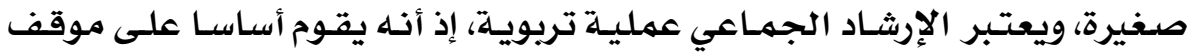

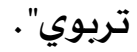

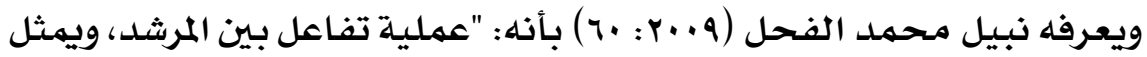

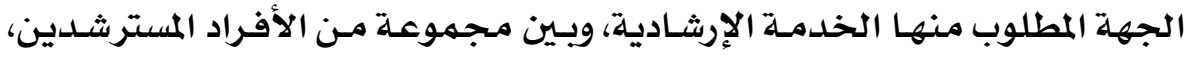

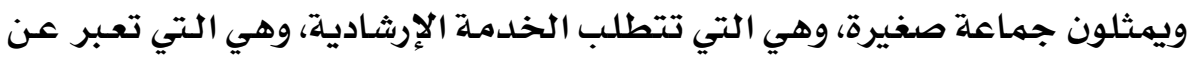

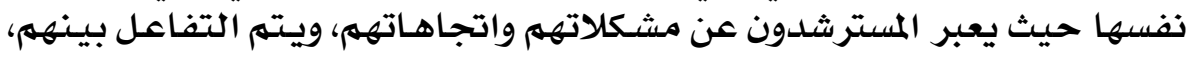

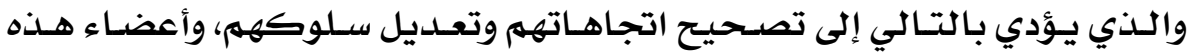

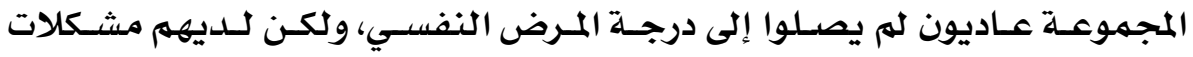
تضعف من توافقهم".

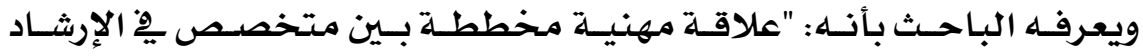

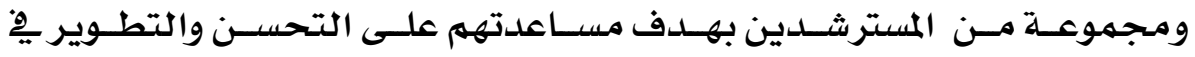

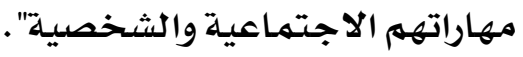

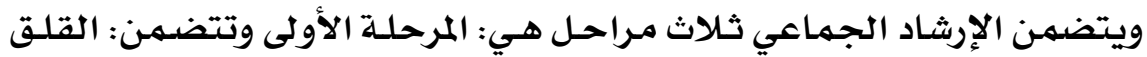

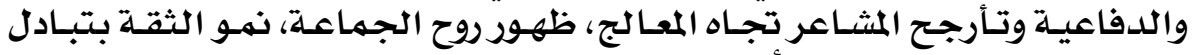

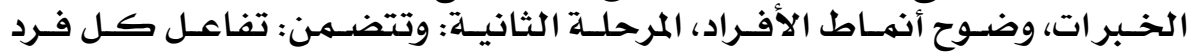

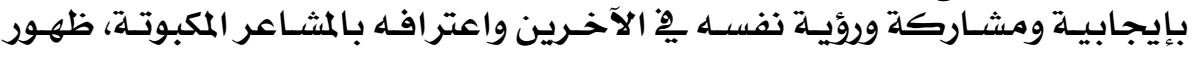

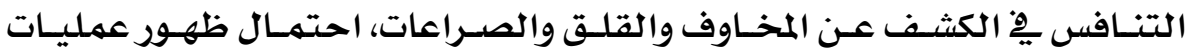

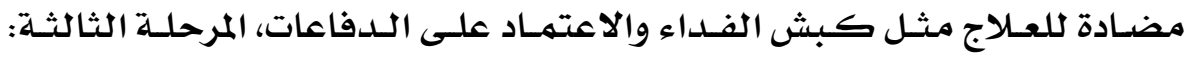

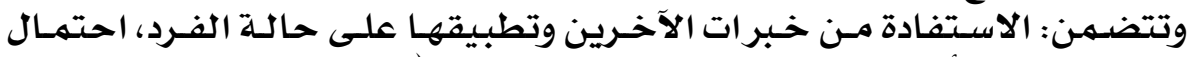

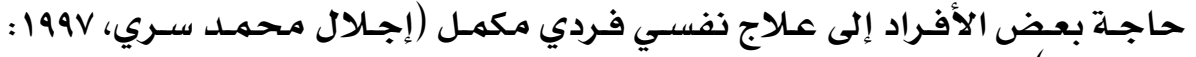
. (Irr - Irr

ويـرى كالا مـن (Yalom \& Leszcz, 2005: 1-2) أن هنـالك أحسد عشـر عـاملاً

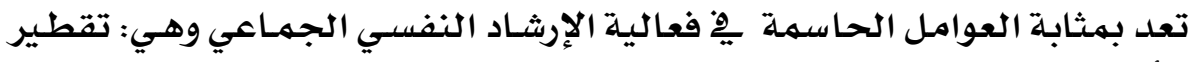

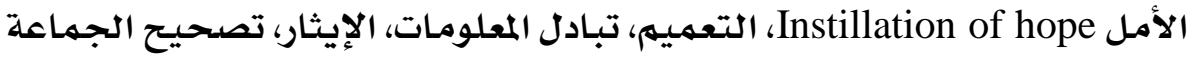

\section{$\Lambda 9$}




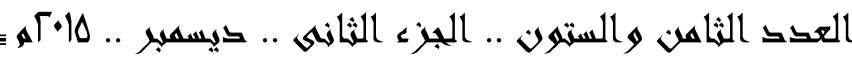

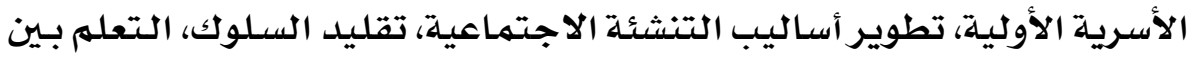

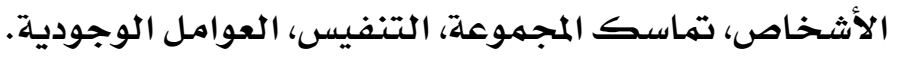

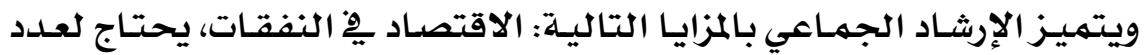

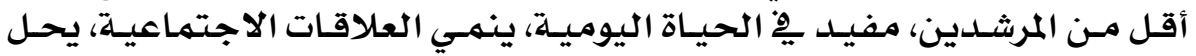

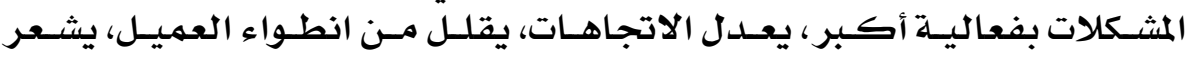

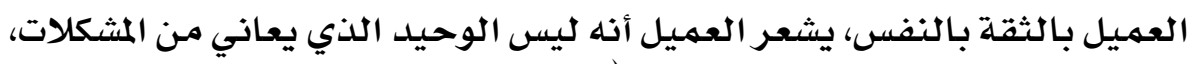

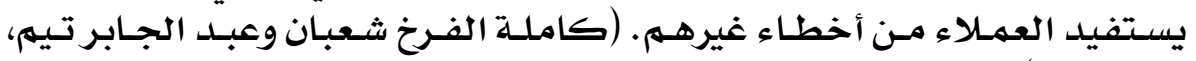
. 1999

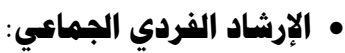

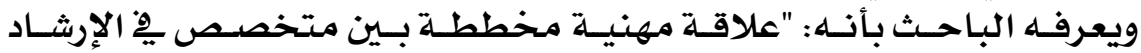

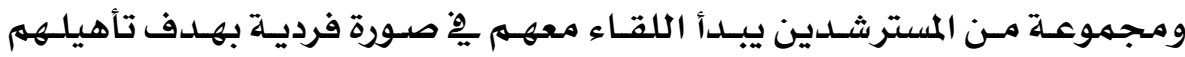

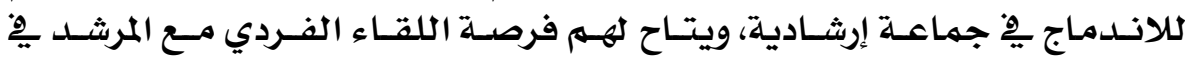

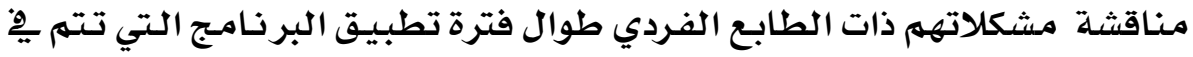

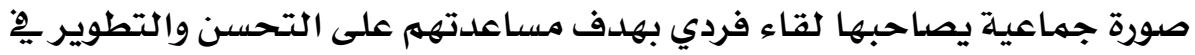

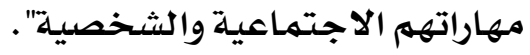

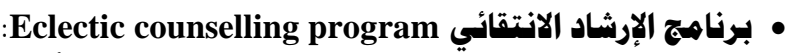

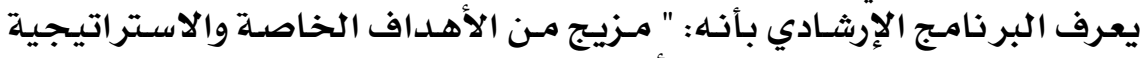

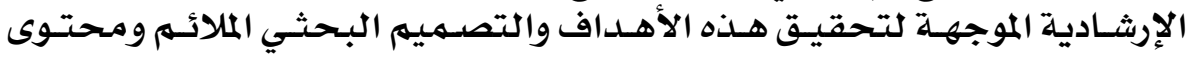

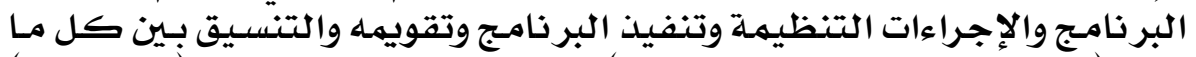

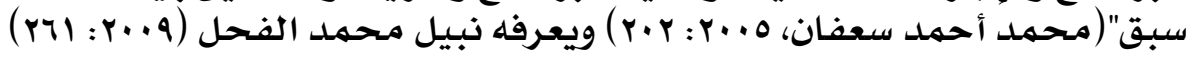

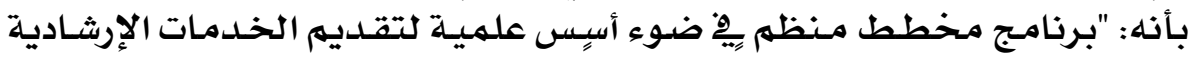

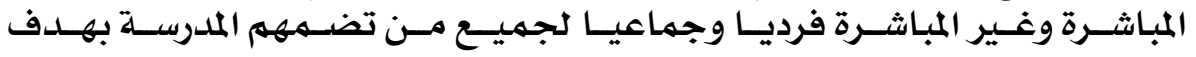

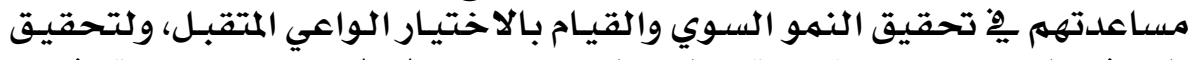

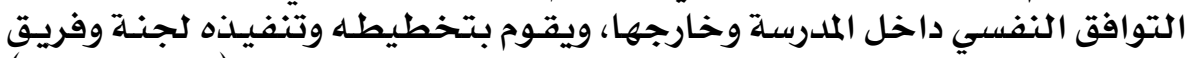

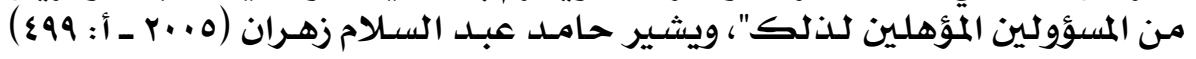

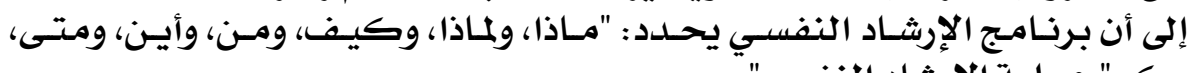

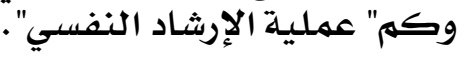

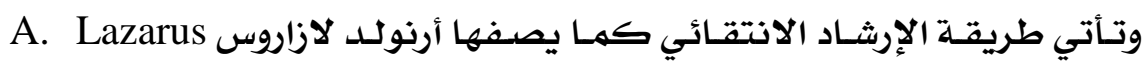

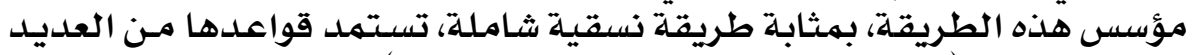

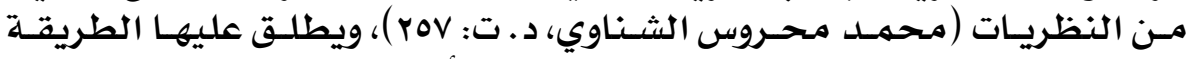

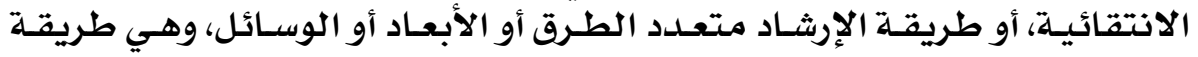

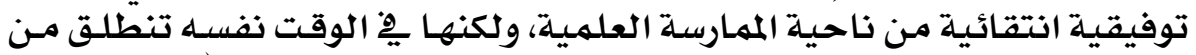

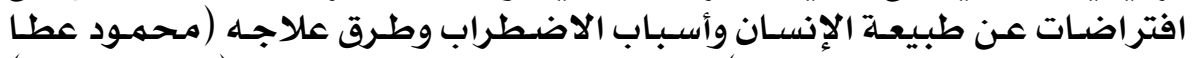

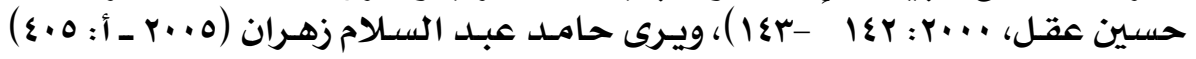

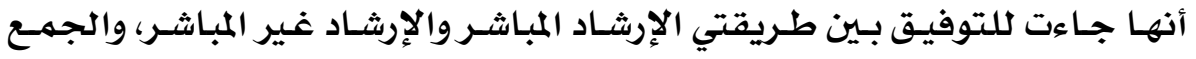

\section{9.}




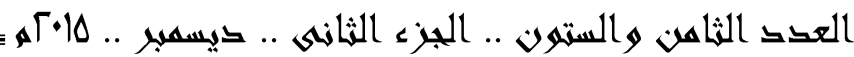

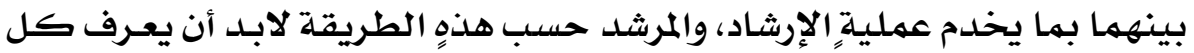

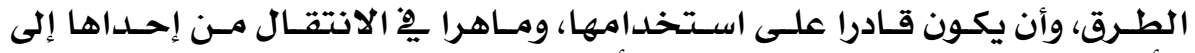

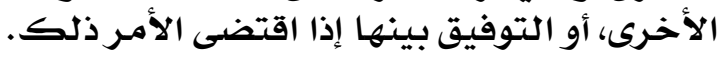

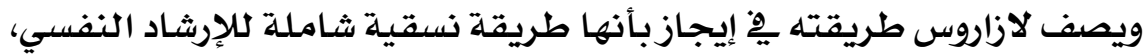

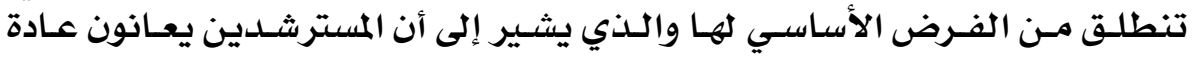

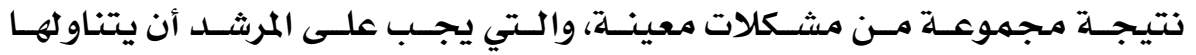

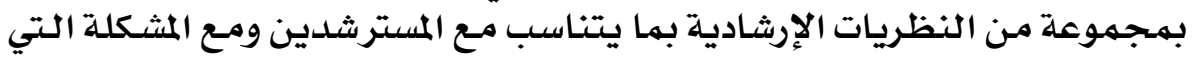

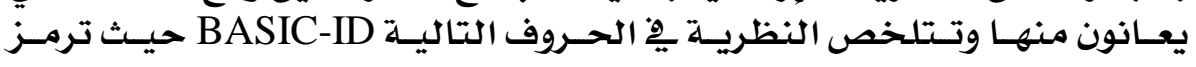

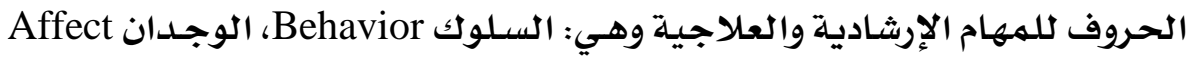

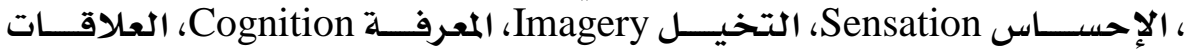

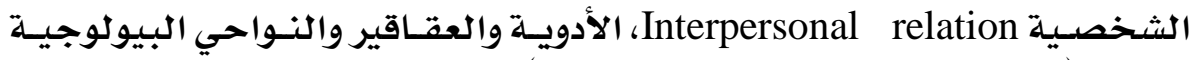
Drugs (محمد محروس الشناوي، د. ت ت: rov ).

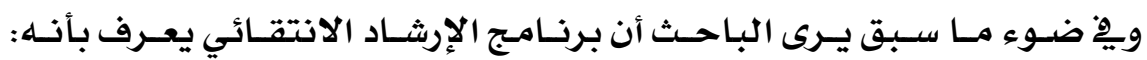

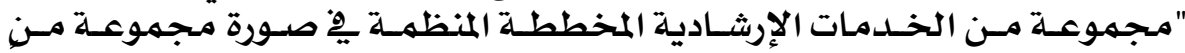

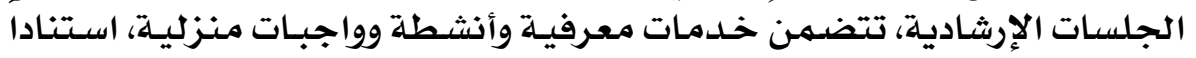

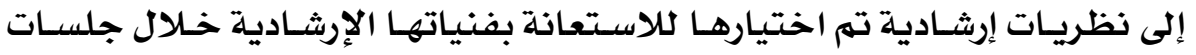

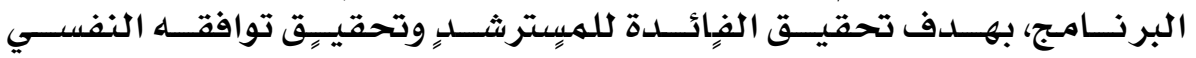

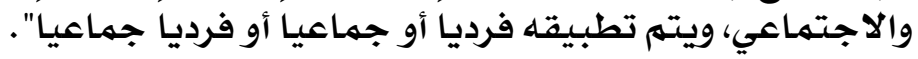

• القلق الاجتهاعي Social Anxiety:

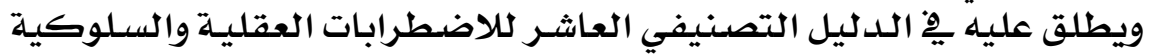

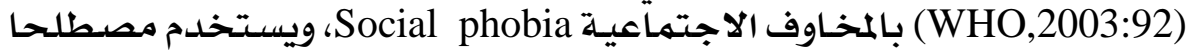

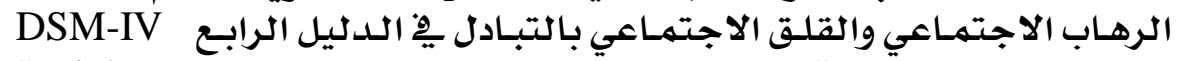

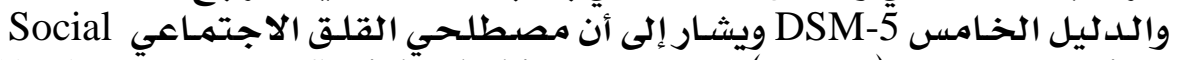

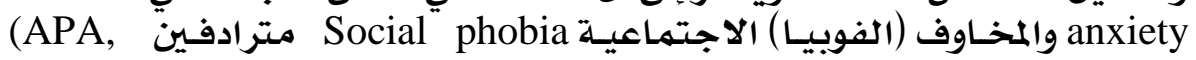
الاجتهاعيـ 1994: 411; APA, 2013: 202)

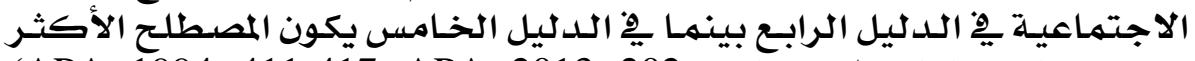

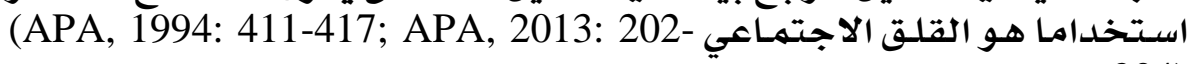

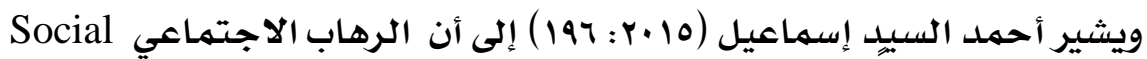

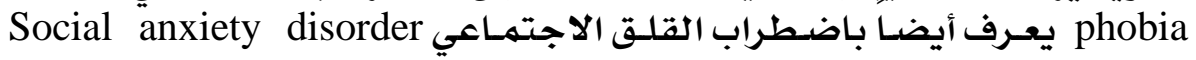

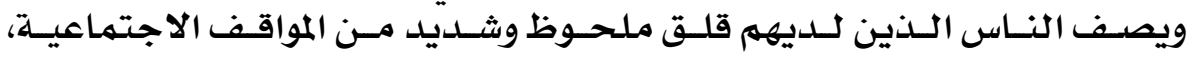

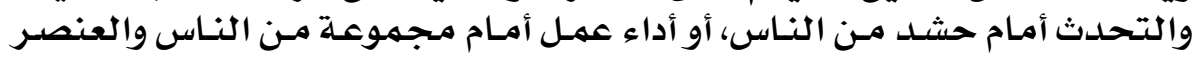

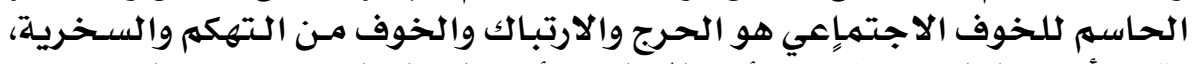

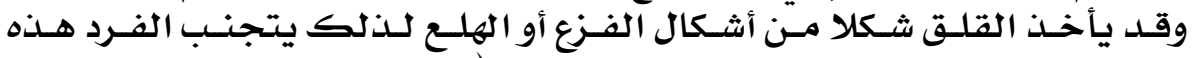

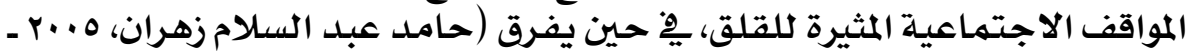

\section{9)}




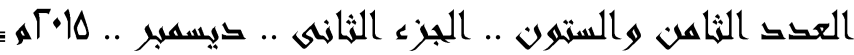

ب: 0.V) بين الخـواف والقلقى، حيث يِّ الخـواف Phobia يسيطر المريض (نسبياً)

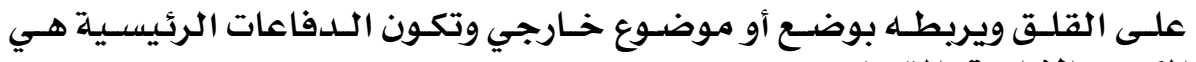

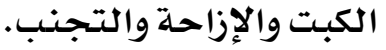

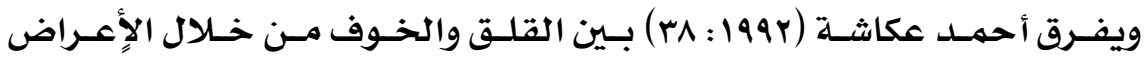

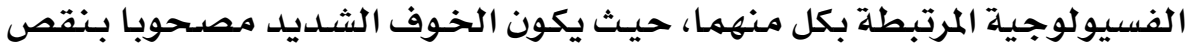

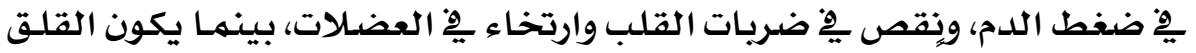

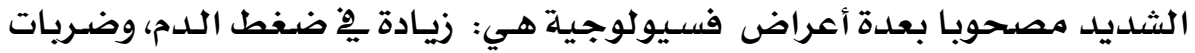

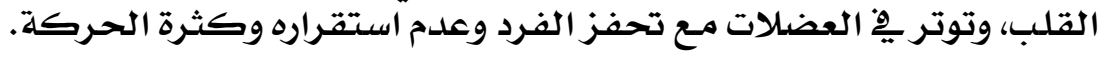

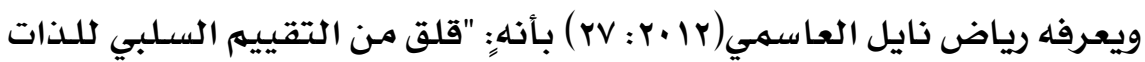

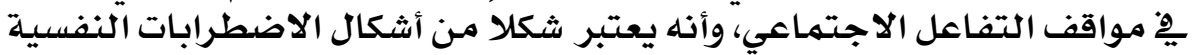

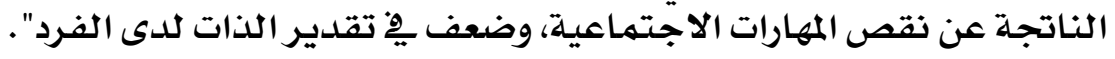

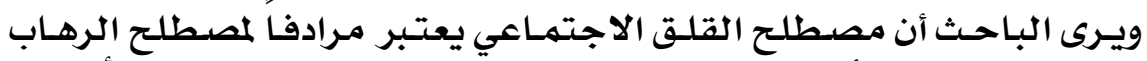

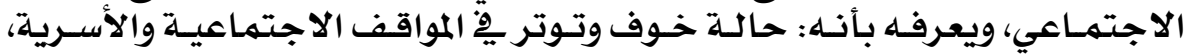

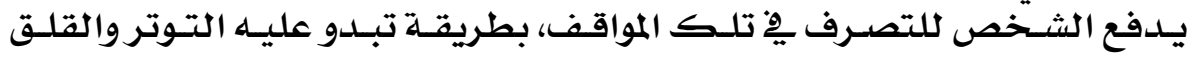

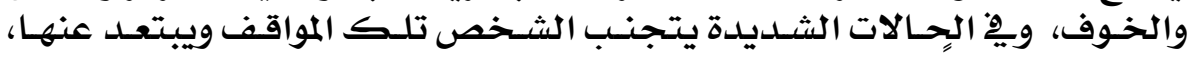

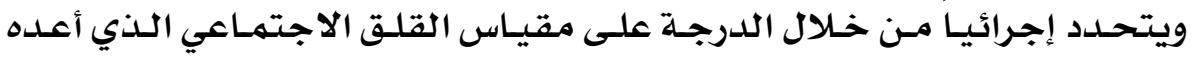

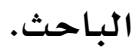

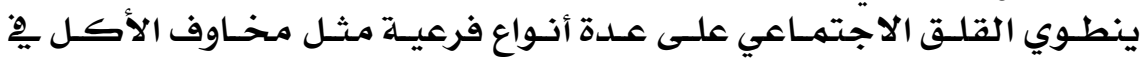

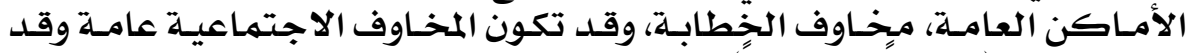

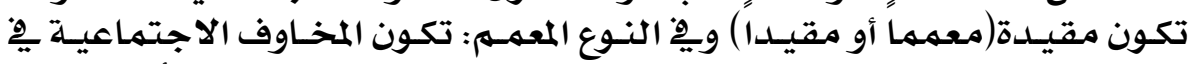

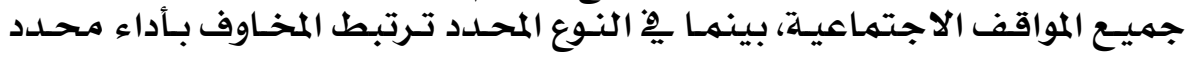

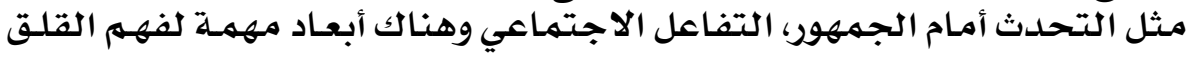

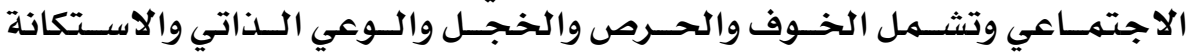

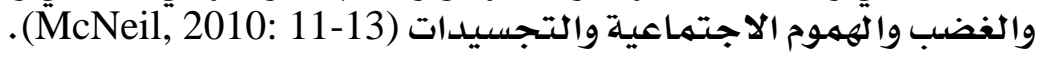

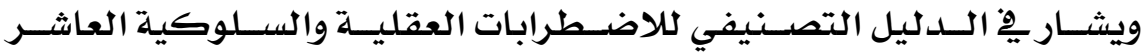

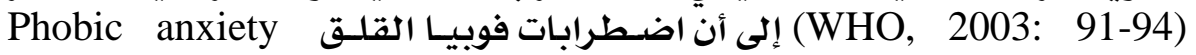
disorders الأخـاوف المحسدة Special phobias الأخـرى Other phobic anxiety disorders واضطرابات قلـق المخـاوف غير فير المحددة Phobic anxiety disorders unspecified الاحتري

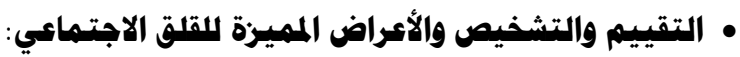

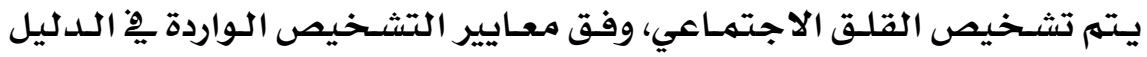

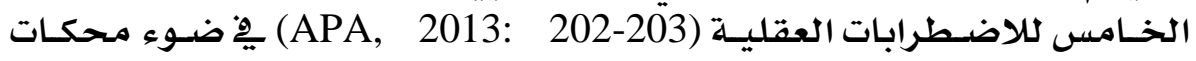

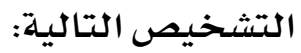

\section{$9 \%$}




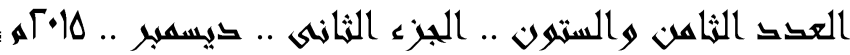

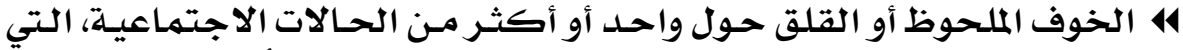

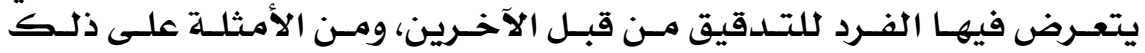

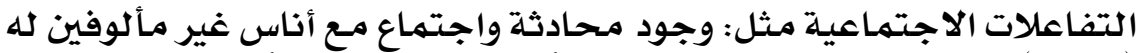

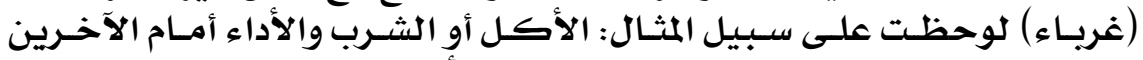

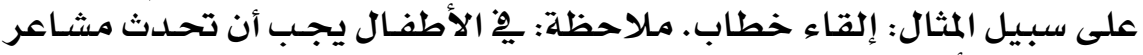

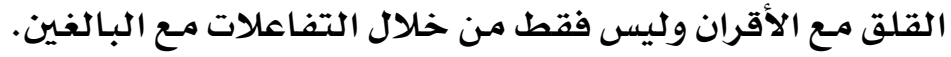

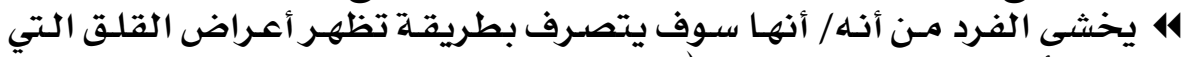

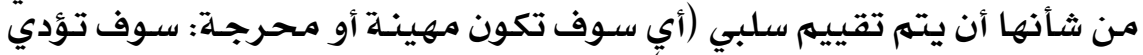

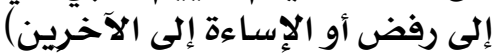

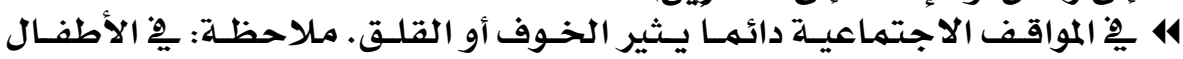

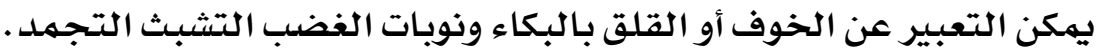

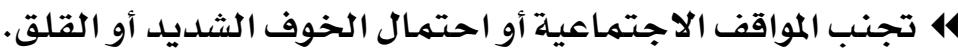

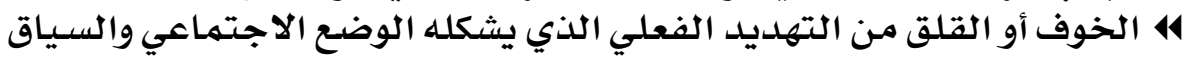
الاجتماعي الثقايقِ.

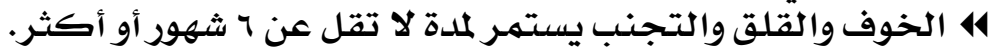

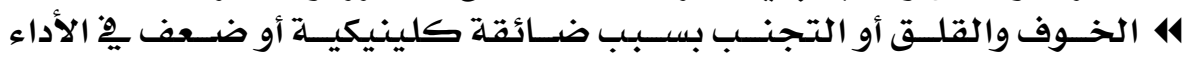

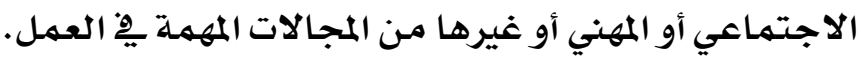

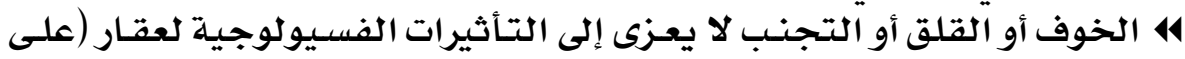

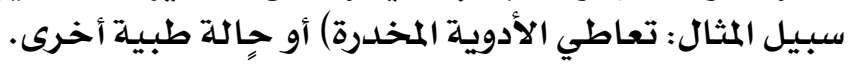

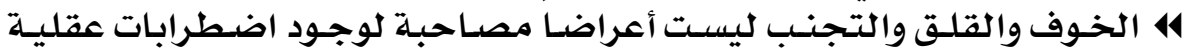

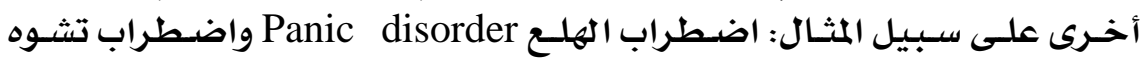

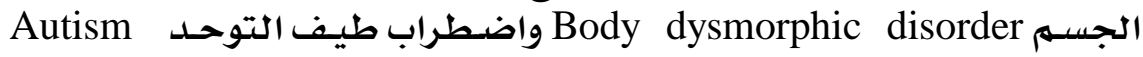
.spectrum disorder

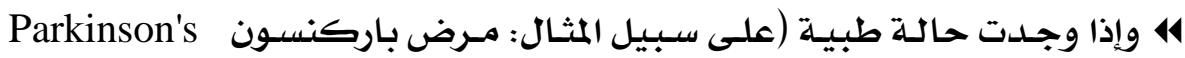

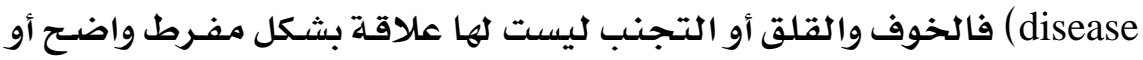
غير مفرط.

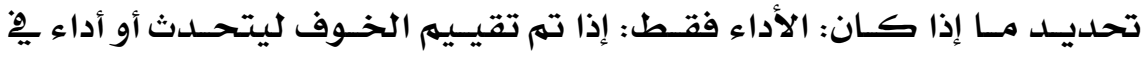
العام.

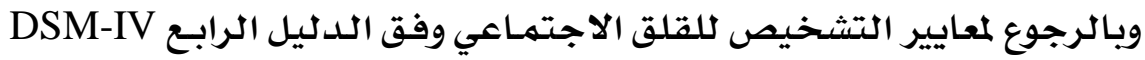

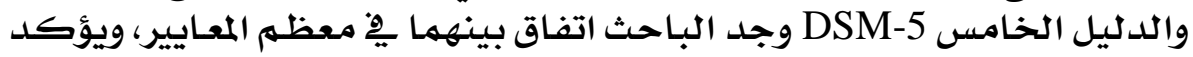

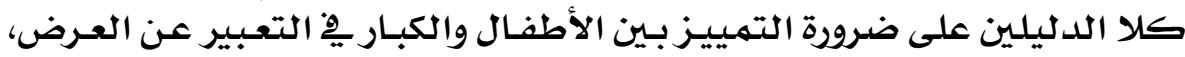

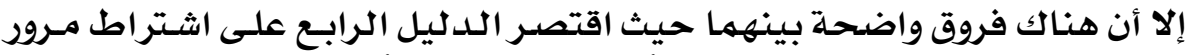

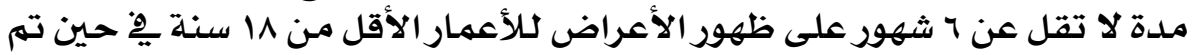

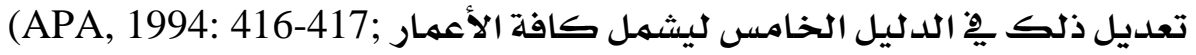
APA,2013: 202-203)

\section{4}




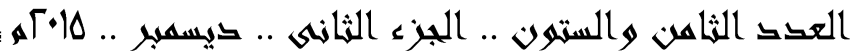

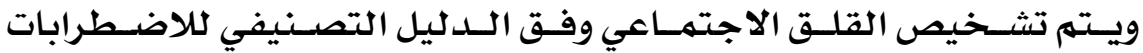

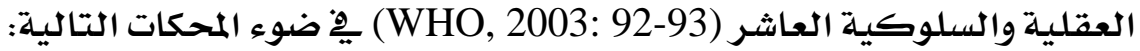

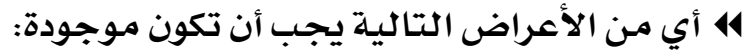

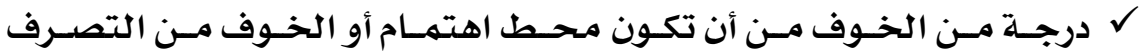
بطريقة محرجة أو مهينة التهنة

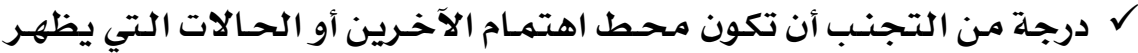

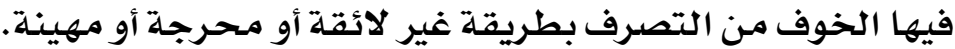

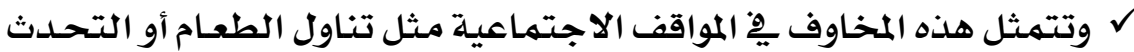

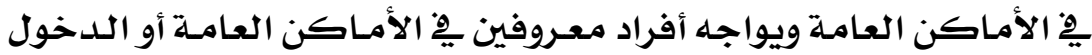

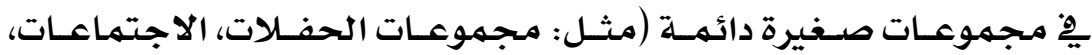

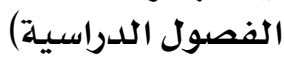

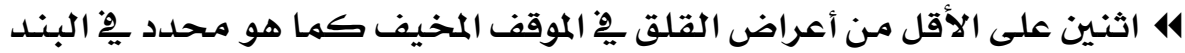

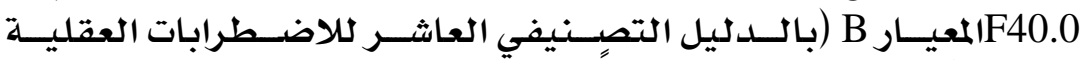

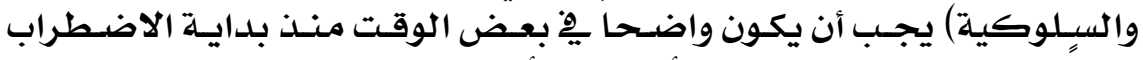

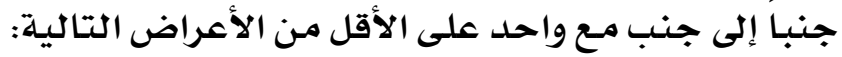

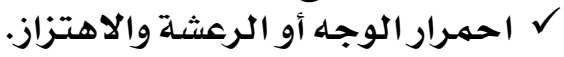
$\checkmark$

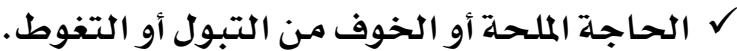

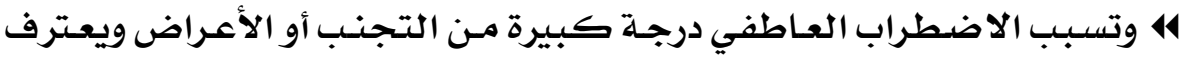

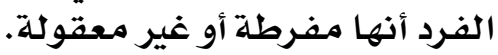

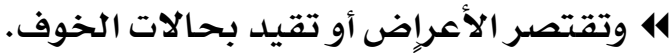

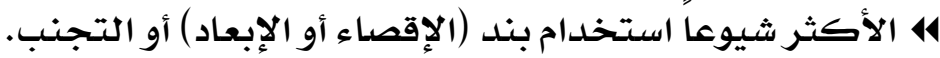

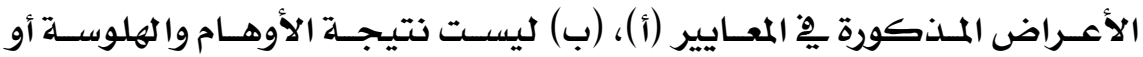

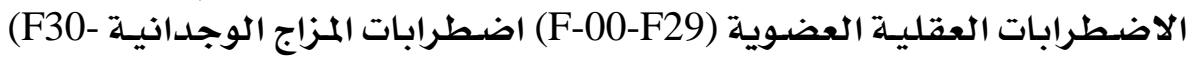

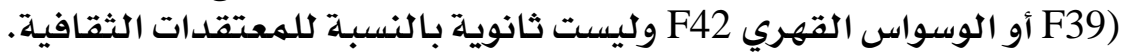

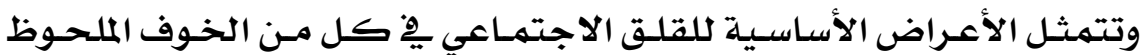

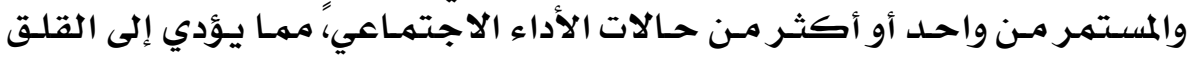

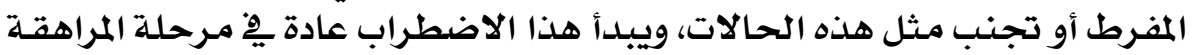

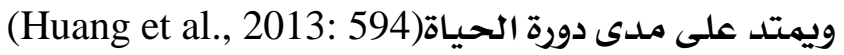

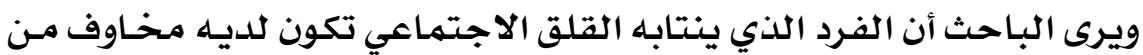

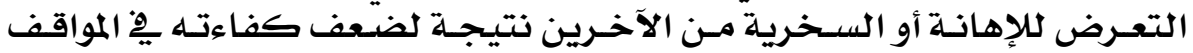

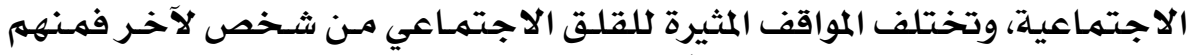

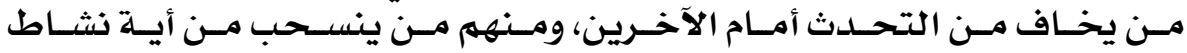
اجتماعي.

\section{$9 \varepsilon$}




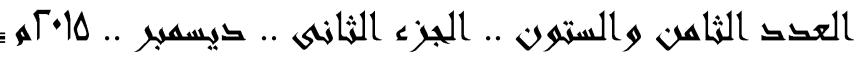

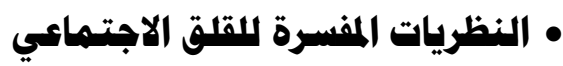

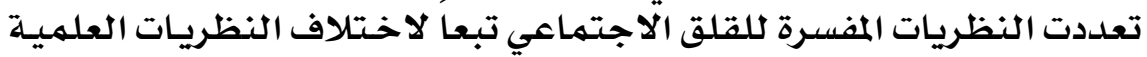

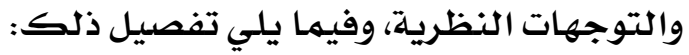

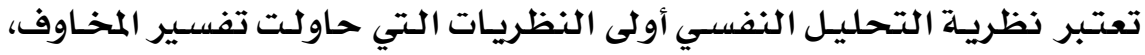

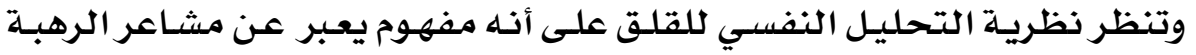

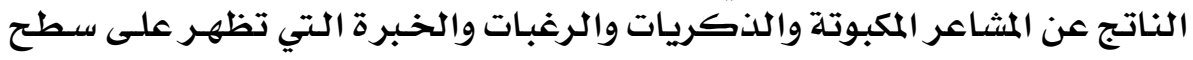

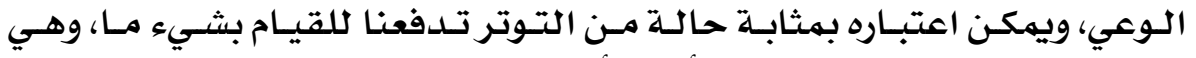

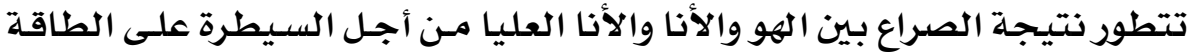

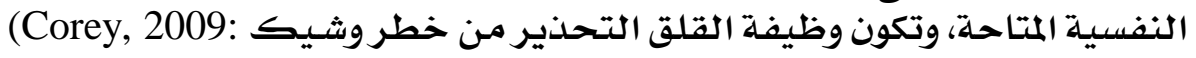

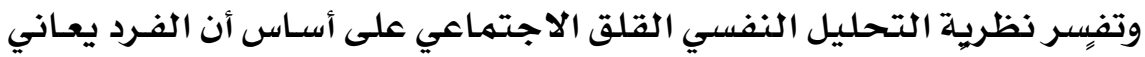

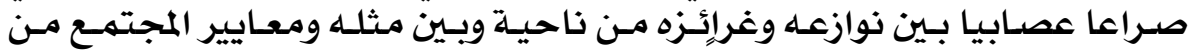

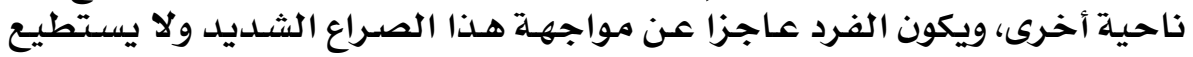

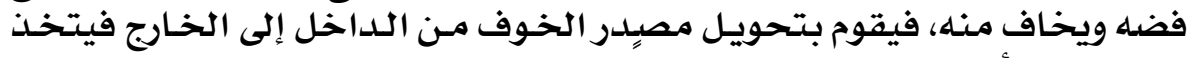

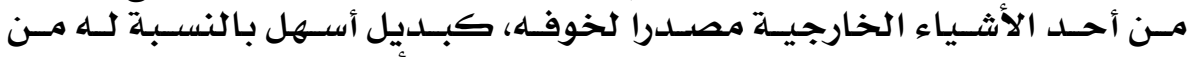

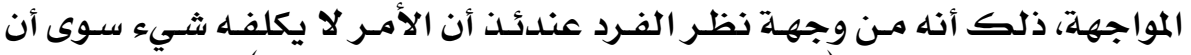

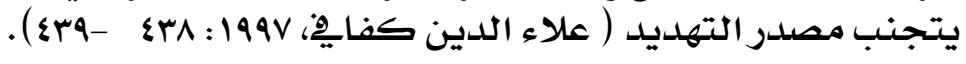

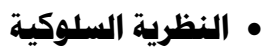

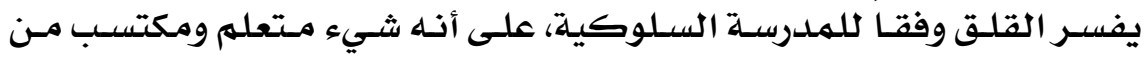

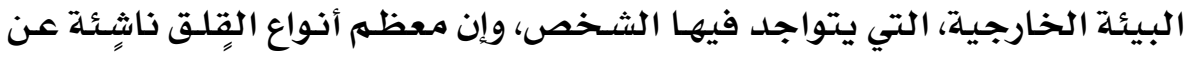

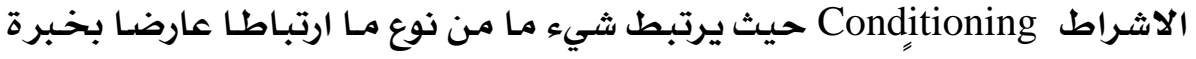

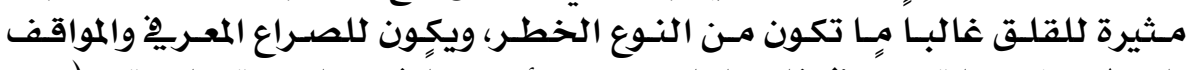

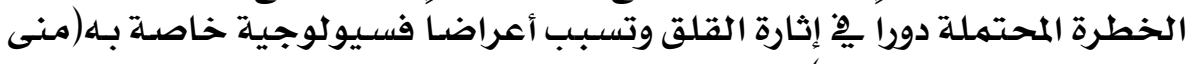

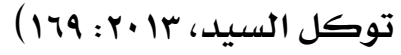

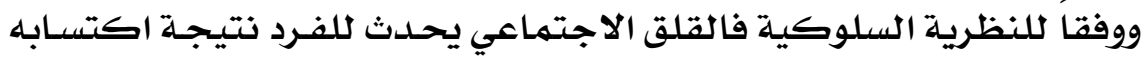

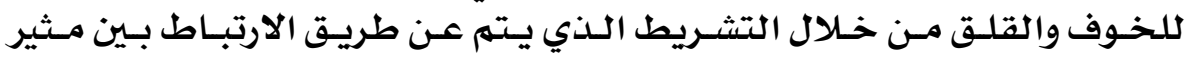

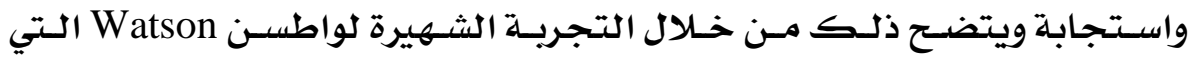

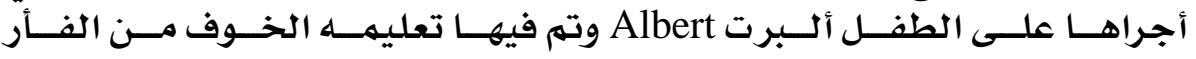
.(Rachman, 1998: 57)

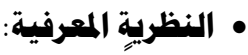

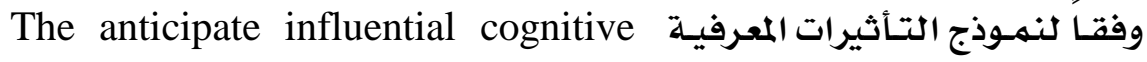

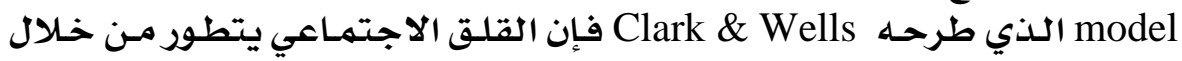

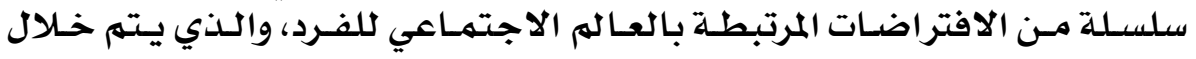

\section{8}




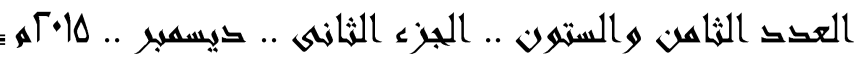

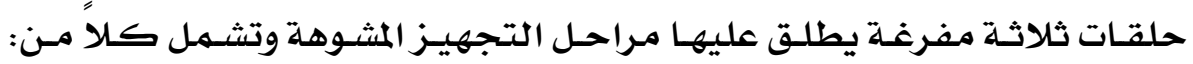

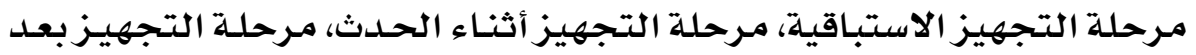

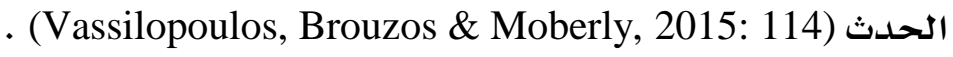

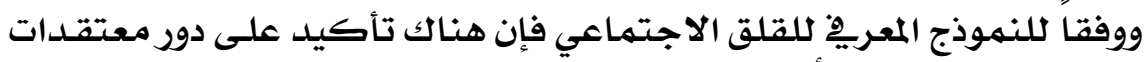

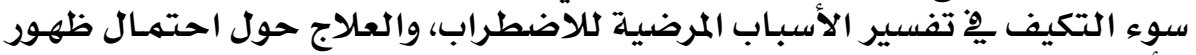

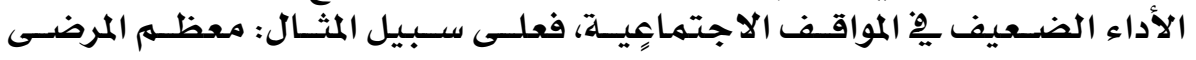

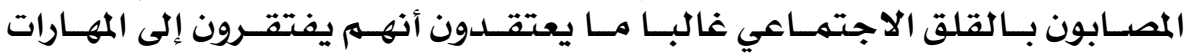

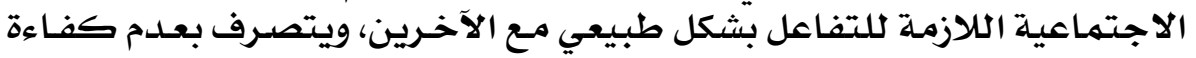

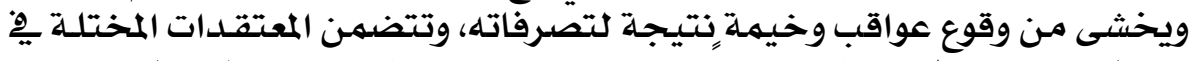

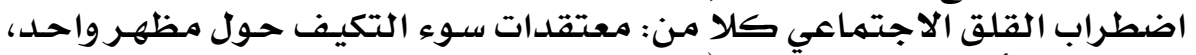

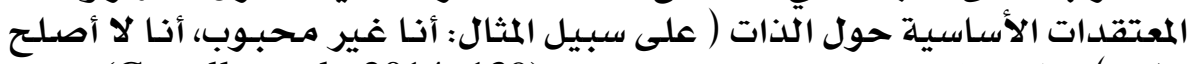

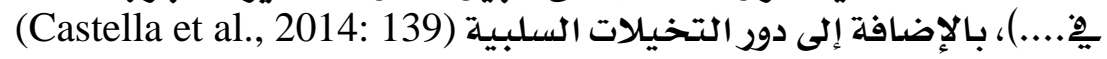

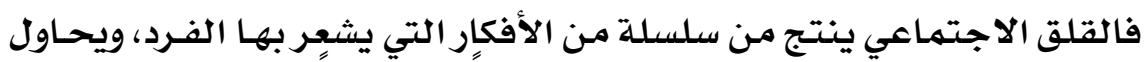

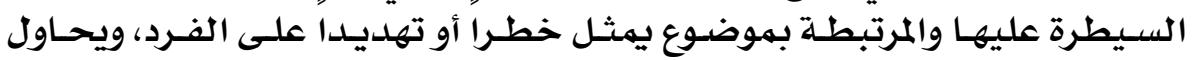

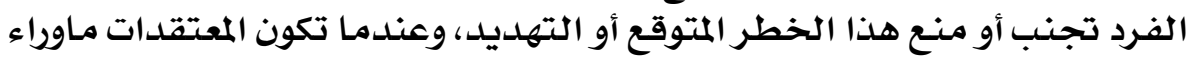

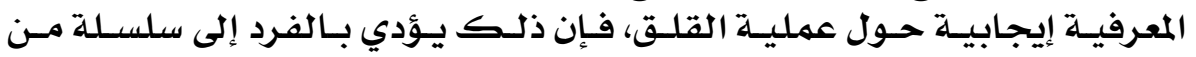

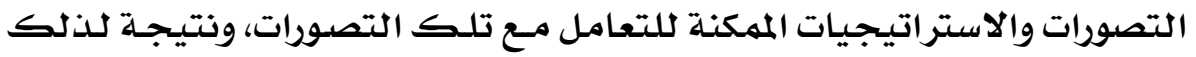

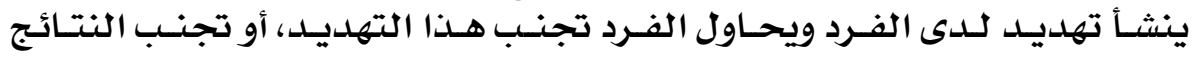

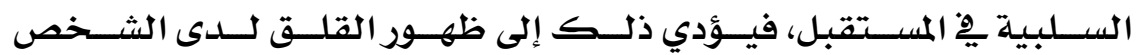

(Vassilopoulos et al., 2015: 114-115)

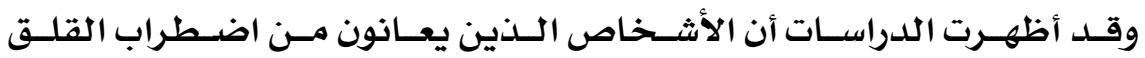

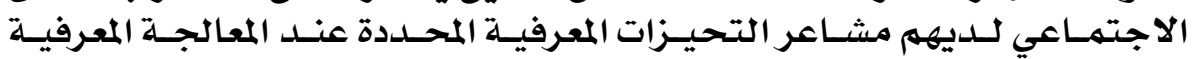
للهـثيرات، (لاعتي (Asnaani, Rinck, Becker \& Hofmann ,2014:

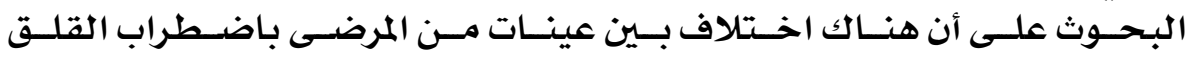

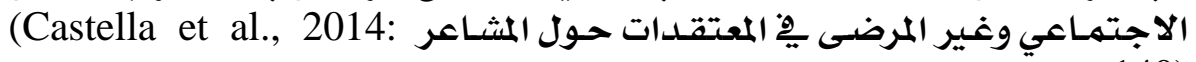
140)

\section{• دراسات سابقة : ماستة}

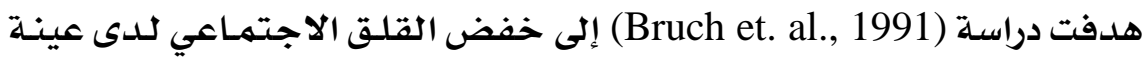

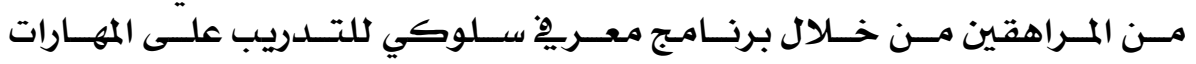

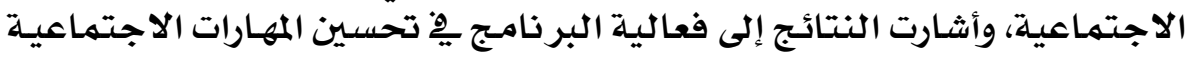

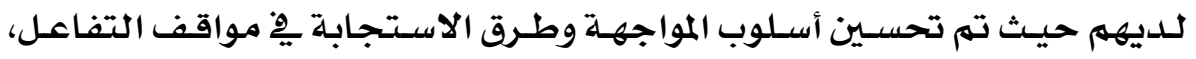

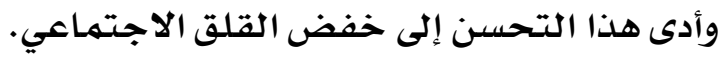

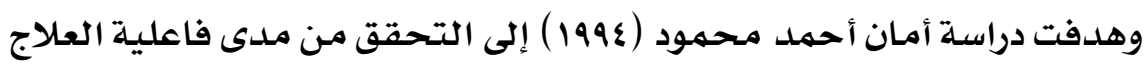

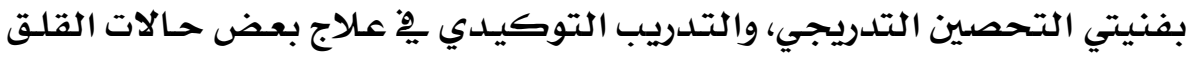

\section{7}




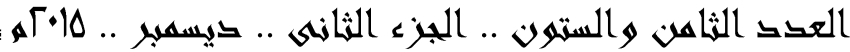

الاجتماعي، وتكونت عينـة الدراسـة من · م مـن طلاب التعليهم الثـانوي والجـامعي،

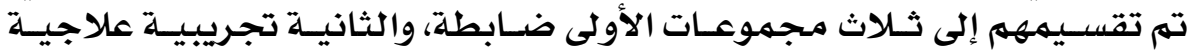

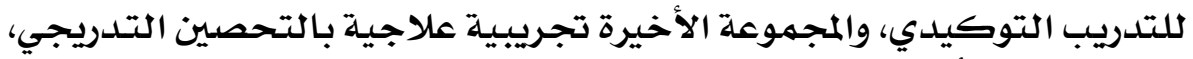

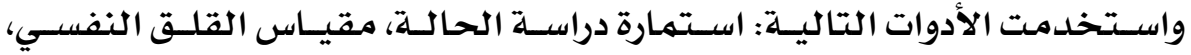

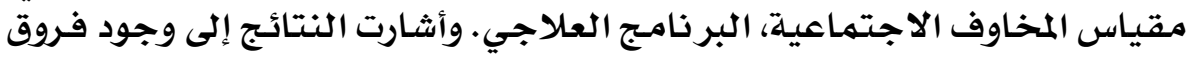

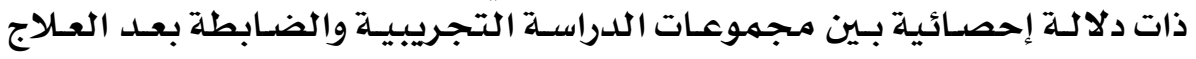

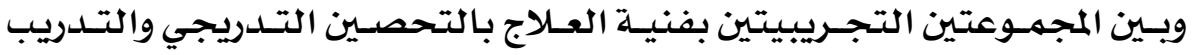

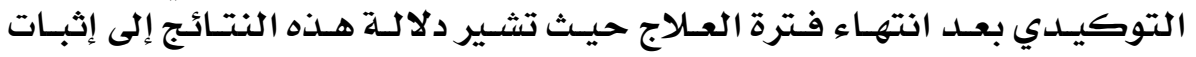

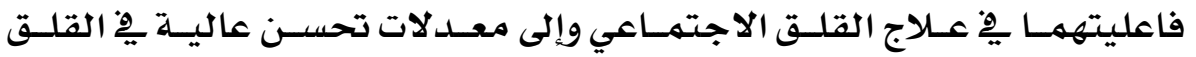

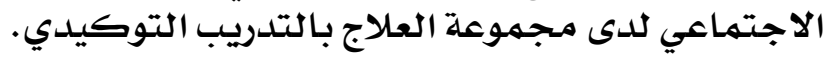

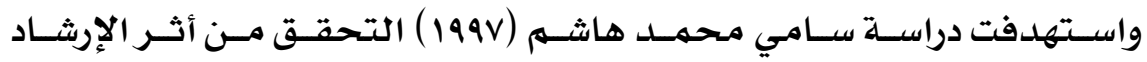

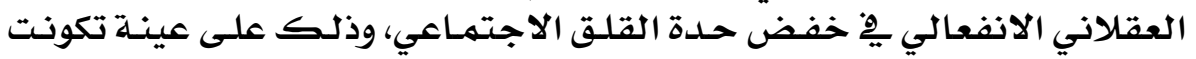

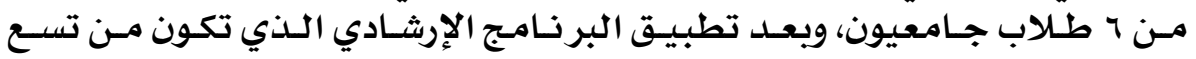

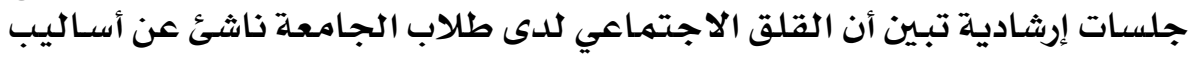

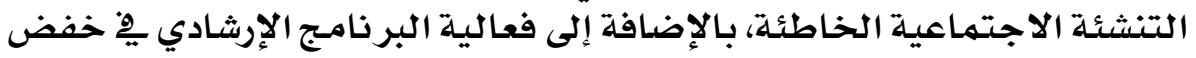
حدة القلق الاجتماعي.

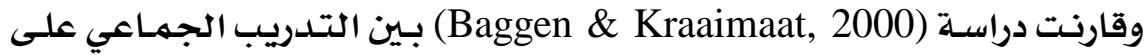

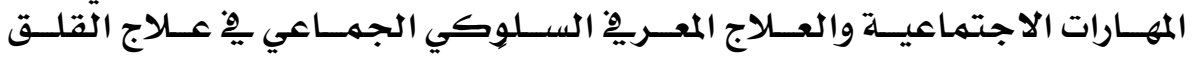

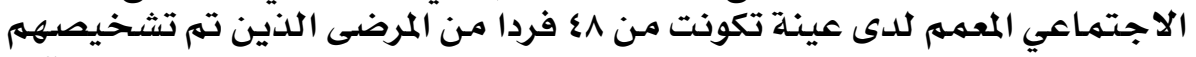

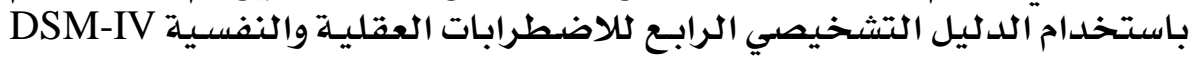

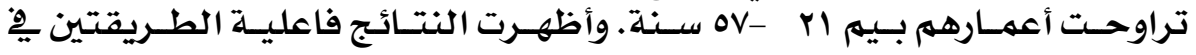

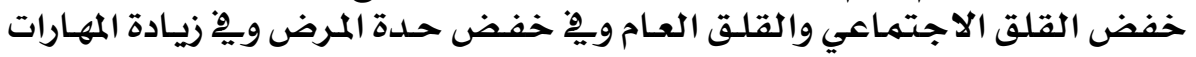
الاجتماعية والتحكم الاجتهاعي والذات.

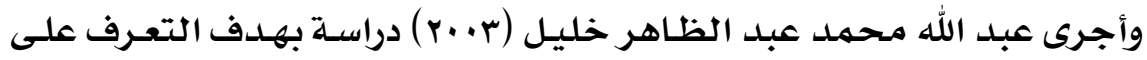

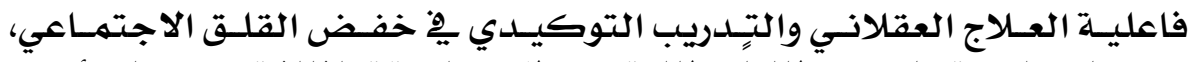

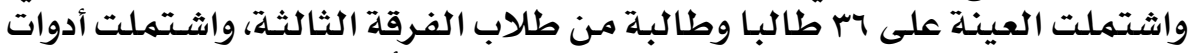

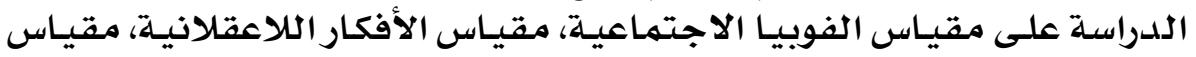

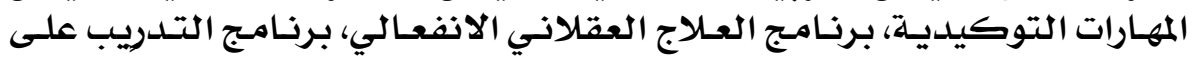

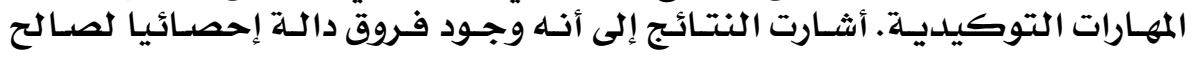

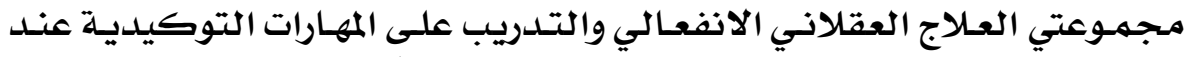

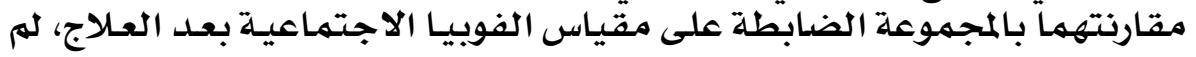

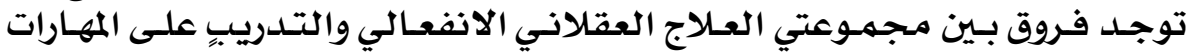

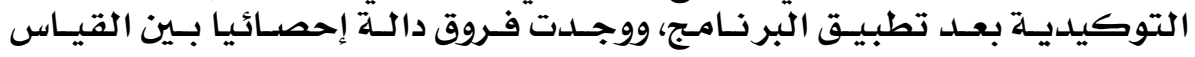

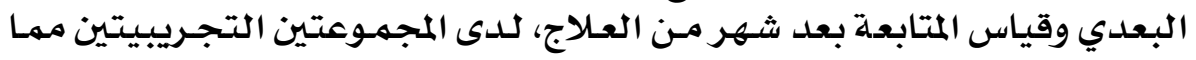

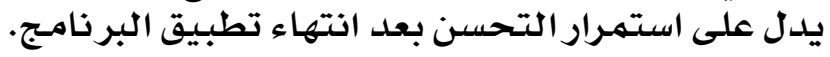




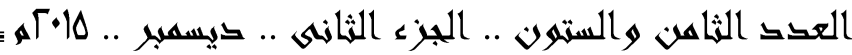

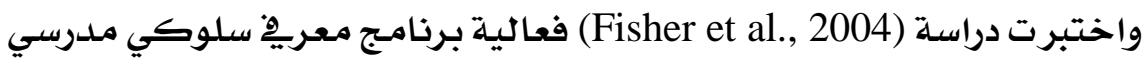

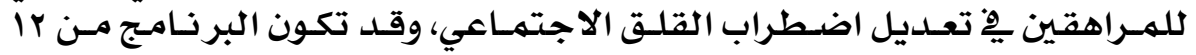

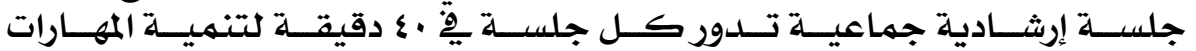

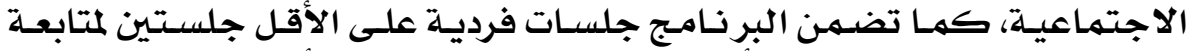

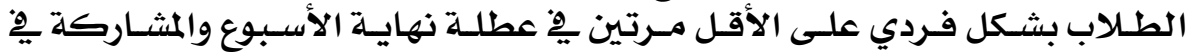

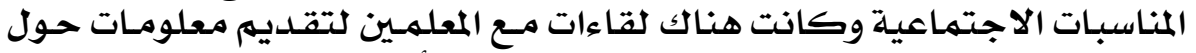

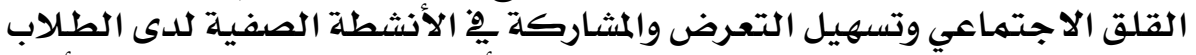

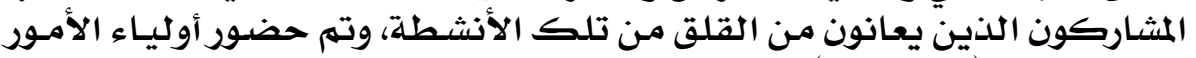

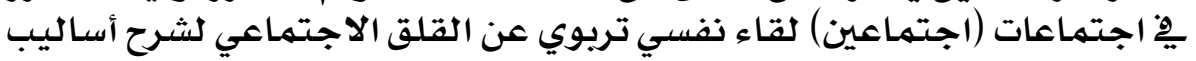

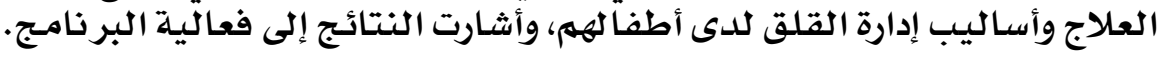

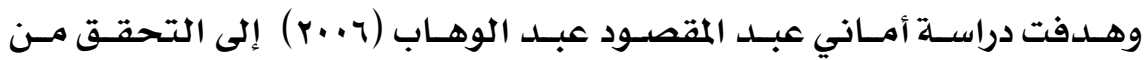

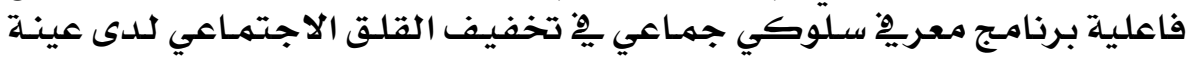

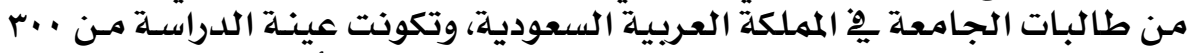

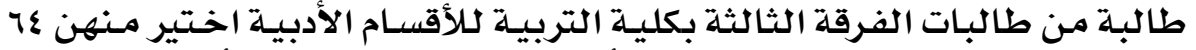

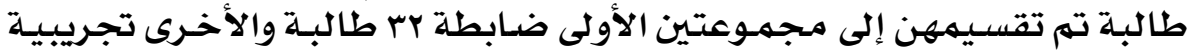

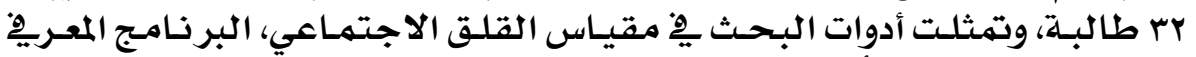

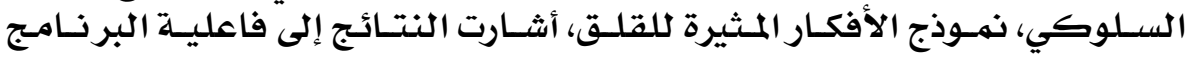

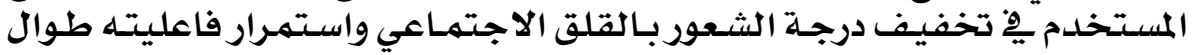
فترة المتابعة.

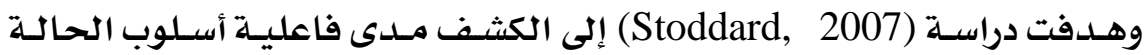

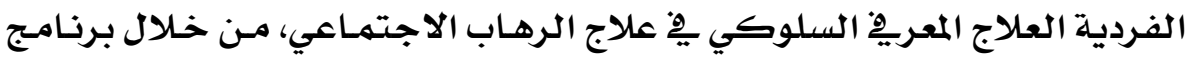

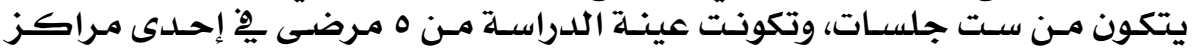

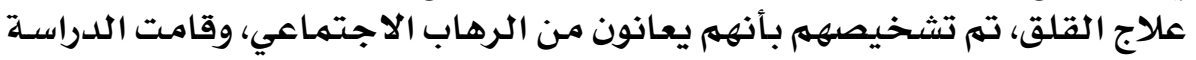

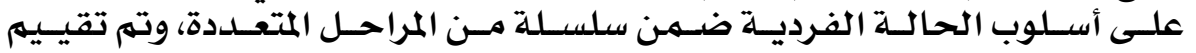

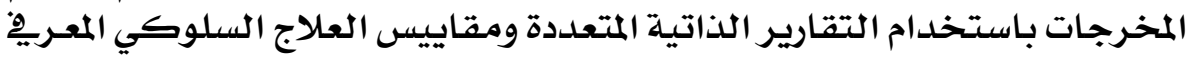

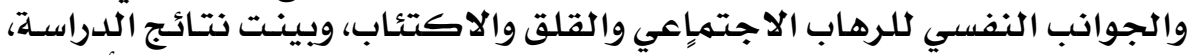

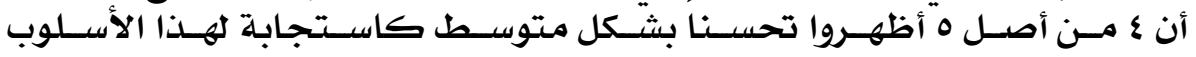

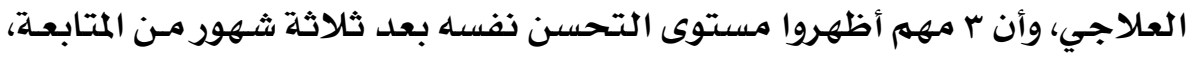

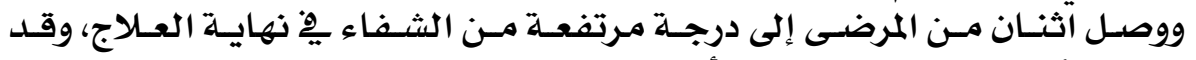

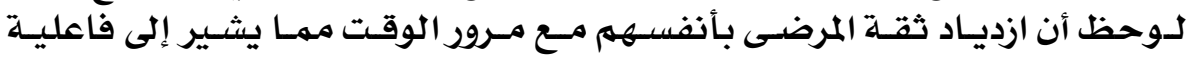

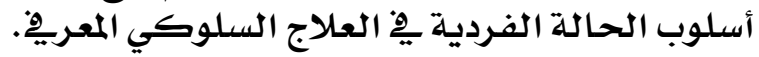

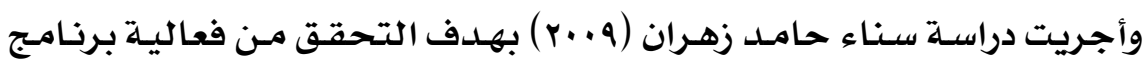

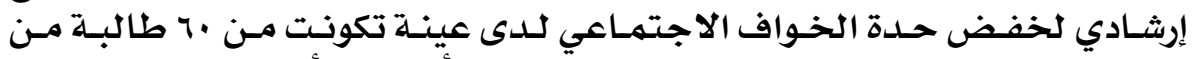

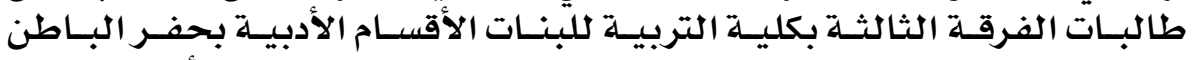

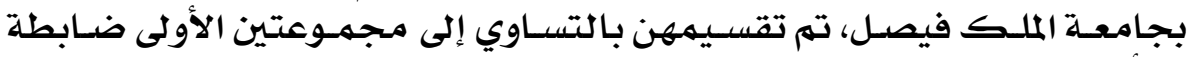

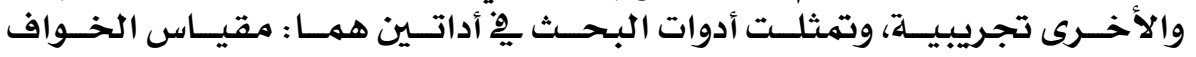

\section{1}




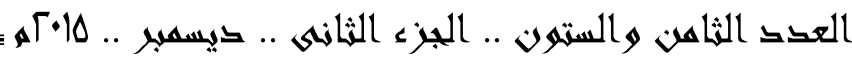

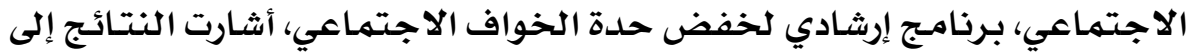

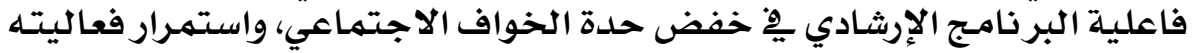
أثناء فترة المتابعة.

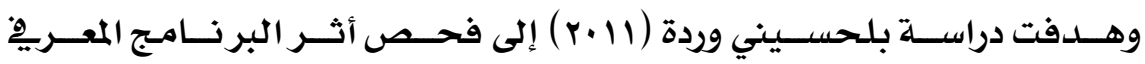

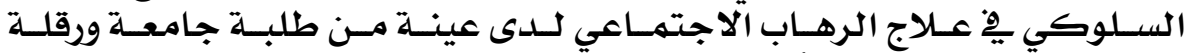

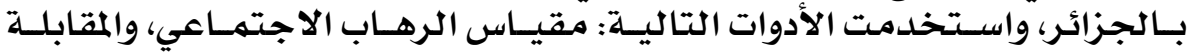

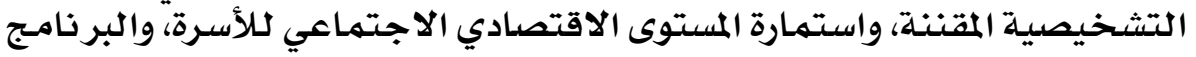

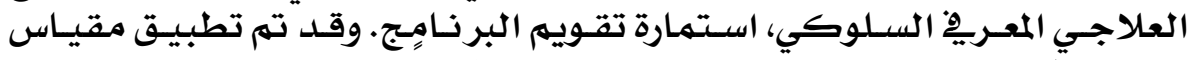

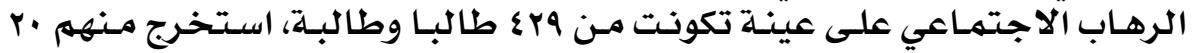

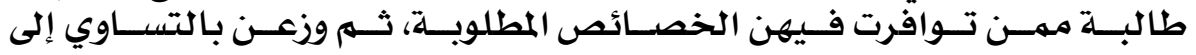

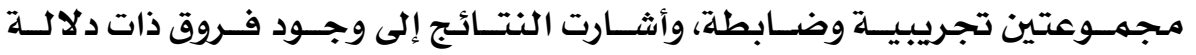

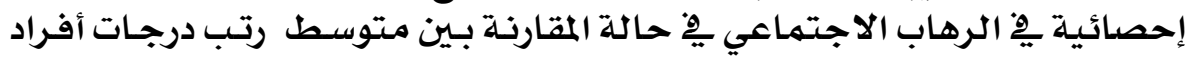

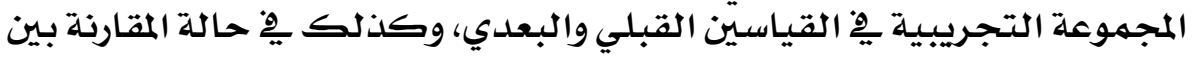

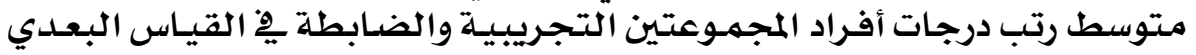

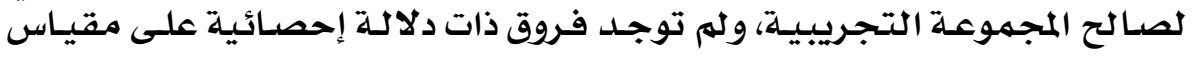

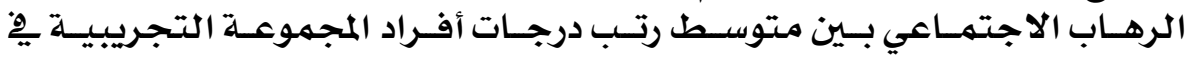

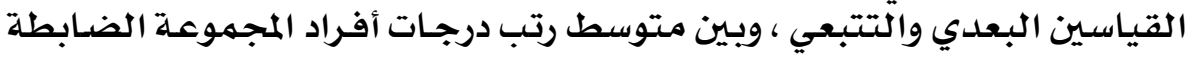

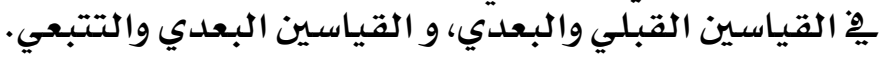

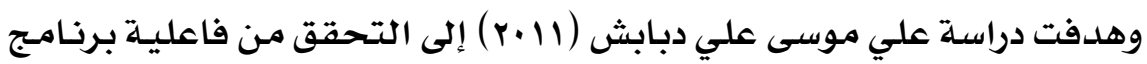

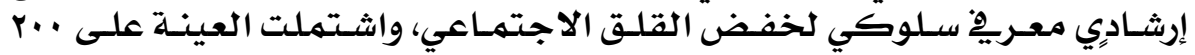

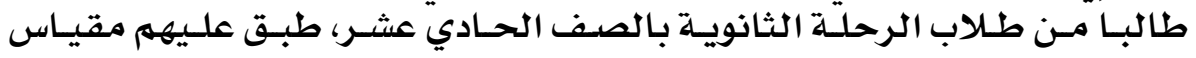

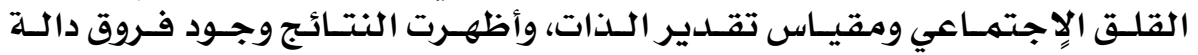

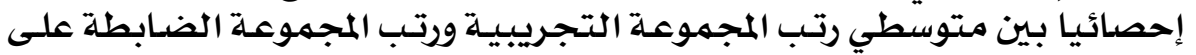

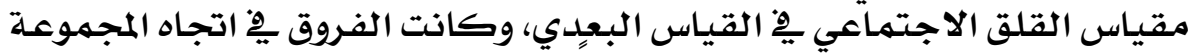

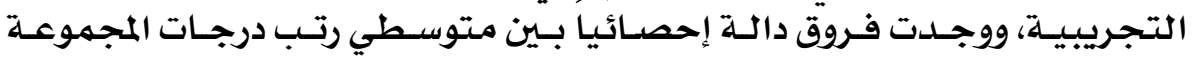

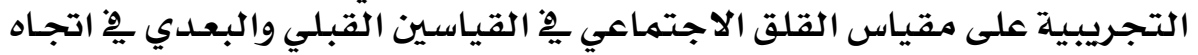
القياس البعدي.

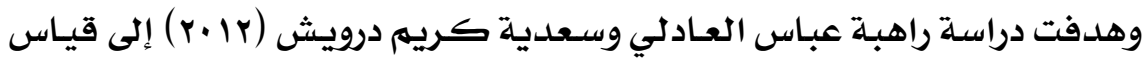

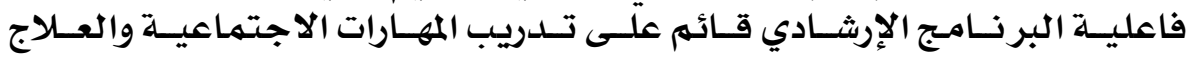

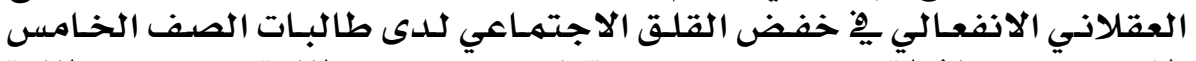

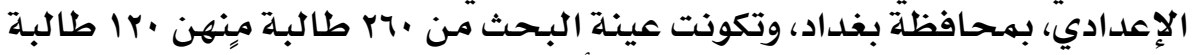

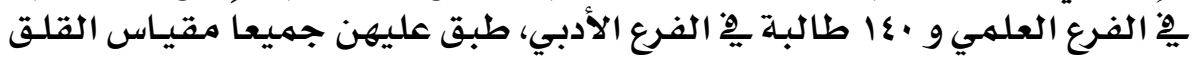

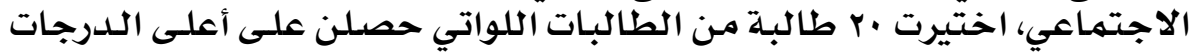

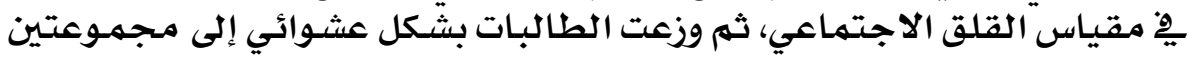

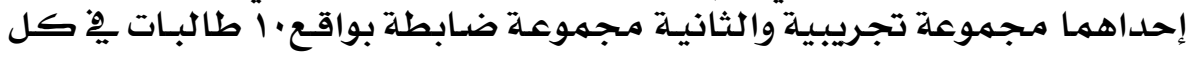

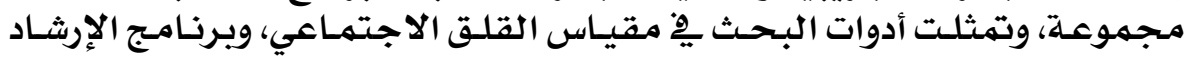

\section{9}




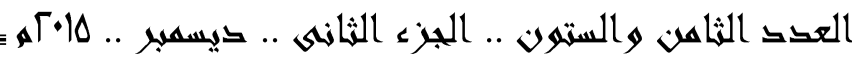

العقلاني الانفعالي، أشـارت النتائج إلى وجود فرق دال إحصائياً عند مستوى ه •. .

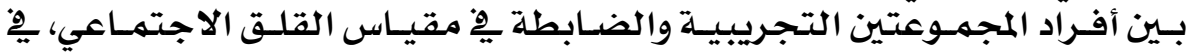
اتجاه المجموعة المراد المجتوعريبية.

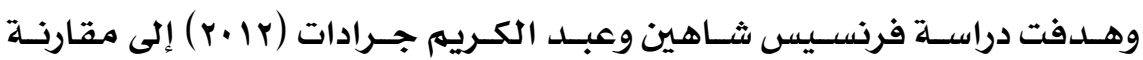

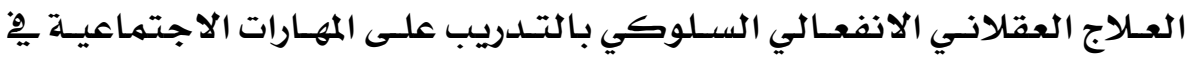

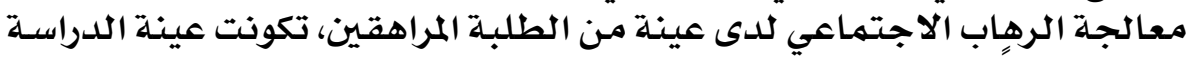

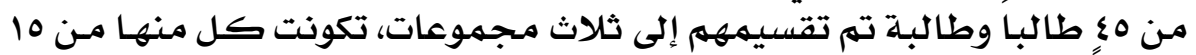

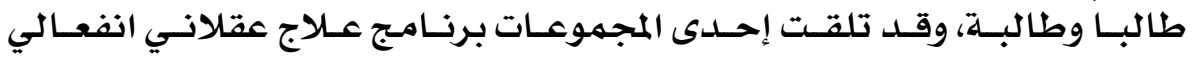

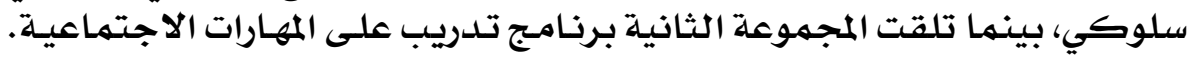

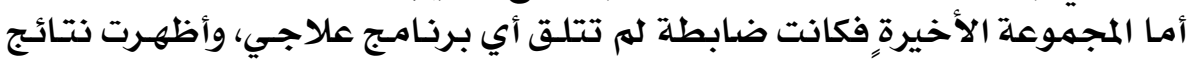

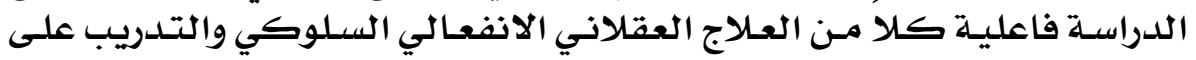

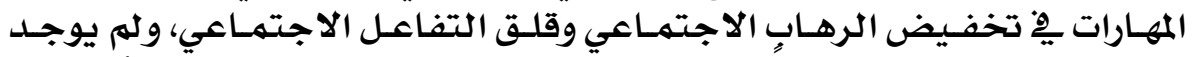

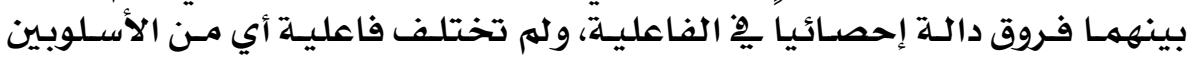
العلاجيين باختلاف الجنس.

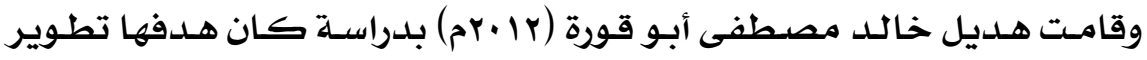

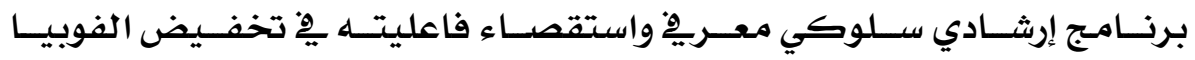

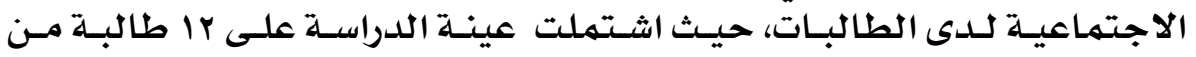

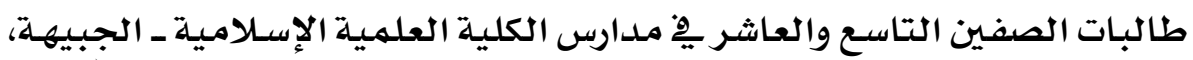

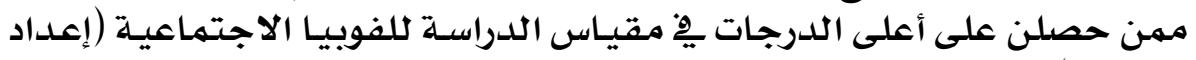

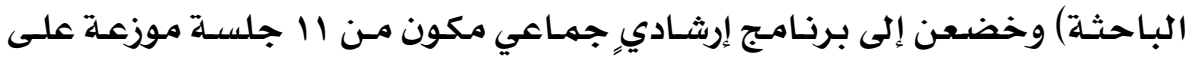

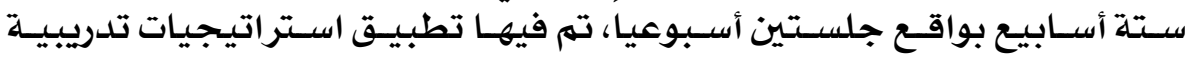

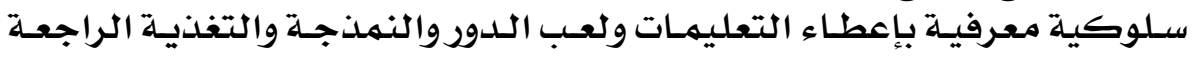

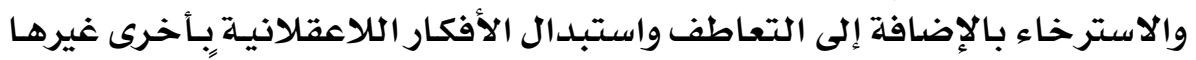

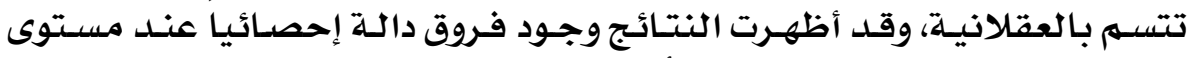

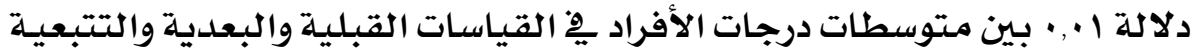

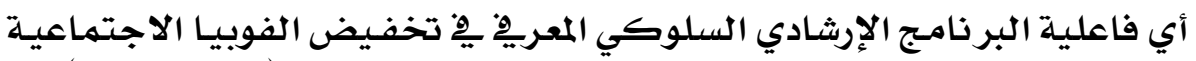

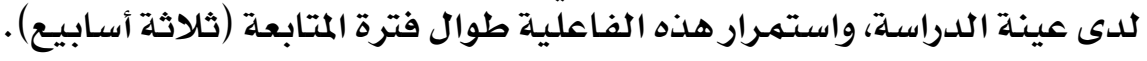

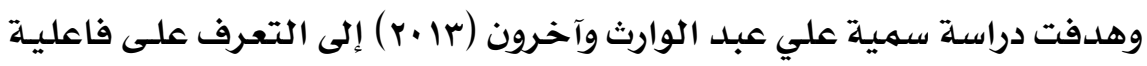

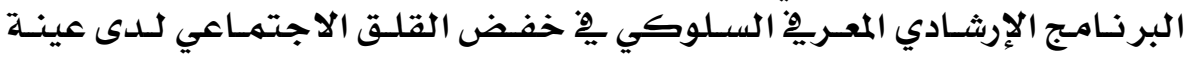

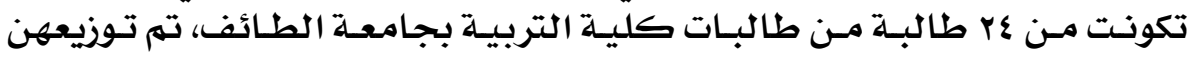

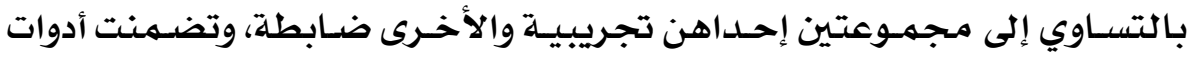

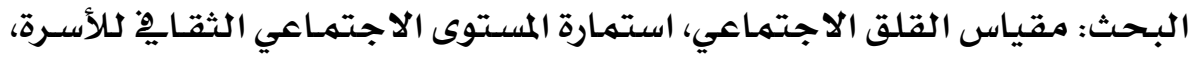

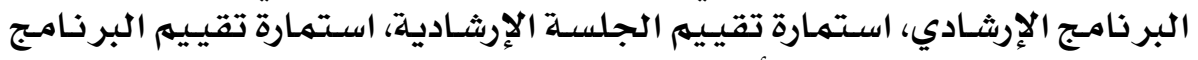

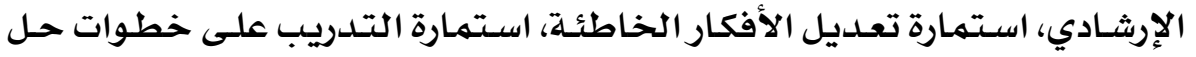

\section{$1 \cdot$}




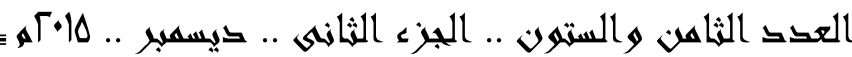

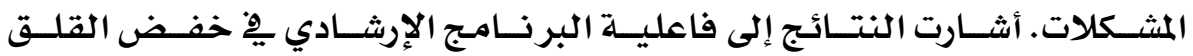

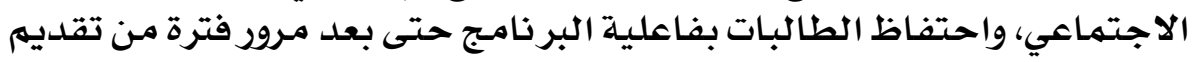
البرنام-جمجاعي، الإرشادي.

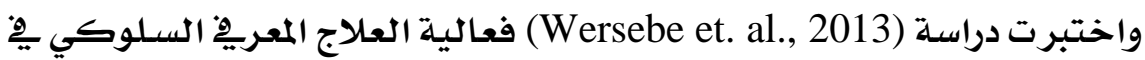

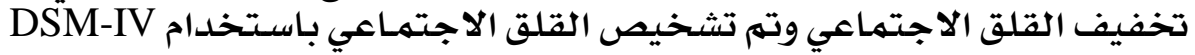

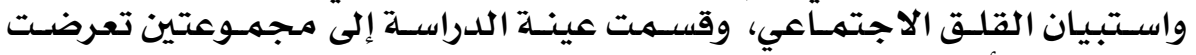

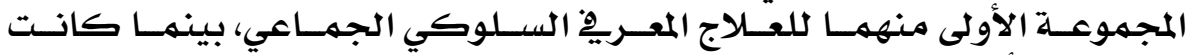

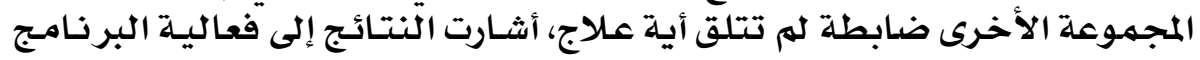

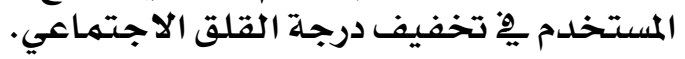

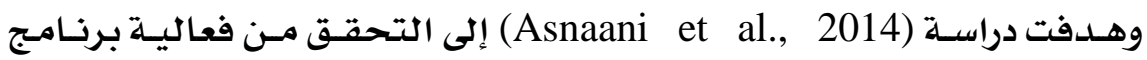

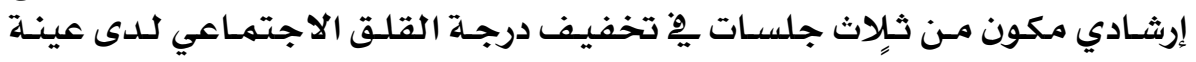

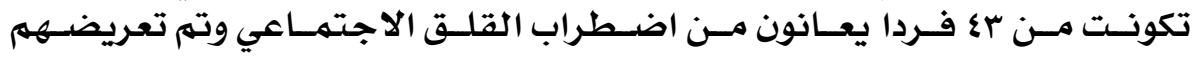

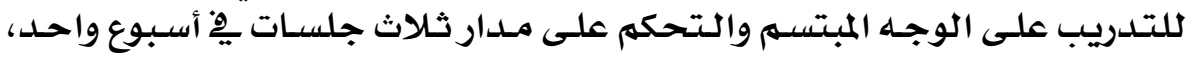

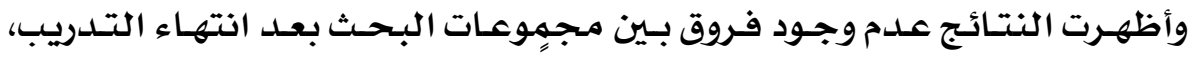

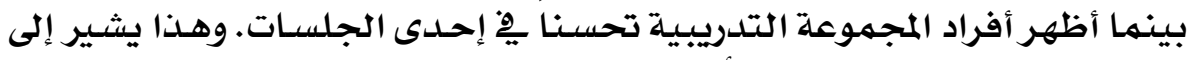

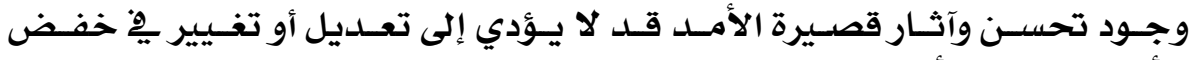

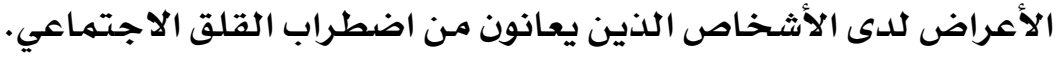

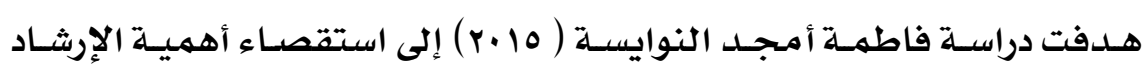

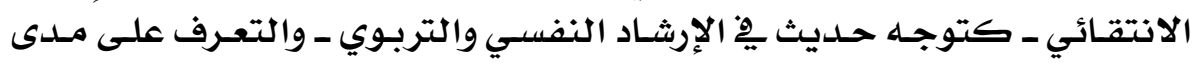

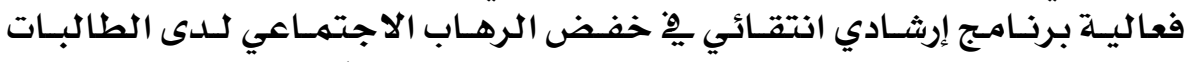

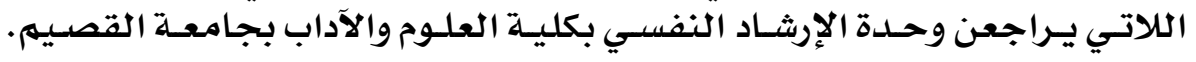

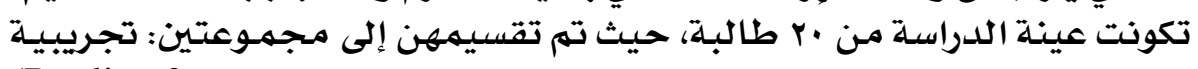

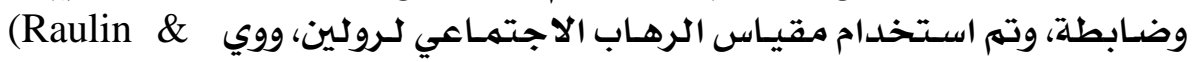

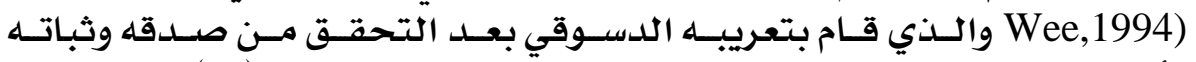

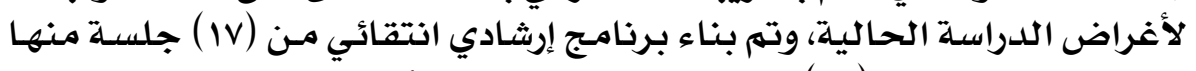

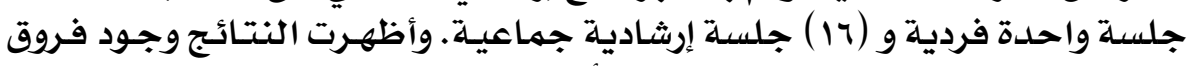

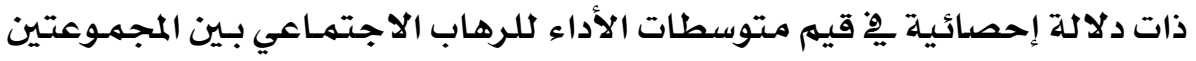

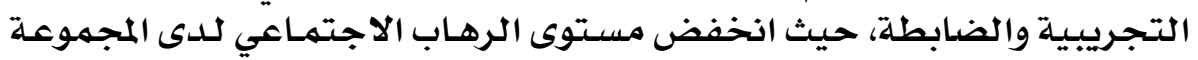

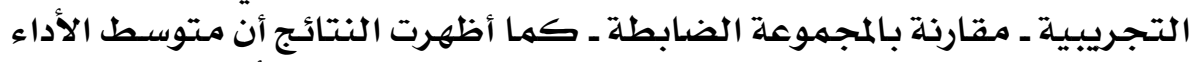

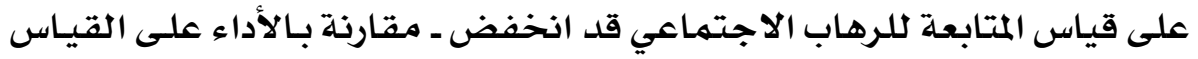
القبلي للمهجموعة المتابعة لترهريبية.

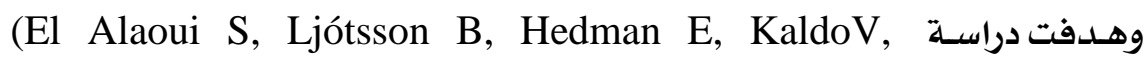
Andersson E, Rück C, Andersson, G. \& Lindefors, N. (2015)

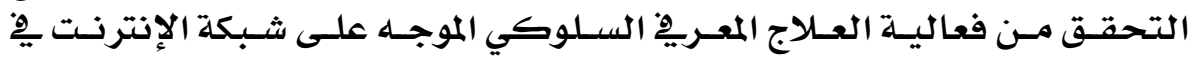




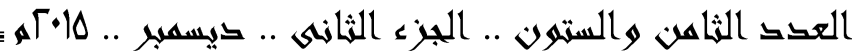

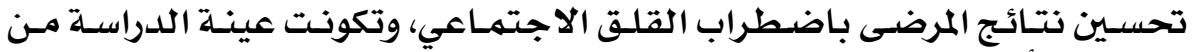

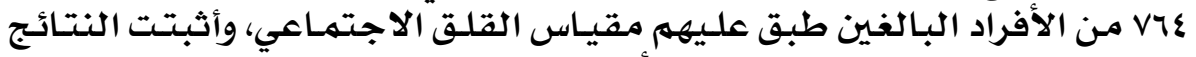

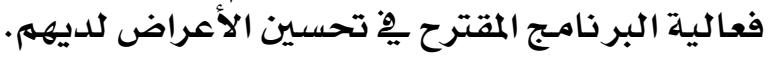

\section{• تعقيب على ها تم عرضه هن دراسات سابقة:}

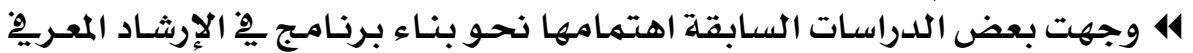

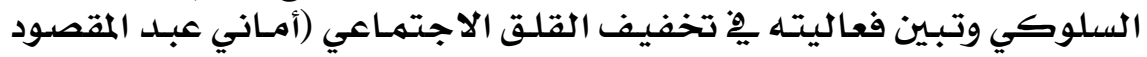

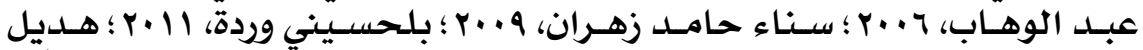

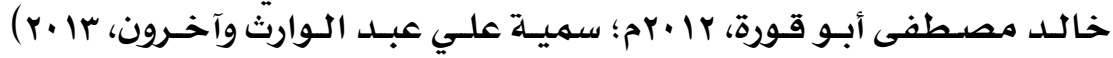
(Bruch et. al., 1991; Baggen \& Kraaimaat, 2000; Wersebe et. al.,

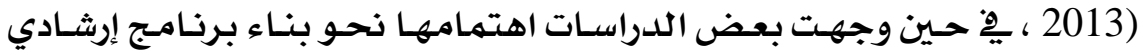

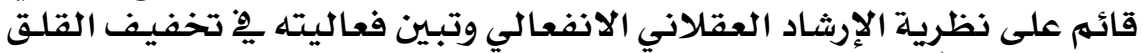

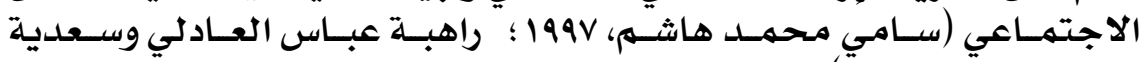

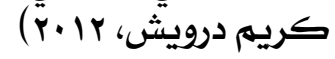

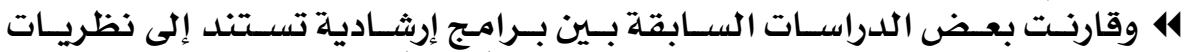

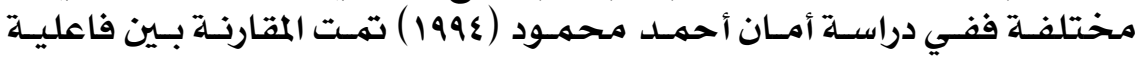

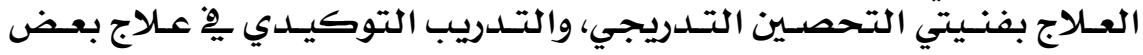

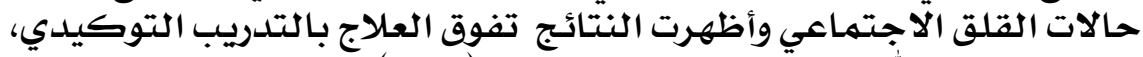

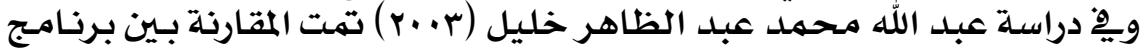

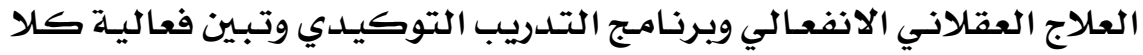

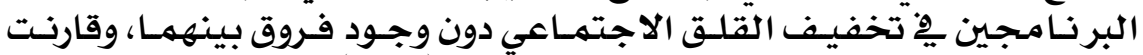

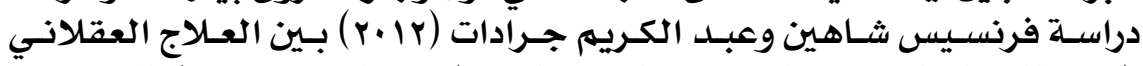

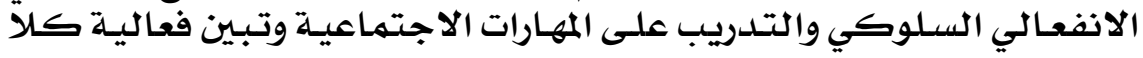

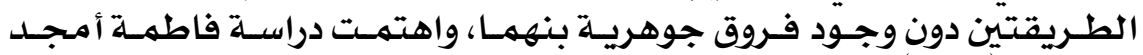

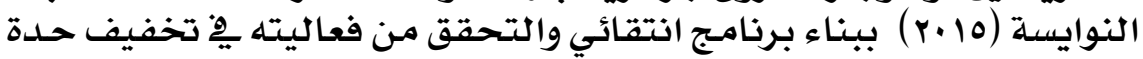

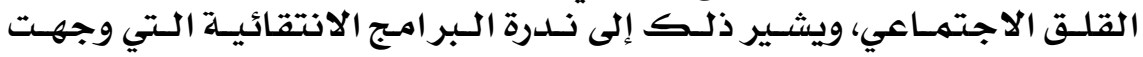

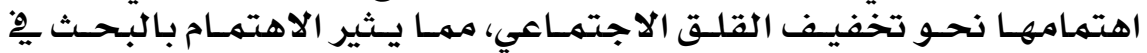
ذلك.

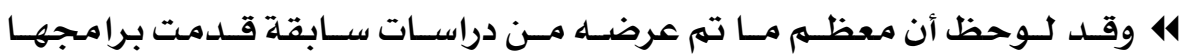

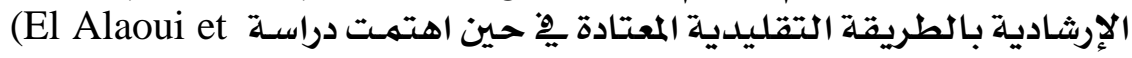

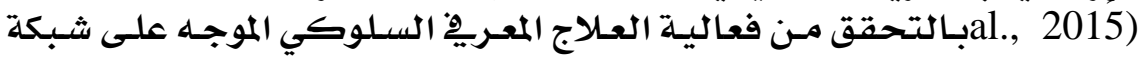

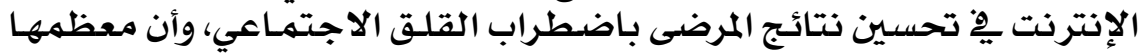

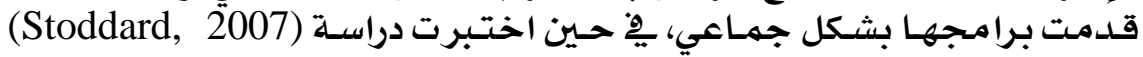

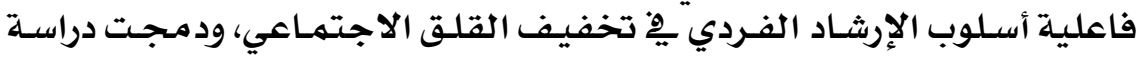
(Fisher et al., 2004)

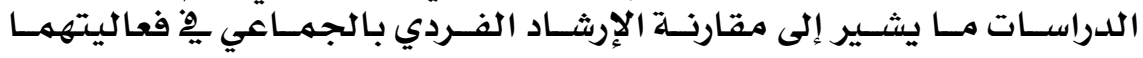

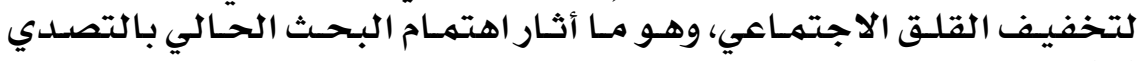
لدنك. 


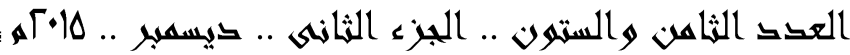

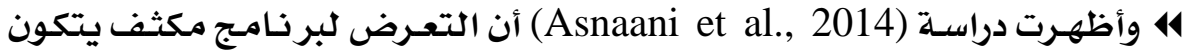

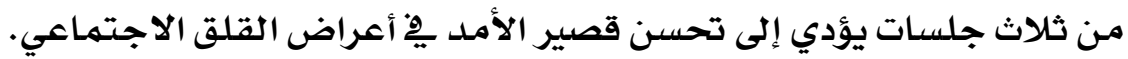

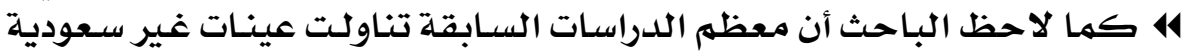

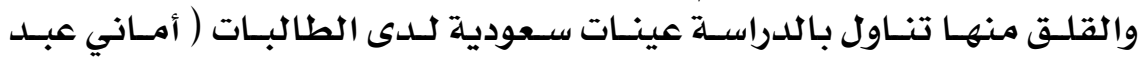

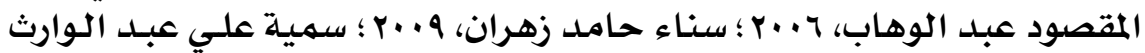

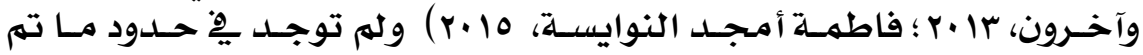

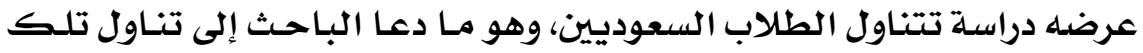
المشكلة بالدراسة والبحث.

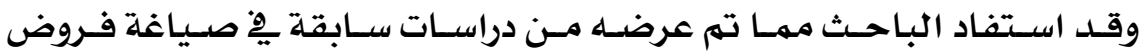

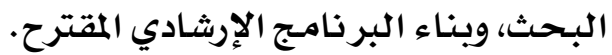

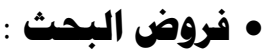

مِّف ضوء الإطار النظري وما تم عرضـه مـن دراسـات سـابقة تم صسياغة الفـروض

التالية:

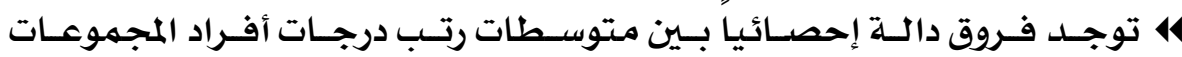

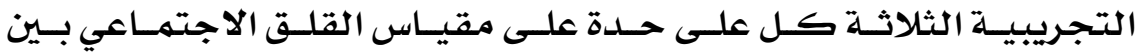

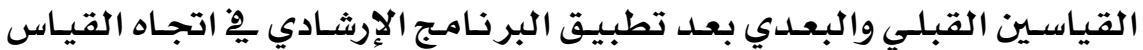
البعدي.

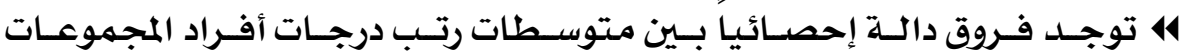

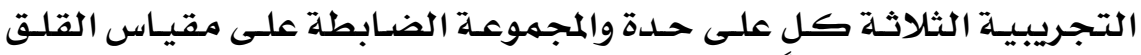

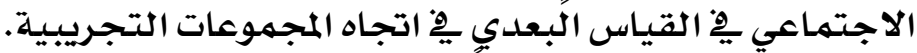

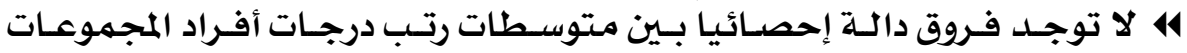

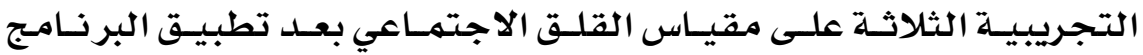
الإرشادي.

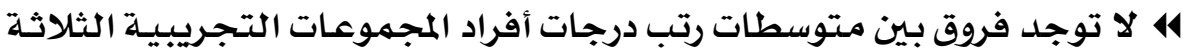

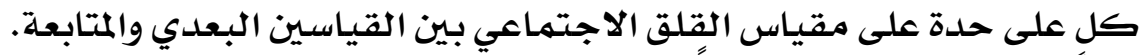

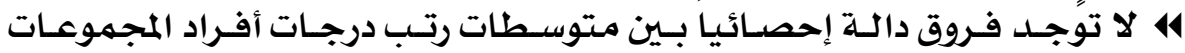

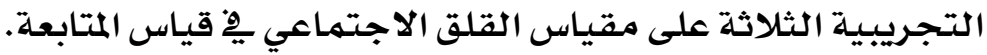

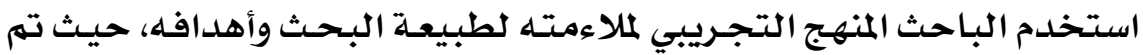

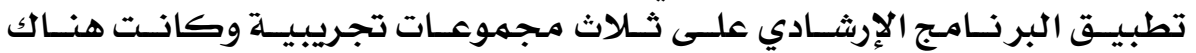

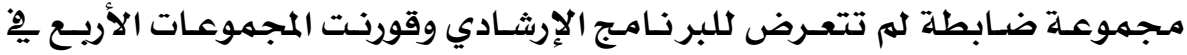

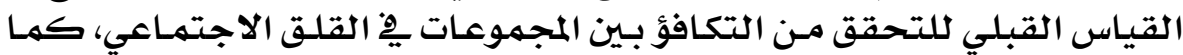

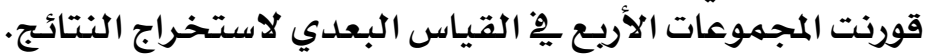

\section{$1 \cdot r$}




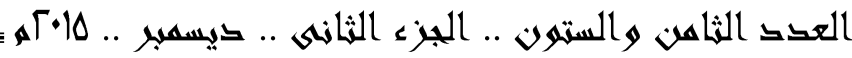

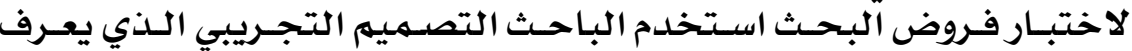

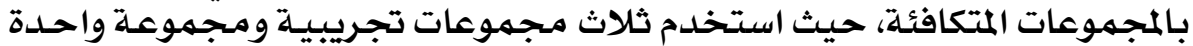

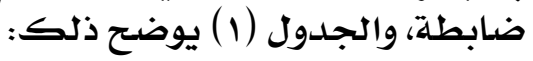

جدول (1) التصميم التجريبي لمجموعات البحث

\begin{tabular}{|c|c|c|c|c|}
\hline قياس متابعة & قياس بعدى & برنامجج إرشاد فردي & قياس قبلي & المجموعة التجريبية 1 \\
\hline قياس متابعة & قياس بعدى & برنامـج إرشاد جماعي & قياس قبلي & المجموعة التحريبيـية r \\
\hline قياس متابعة & قياس بعدى & برنامـج إرثاد فردي جماعي & قياس قبلي & المجموعة التحربيبية r \\
\hline--- & قياس بعدى & --- & قياس قيلي & المحموعة الضاططة \\
\hline
\end{tabular}

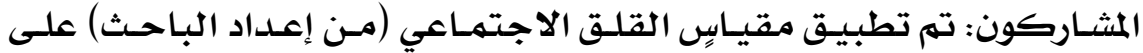

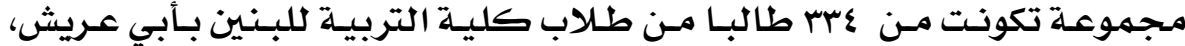

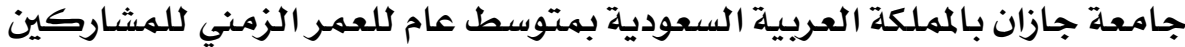

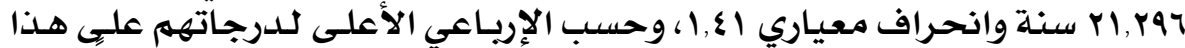

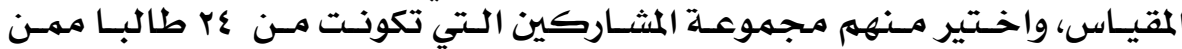

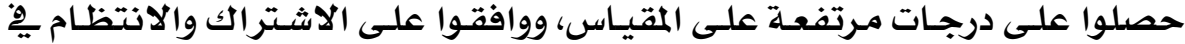

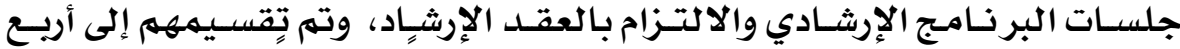

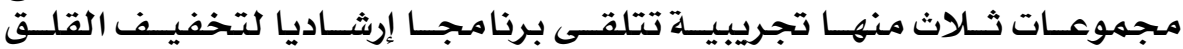

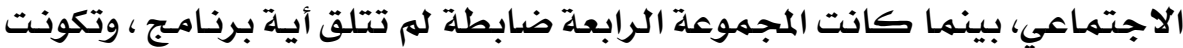

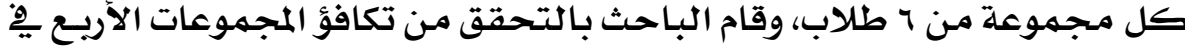

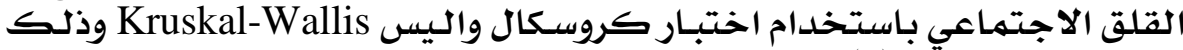

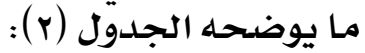

جدول (r) الفروق بين متوسطي رتب درجات القياس القبلي على مقياس القلق الاجتماعي للدى أفراد

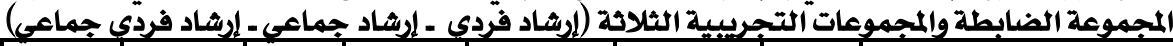

\begin{tabular}{|c|c|c|c|c|c|c|c|}
\hline الدستلوي & الحرجة & كاי & متوتبط & الالنحياري & المتوسط & العدد & المجموعات \\
\hline \multirow{4}{*}{ دائة } & \multirow{4}{*}{$r$} & \multirow{4}{*}{$\cdot, \cdot \mathrm{V}$} & ir & Y,YIV & $\mathrm{rA,ITV}_{\mathrm{N}}$ & 1 & مجموعة ضابطة \\
\hline & & & $\mid r, \varepsilon r$ & Y.QYV & $r_{\Lambda, 1 T V}$ & 7 & تجريبية| : إرشاد فردي \\
\hline & & & $11,9 Y$ & $Y, \Lambda Y \Lambda$ & $r \Lambda$ & 7 & تجريبية"r : إرشاد جماعى \\
\hline & & & Ir,TV & r.ר & rN,1TV & 1 & تجريبية"r: إرشاد فردي \\
\hline
\end{tabular}

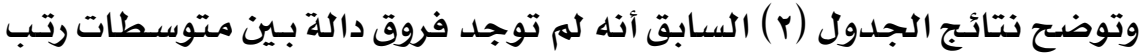

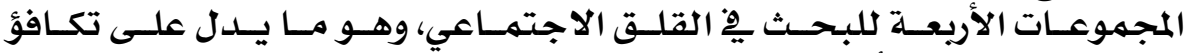

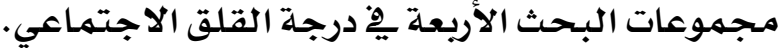

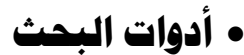

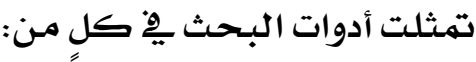

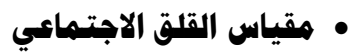

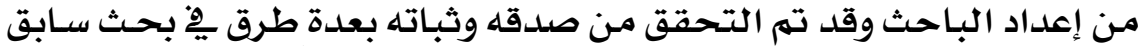

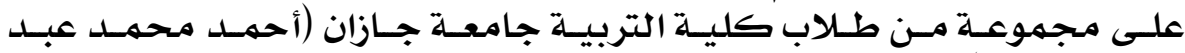

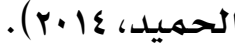




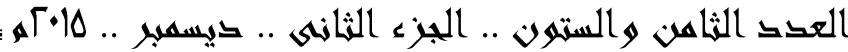

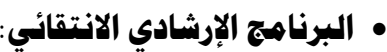

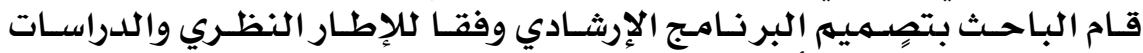

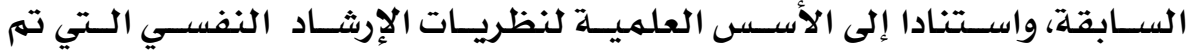

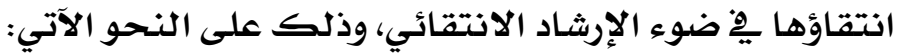

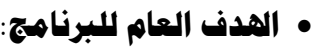

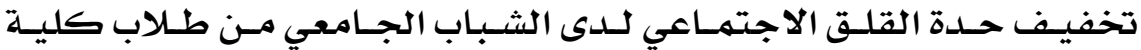

التربية جامعلة جازان.

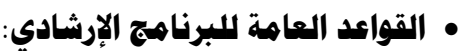

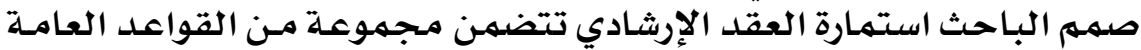

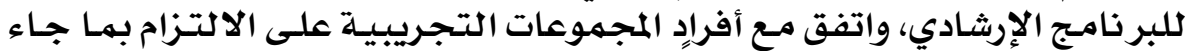

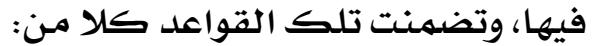

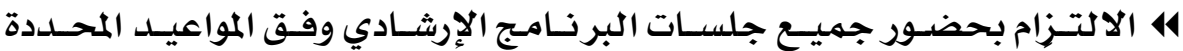

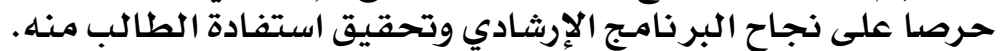
4 احترام الخصوصيلة احتية لكل طالب.

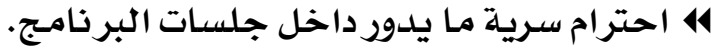

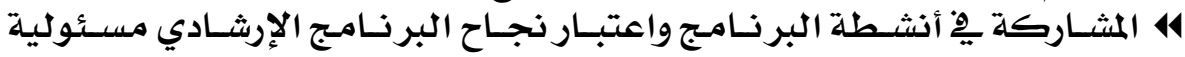

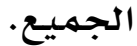

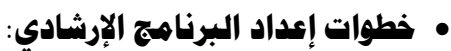

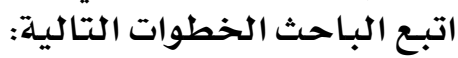

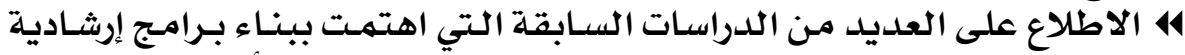

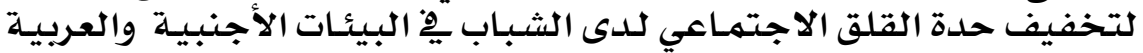

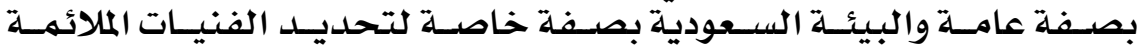

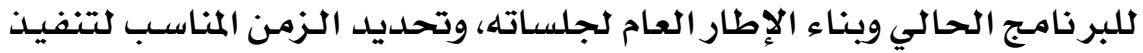

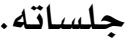

4 بنـاء البر نـامـج ِِِ صـورته الأوليـة اسـتنادا إلى الدراسـات السـابقة والنظريـات

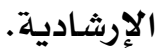

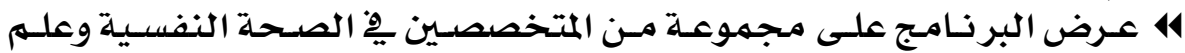

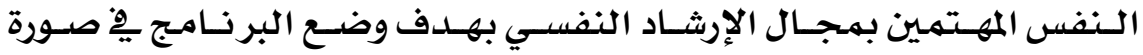

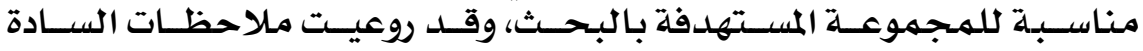

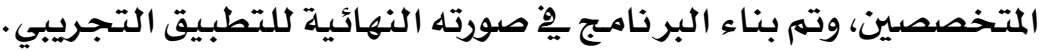

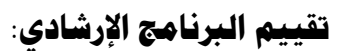

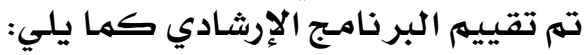

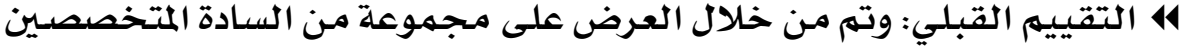

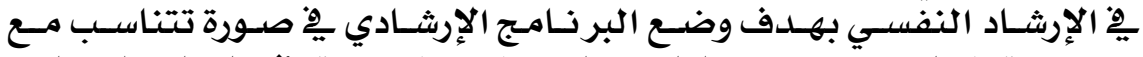

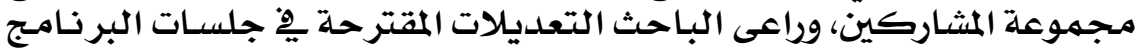

قبل تنفيذه.

\section{$1 \cdot 0$}




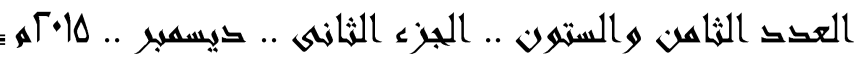

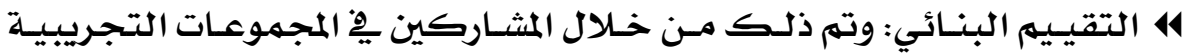

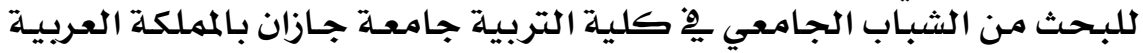

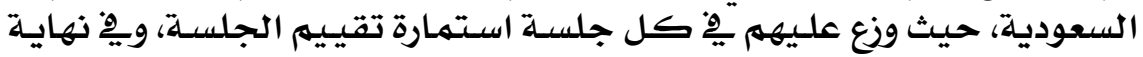

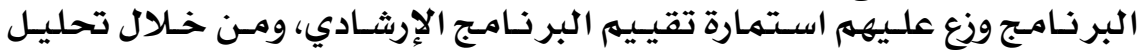

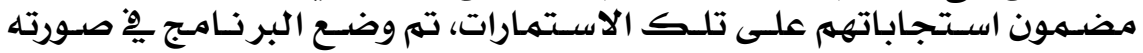

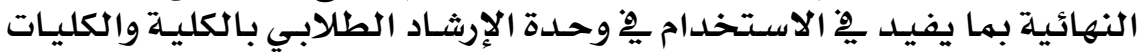

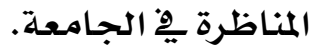

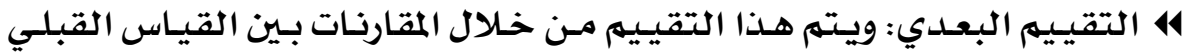

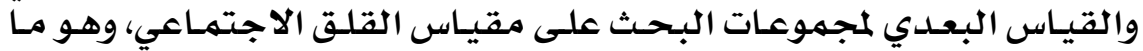

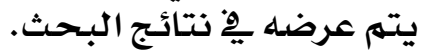

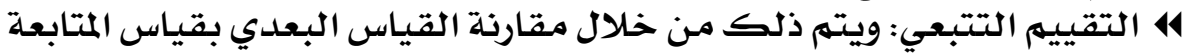

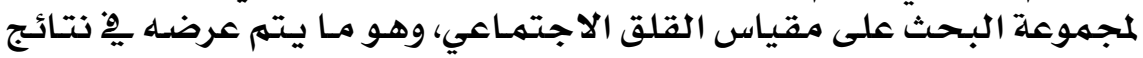
البحثث.

\section{• هنطط جلسات البرناهمج:}

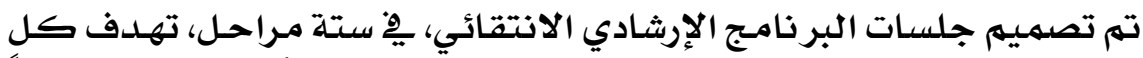

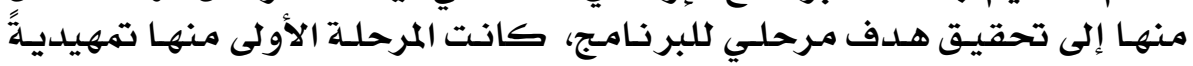

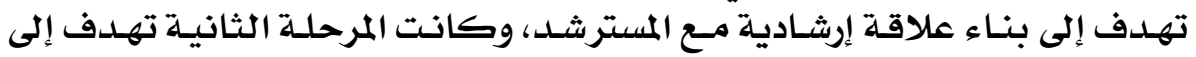

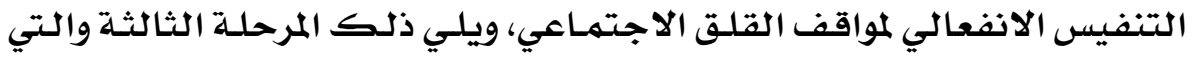

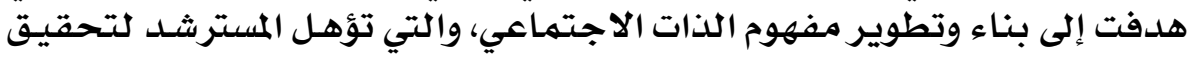

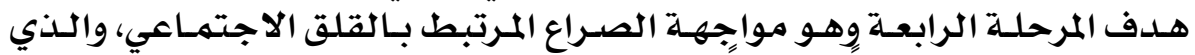

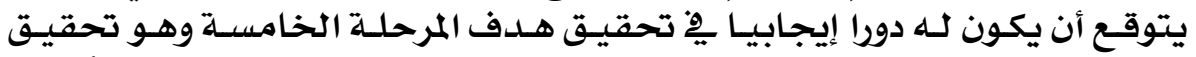

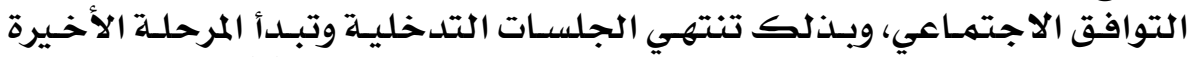

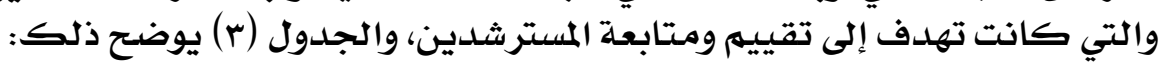

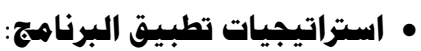

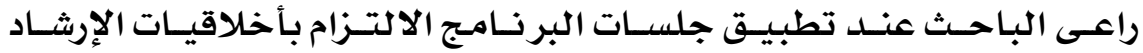

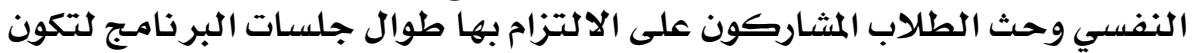

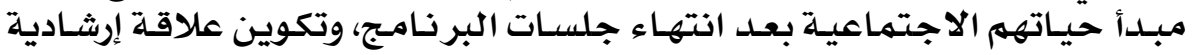

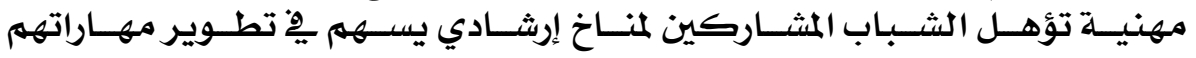

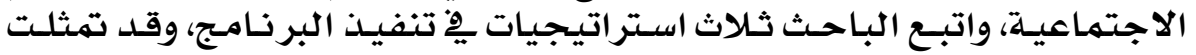

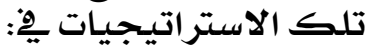

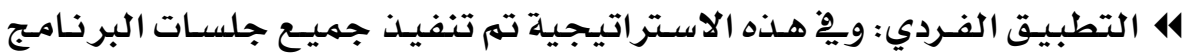

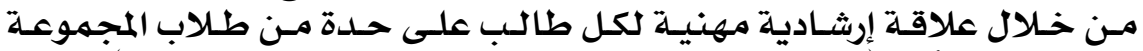

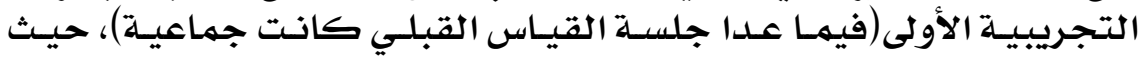

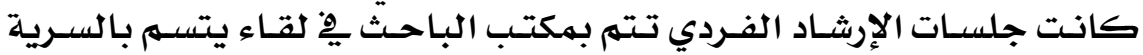

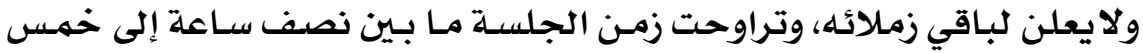




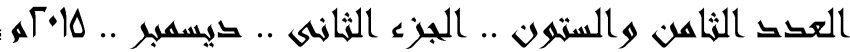

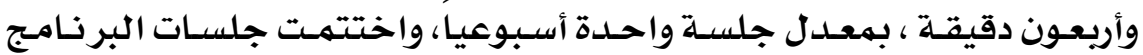

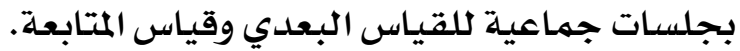

جدول (r) مخطط جلسات البرنامج

\begin{tabular}{|c|c|c|c|c|}
\hline الأدوات & الفنيات الإرشادية & الإزشادية & النظريـة & المالمرحلة المادية \\
\hline مقياس القلق الاجتماعي & --- & 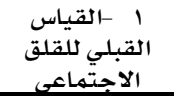 & \multirow{3}{*}{ 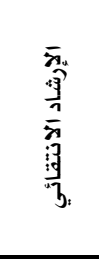 } & \multirow{3}{*}{ التمهيدية } \\
\hline استمارة المقابلة الكلينيكية استمارة & مقابلة كلينيكية - مقخيل & 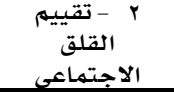 & & \\
\hline استمارة العقد الإرشادي استمارة & $\begin{array}{l}\text { - المحاضرة والمناقشة } \\
\text { - التعزيز }\end{array}$ & 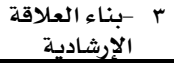 & & \\
\hline 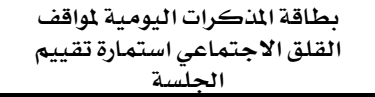 & $\begin{array}{l}\text { السيكودرامـا أو الكرسي - التنفيسي } \\
\text { الانفعالى }\end{array}$ & ع - قلقلق المواقفة & \multirow{2}{*}{ 承事 } & \multirow{2}{*}{ الالانفعاليس الاجفت القتلق } \\
\hline 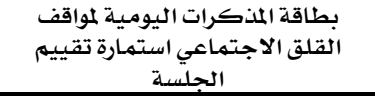 & التداعي الحرر - التنفيس & 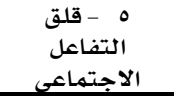 & & \\
\hline بطاقة المذكرات استمارة اليومييم للسلوكة الجلسة & 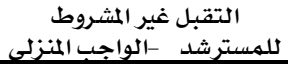 & 1 & \multirow{3}{*}{ 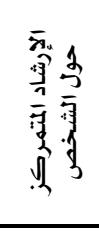 } & \multirow{3}{*}{ بناء وتطوم الذات } \\
\hline 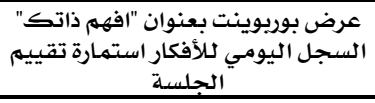 & 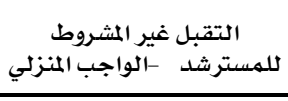 & 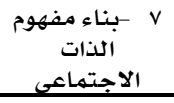 & & \\
\hline 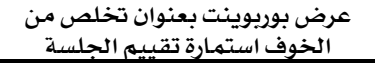 & 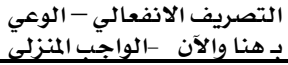 & 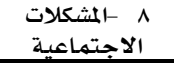 & & \\
\hline 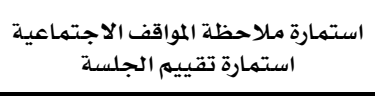 & 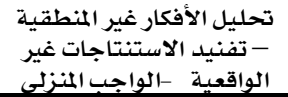 & 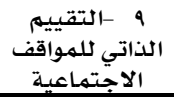 & \multirow{3}{*}{ 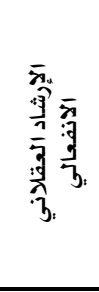 } & \multirow{3}{*}{ الماجراجهة المرتبط المبلق } \\
\hline 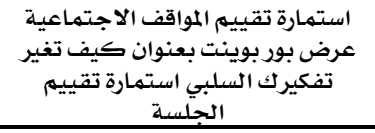 & الأفكار -الواجناع المنطقي -وقاجفئي & الأفكار غير العنيد & & \\
\hline بطاقة ملاحظة التواصل مـع الآخرين & 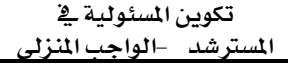 & $\begin{array}{l}11 \\
\text { المسئولية - تحملة }\end{array}$ & & \\
\hline 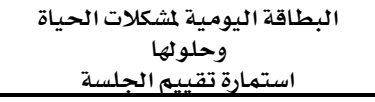 & 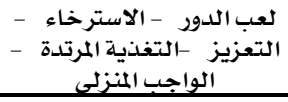 & 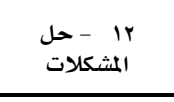 & \multirow{3}{*}{ 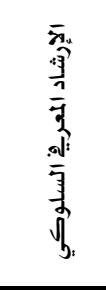 } & \multirow{3}{*}{ الاجتوافقيق } \\
\hline 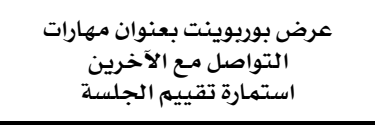 & 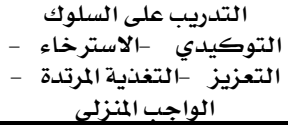 & الاجتماعية - المهارات & & \\
\hline التفكير الناقدر استتمارة تقييـيم الجلسـة مهارات & النمذجة - الاسترخاء - التعزيز & 1 1 الناقد -التفكير & & \\
\hline مقياس القلق الاجتماعي استمـارة & --- & 10 & & \multirow{2}{*}{ والتتقييم } \\
\hline مقياس القلق الاجتمـاعي & $-\quad-\quad-\quad-$ & 17 - 17 & & \\
\hline
\end{tabular}

4 التطبيق الجماعي: ويْ هذه الاستراتيجيـة تم تنفيذ جميـع جلسـات البرنامـج

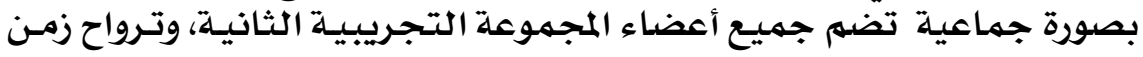

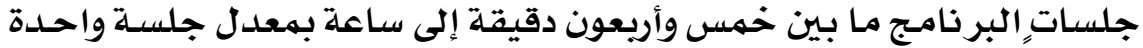
أسبوعيا. 


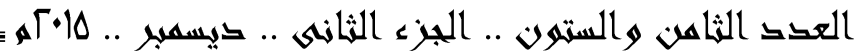

414

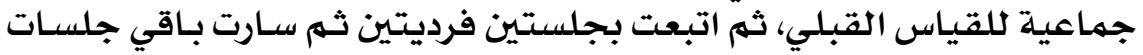

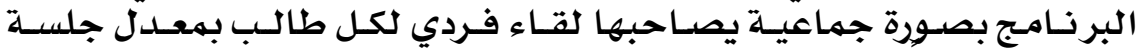

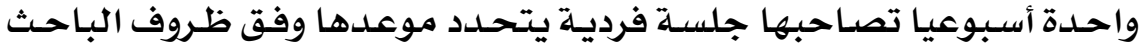

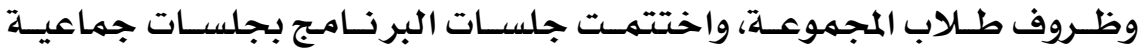

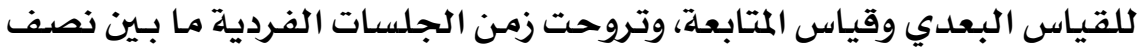

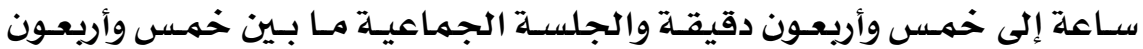
دقيقة إلى سـاعة.

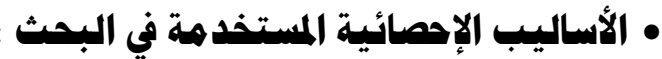

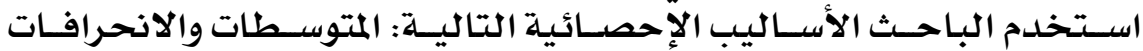

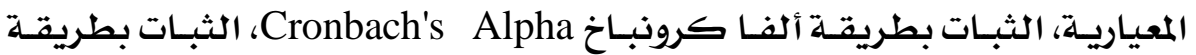

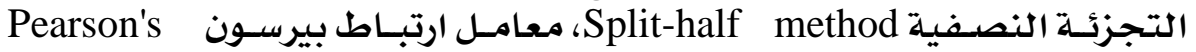

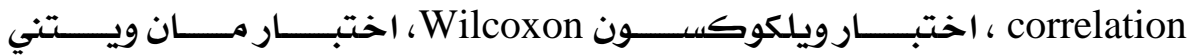

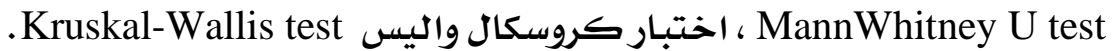

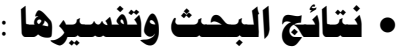 \\ • ن نتائج اختبار الفرض الأول وتفسيرها:}

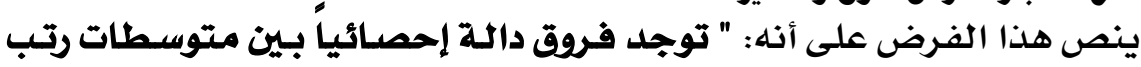

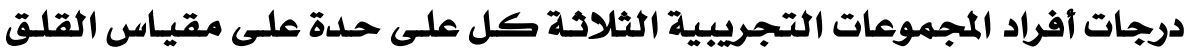

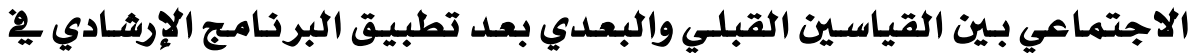

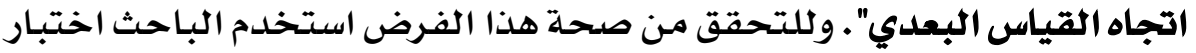

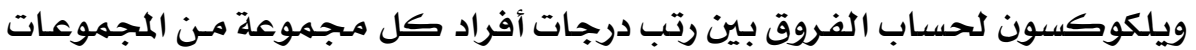

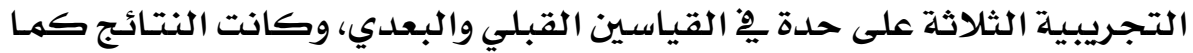

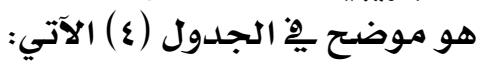

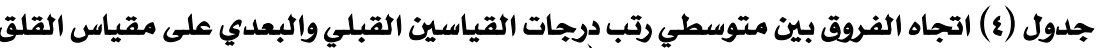

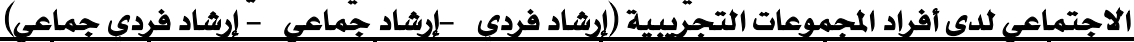

\begin{tabular}{|c|c|c|c|c|c|c|c|c|c|c|}
\hline \multirow[b]{2}{*}{ مستولى الدلادي } & \multirow[b]{2}{*}{ قيمة } & \multicolumn{2}{|c|}{ الرتب الموجبة } & \multicolumn{2}{|c|}{ الرتب السـالبـة } & \multicolumn{2}{|c|}{ القياس البعدىى } & \multicolumn{2}{|c|}{ القياس القبلي } & \multirow{2}{*}{ التجريبيية } \\
\hline & & المجموع & المتوسط & المجموع & المتوسط & معياري & متوسط & معياري & متوسط & \\
\hline$\cdot, 0$ & $\begin{array}{l}- \\
Y, Y \backslash\{ \\
\end{array}$ & صفر & صفر & $r 1, \cdot$. & r.o. & $\cdot, 9 \wedge r$ & Y0,1TV & Y.QYV & rA,ITV & فرردي \\
\hline., 0 & $\begin{array}{c}- \\
Y, Y \cdot V\end{array}$ & صفر & صفر & $r 1, \cdot \cdot$ & r.o. & • AIV & ro,T V V & Y,AYA & rı & جماعي \\
\hline$\because, 0$ & $\begin{array}{l}- \\
r, r \cdot I\end{array}$ & صفر & صفر & $r 1, \cdot \cdot$ & r.o. & $\cdot, \Lambda T V$ & r $1,0$. & r.ד & rA, ITV & جماعي \\
\hline
\end{tabular}

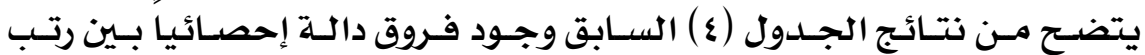

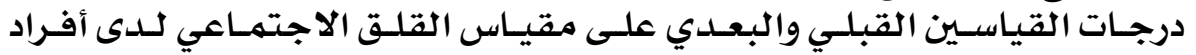




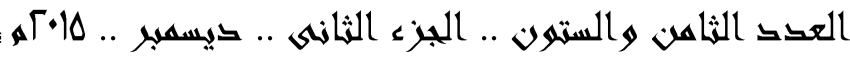

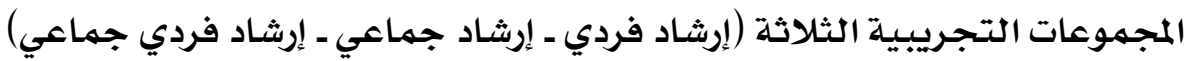

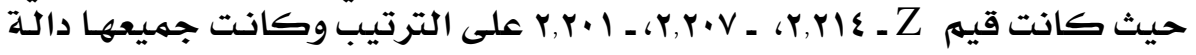

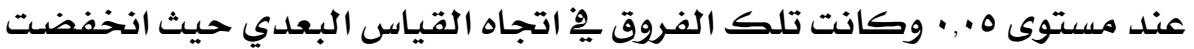

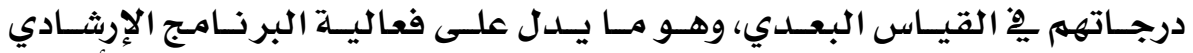

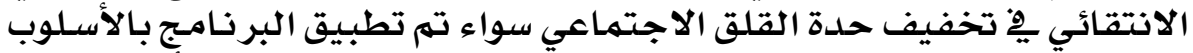

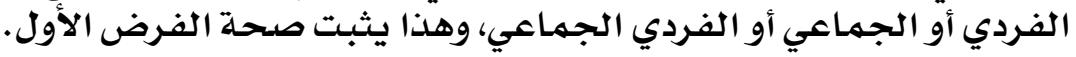

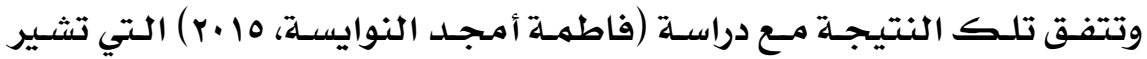

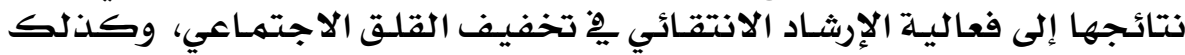

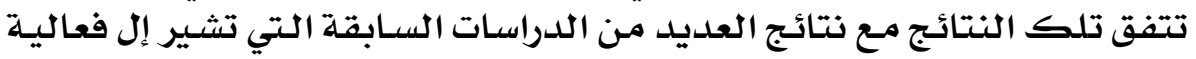

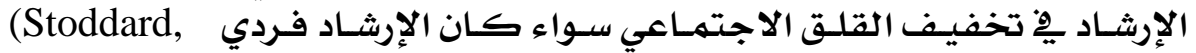

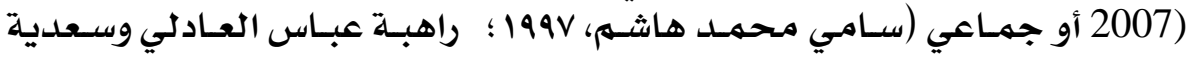

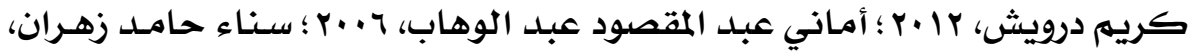

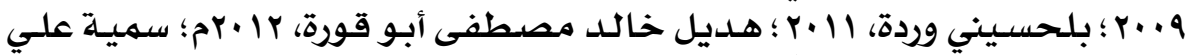

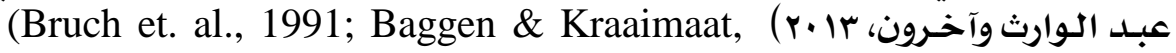
(Fisher et al., 2004) (2000; Wersebe et. al., 2013)

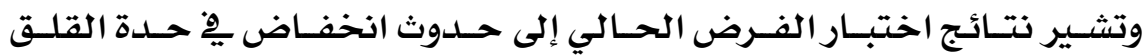

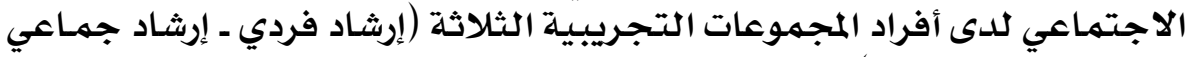

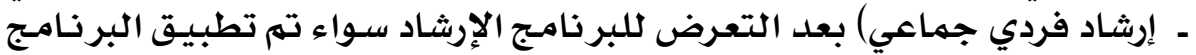

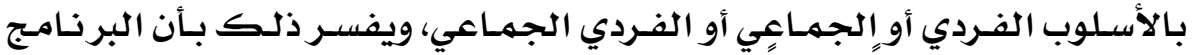

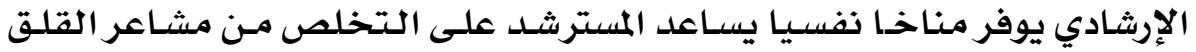

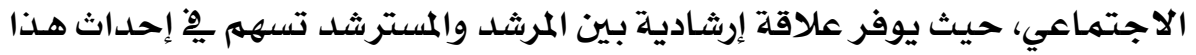

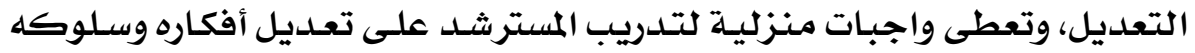

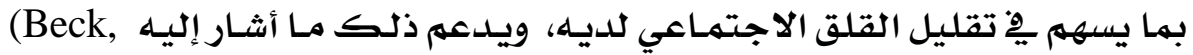

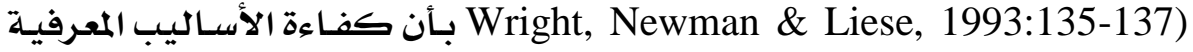

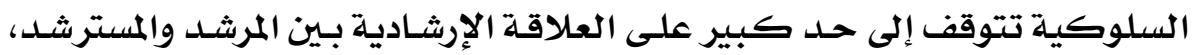

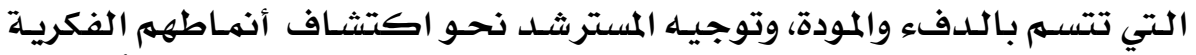

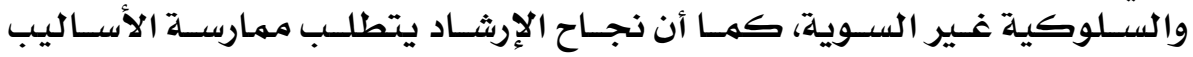

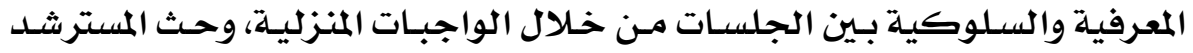

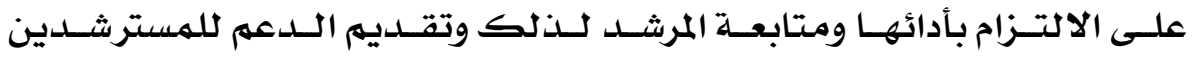

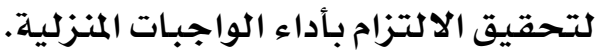

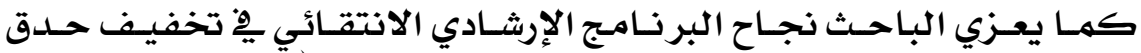

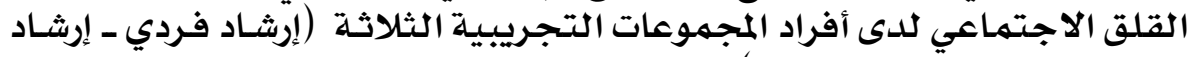

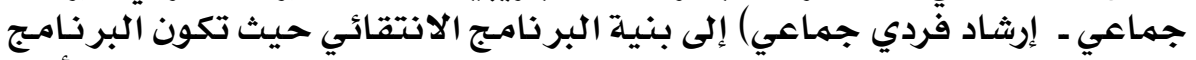

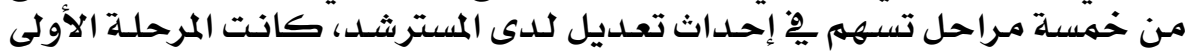




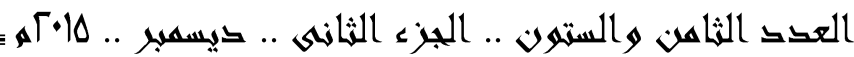

تمهيدية تهدف لبناء علاقة إرثادية مهنية تتسهم بالدفء والمودة، وكانت الماند المرحلـة

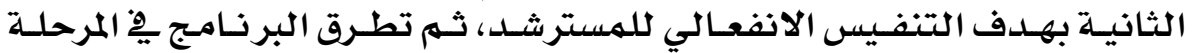

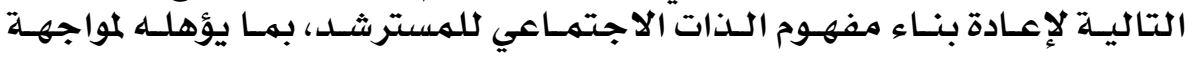

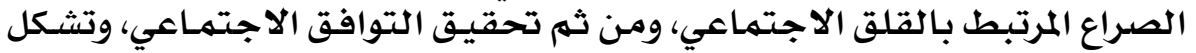

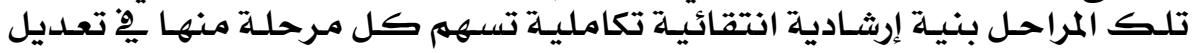

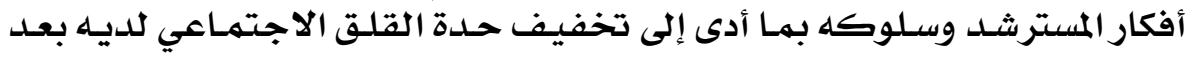

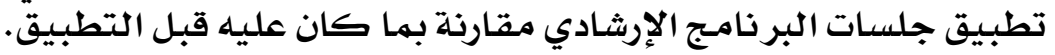

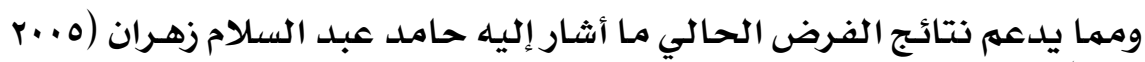

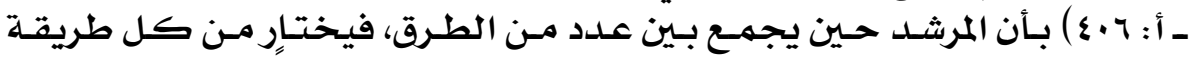

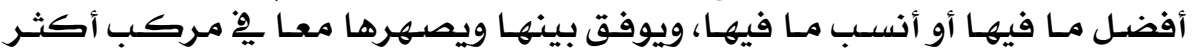

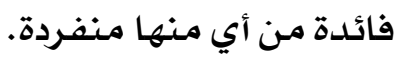

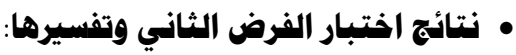

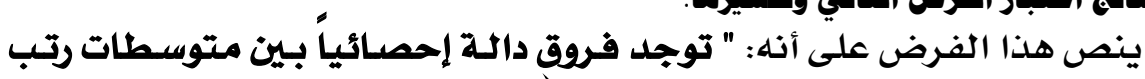

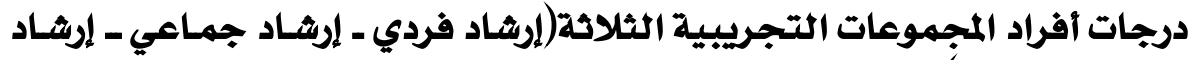

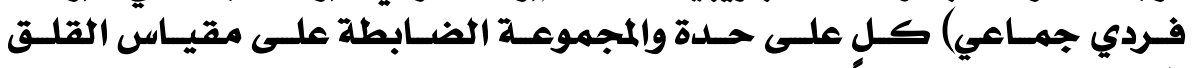

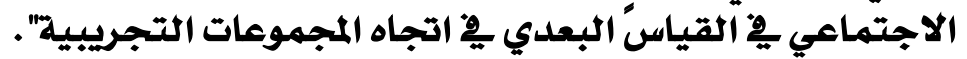

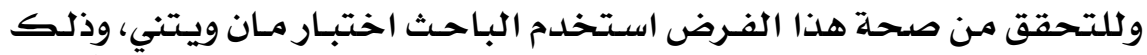

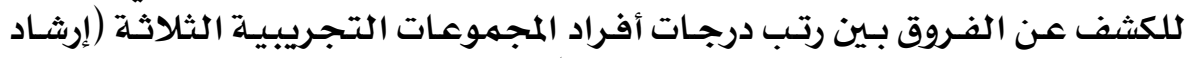

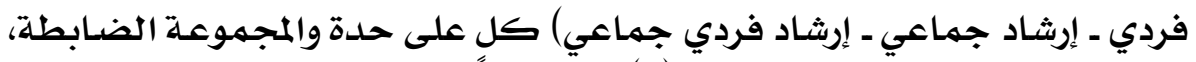

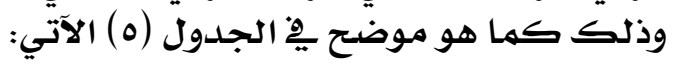

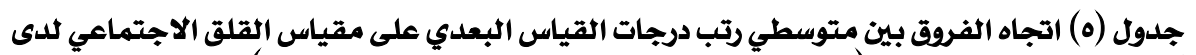

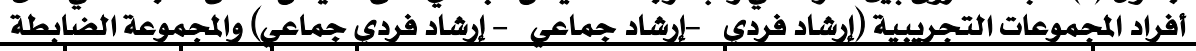

\begin{tabular}{|c|c|c|c|c|c|c|c|c|c|c|c|c|}
\hline \multirow[b]{2}{*}{ مستوى الدلادة } & \multirow[b]{2}{*}{ قيمة Z } & \multirow[b]{2}{*}{ قيمـة } & \multirow[b]{2}{*}{ قيمة } & \multicolumn{4}{|c|}{ المجموعة الضابطة } & \multicolumn{4}{|c|}{ المجموعة التجريبية } & \multirow[b]{2}{*}{ المجرموعادية } \\
\hline & & & & 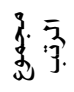 & 多等 & $\frac{\bar{\gamma}}{\bar{g}} \frac{\xi}{y}$ & 多 & 多等 & 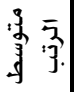 & $\frac{\bar{y}}{\bar{g}} \frac{\xi}{y}$ & 季 & \\
\hline$\cdot, \cdot 1$ & r.q1r- & $r ı, \cdots$ & صفر & ov,,$\cdot$ & $9,0$. & r,AVO & rוr.r & $r 1, \cdots$ & r.o. & $\cdot, 9 \wedge \mathrm{r}$ & Y0,17V & إرشاد فردي \\
\hline$\cdot, \cdot 1$ & Y,Q1r- & $r{ }_{1}, \cdots$ & صفر & ov,,$\cdot$ & $9,0$. & Y,AVO & rیrrr & $r_{1}, \cdots$ & r.o. & $\cdot, \Lambda ו \vee$ & Y0,TTV & جماعي \\
\hline$\cdot, \cdot 1$ & ห.१९९- & $r_{1}, \cdot$ & صفر & ov,,$\cdot$ & $9,0$. & Y,AVO & ru,rrr & $r_{1}, \cdots$ & r.o. & $\cdot, \Lambda \mathrm{rV}$ & ri,o. & إرشاد فردي \\
\hline
\end{tabular}

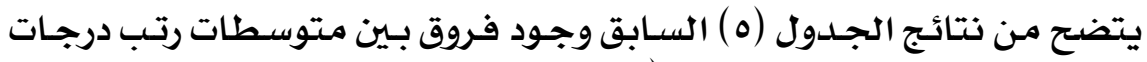

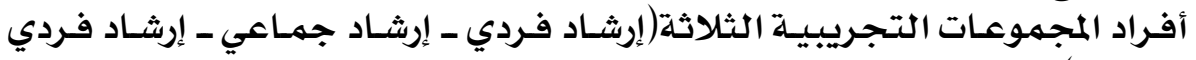

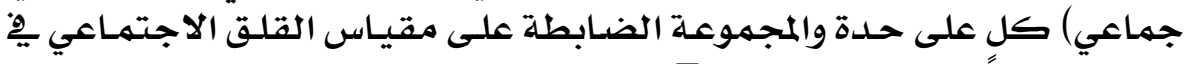

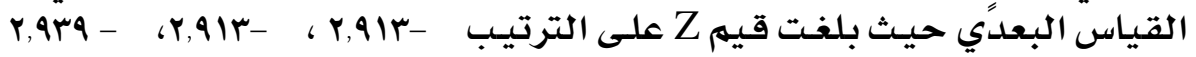

\section{1.}




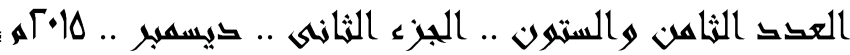

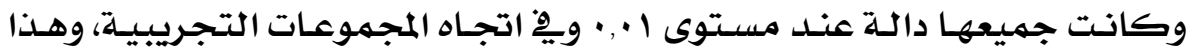

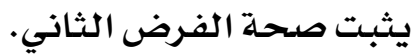

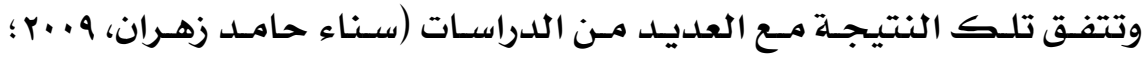

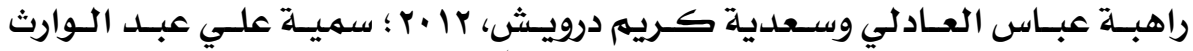

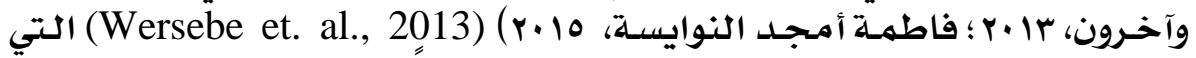

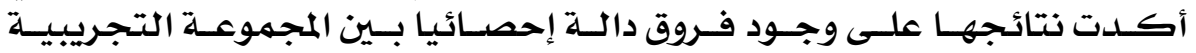

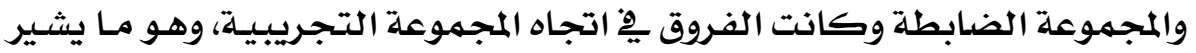

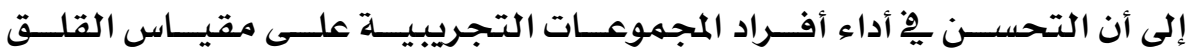

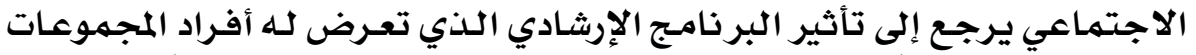

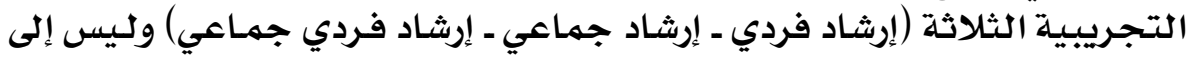

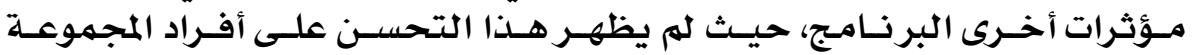

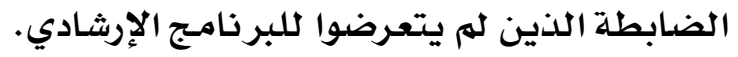

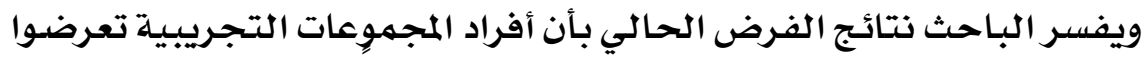

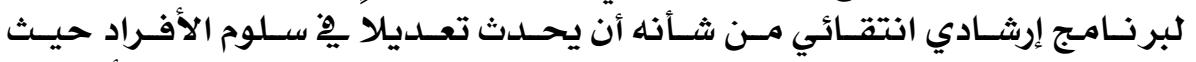

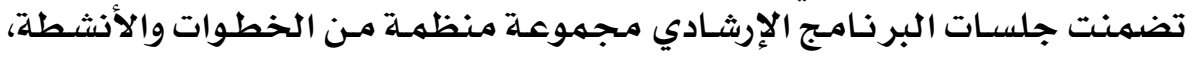

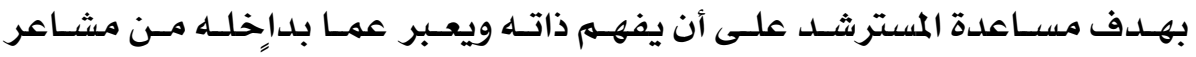

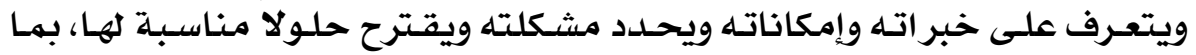

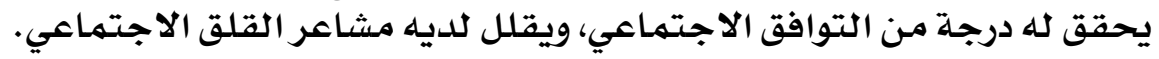

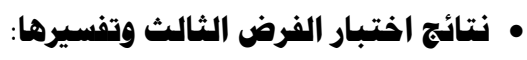

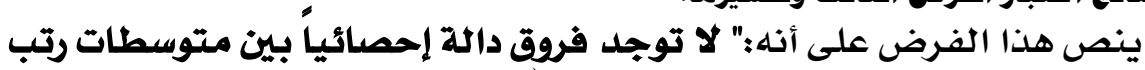

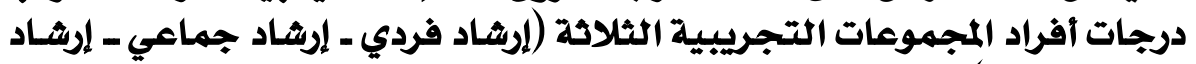

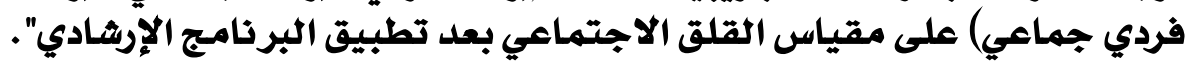

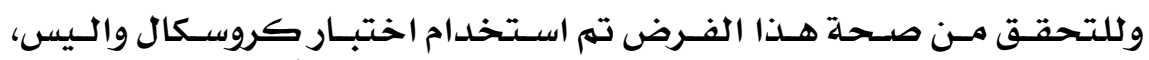

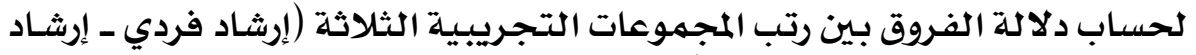

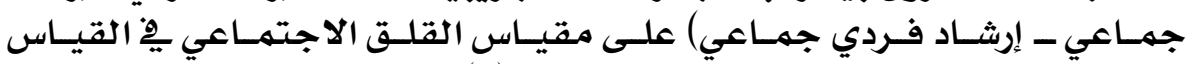

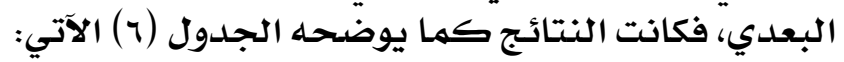

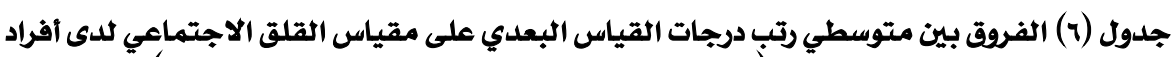

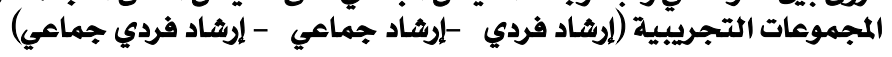

\begin{tabular}{|c|c|c|c|c|c|c|c|}
\hline مستوى & الحرية & كاי & متوسط الرتب & الالنحراف & المتوسط & العدد & المجرموعاتية \\
\hline \multirow{3}{*}{$\cdot,+1$} & \multirow{3}{*}{ r } & \multirow{3}{*}{$1 r, 111$} & 11,20 & $\cdot 9 \wedge r$ & Y0,17V & 7 & إرشاد فردي \\
\hline & & & Ir,Yo & $\cdot, \Lambda 1 V$ & Y0,TYV & 1 & إرشاد جماعي \\
\hline & & & r,o. & $\cdot, \wedge r V$ & r $1,0$. & 7 & إرشاد فردي جماعى \\
\hline
\end{tabular}




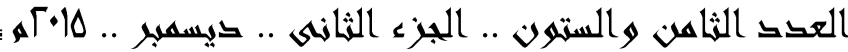

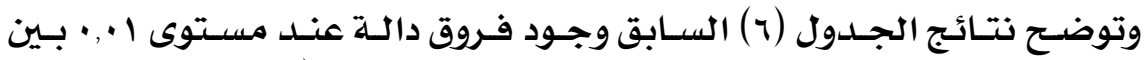

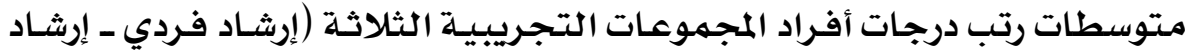

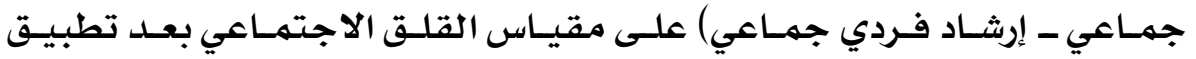

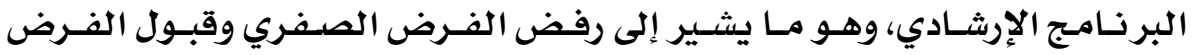

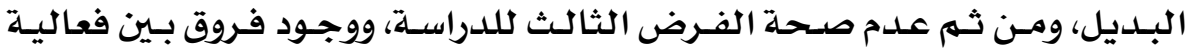

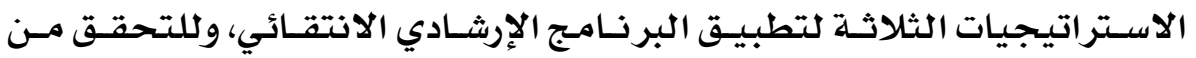

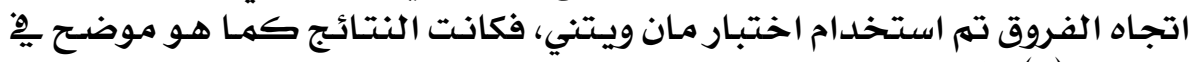

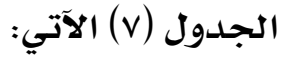

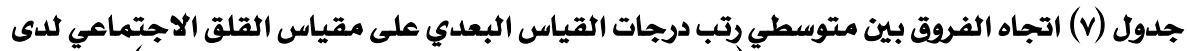

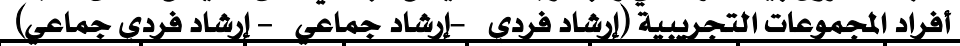

\begin{tabular}{|c|c|c|c|c|c|c|c|c|}
\hline مستوى الدلادي & قيمة Z & قيمة & قيمة & مجموع & متوسط & الانحياري & المتوسط & التجريبية \\
\hline \multirow{2}{*}{ غير دال } & \multirow{2}{*}{ - VTr- } & \multirow{2}{*}{$r \leqslant, 0}$. & \multirow{2}{*}{$1 r, 0}$. & $r \xi, 0$. & $0, V_{0}$ & $\cdot, 9 \wedge \mu$ & Y0,17V & إرشاد فردي \\
\hline & & & & $\{r, 0$. & $V, Y O$ & $\cdot, \Lambda 1 V$ & Y0,7TV & إرشاد جماعي \\
\hline \multirow[b]{2}{*}{$\cdot, \cdot 1$} & \multirow[b]{2}{*}{ Y.971- } & \multirow[b]{2}{*}{ rI,.. } & \multirow[b]{2}{*}{ صفر } & $\Delta v, \cdot \cdot$ & $9,0$. & $.9 \wedge r$ & Y0,17V & إرشـاد فردى \\
\hline & & & & $r 1, \cdot \cdot$ & r.o. & •,ArV & Y $1,0$. & إرشـاد فردي \\
\hline \multirow[b]{2}{*}{$\cdot, \cdot 1$} & \multirow[b]{2}{*}{ Y.971- } & \multirow[b]{2}{*}{ r $1, \cdots$} & \multirow[b]{2}{*}{ صفر } & $\Delta \mathrm{V}, \cdot \cdot$ & $9,0$. & $\cdot, \Lambda I V$ & Y0,TTV & إرشاد جماعى \\
\hline & & & & $r 1, \cdot \cdot$ & r.,. & - ArV & Y $1,0$. & إرشـاد فردي \\
\hline
\end{tabular}

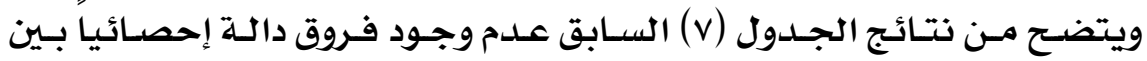

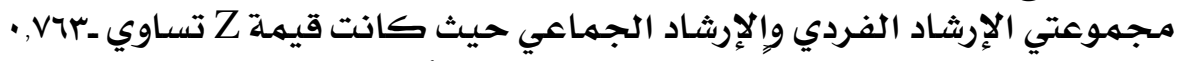

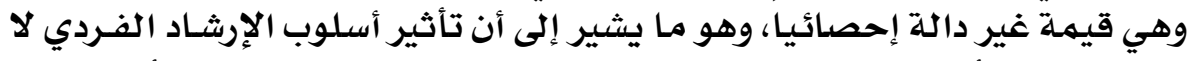

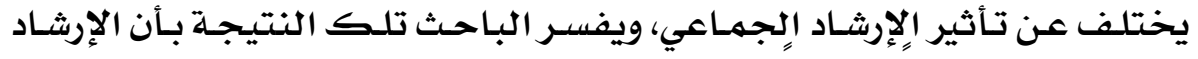

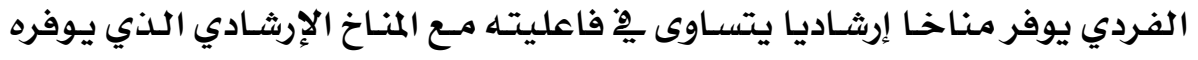

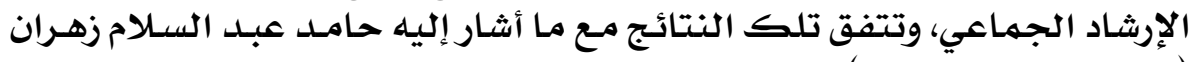

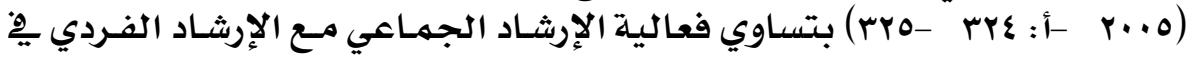

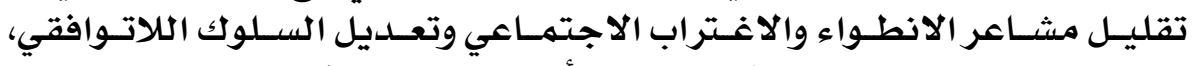

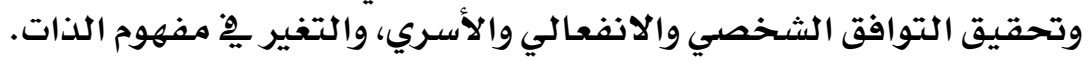

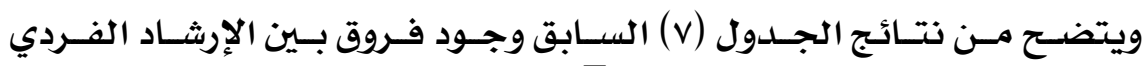

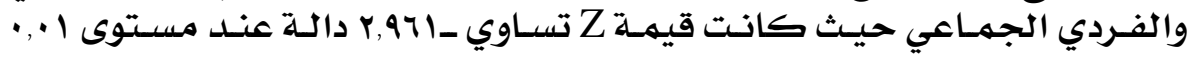

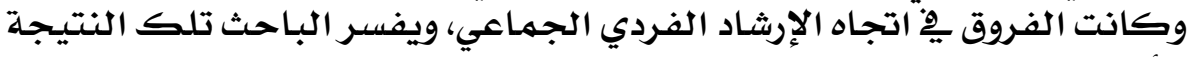

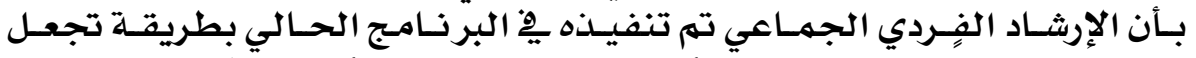

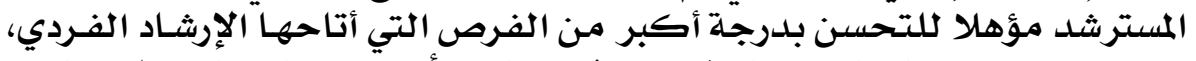

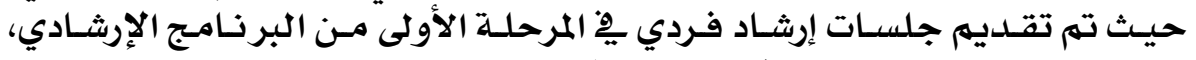

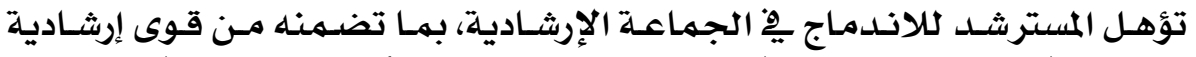

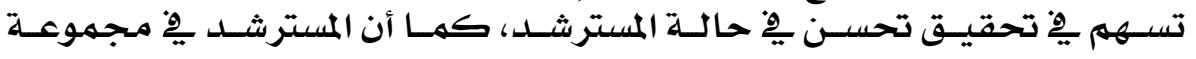

\section{$11 Y$}




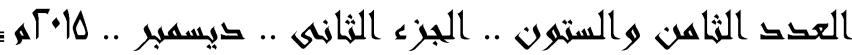

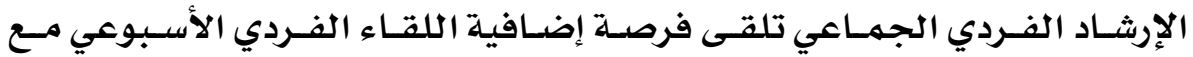

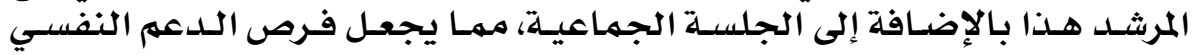

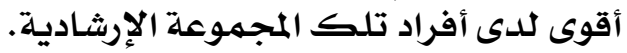

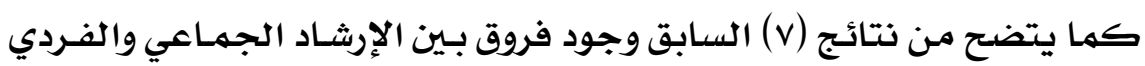

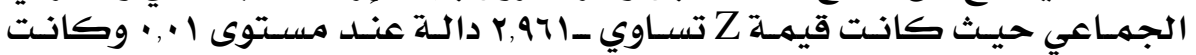

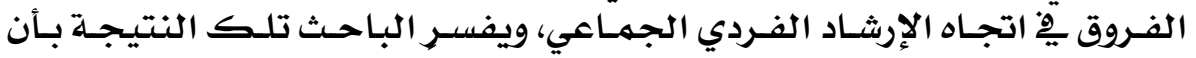

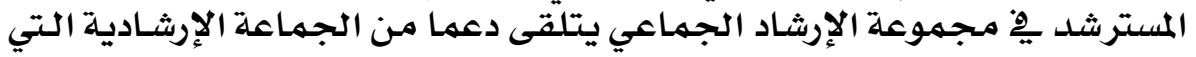

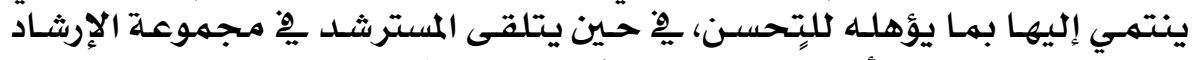

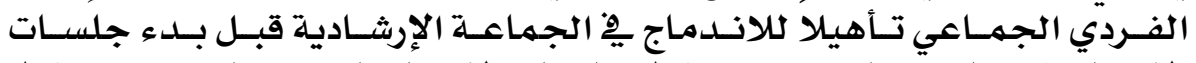

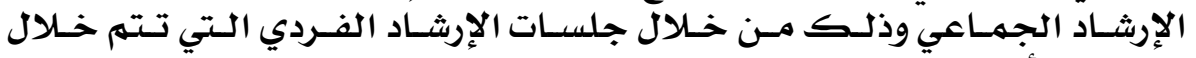

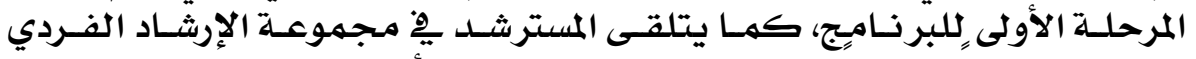

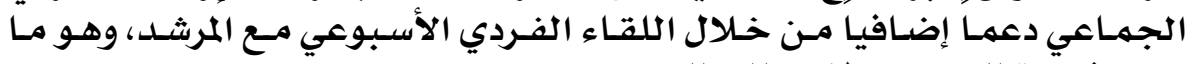

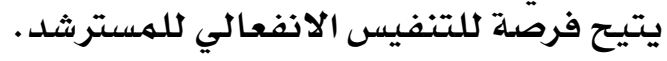

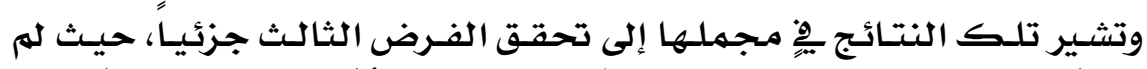

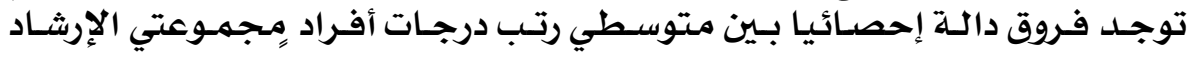

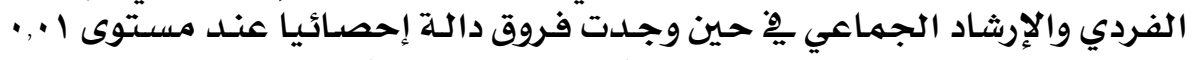

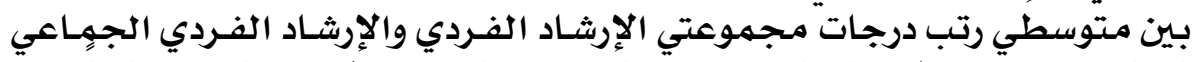

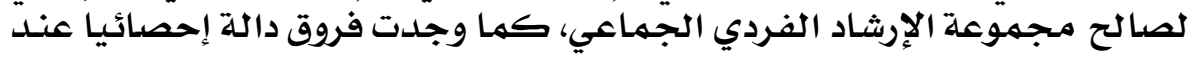

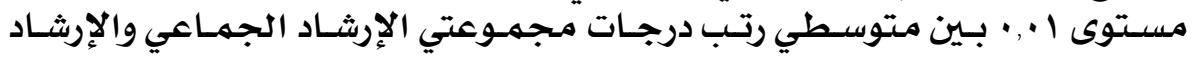

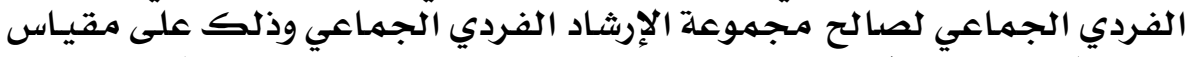

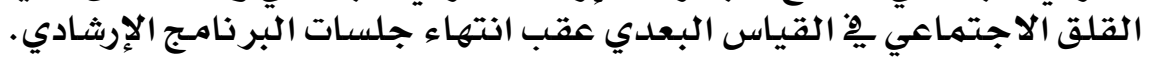

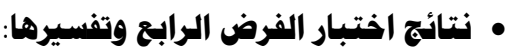

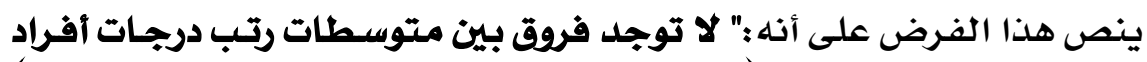

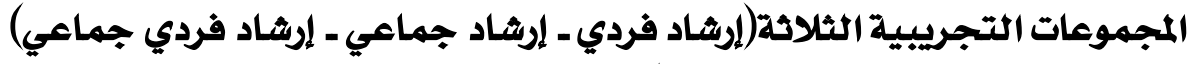

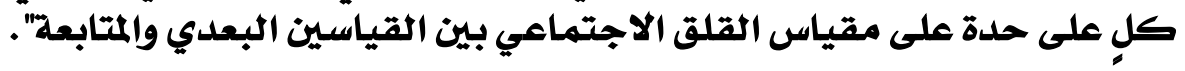

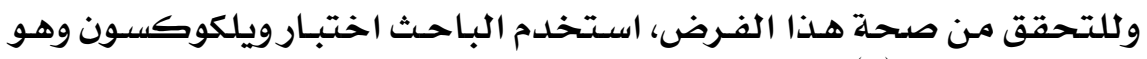

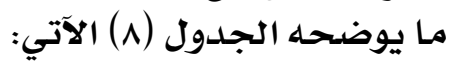

جدول (^) اتجاه الفروق بين متوسطي رتب درجات القياسين البعدي والمتابعة على مقياس القلق القادئ

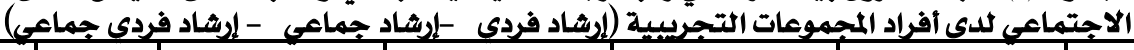

\begin{tabular}{|c|c|c|c|c|c|c|c|c|c|c|}
\hline \multirow{2}{*}{ مستوى الدلالة } & \multirow[b]{2}{*}{ قيمة Z } & \multicolumn{2}{|c|}{ الرتب الموجبة } & \multicolumn{2}{|c|}{ الرتب السـالبـة } & \multicolumn{2}{|c|}{ قياس المتابعـة } & \multicolumn{2}{|c|}{ القياس البعدي } & \multirow{2}{*}{ الإجرشموعادية } \\
\hline & & المجموع & المتوسط & المجموع & المتوسط & انحيراف & متوسط & انحريافي & متوسط & \\
\hline غير دالة & $\cdot, \varepsilon \leqslant V_{-}$ & $7, \cdots$ & $r, \cdots$ & $9, \cdots$ & $r, \cdots$ & $1, .97$ & ro & •, ৭४ץ & ro, 1TV & إرثاد فردي \\
\hline غير دالة & $1, \cdots-$ & r.O. & Y.O. & $\mathrm{v}, \mathrm{O}$. & r.O. & $1, Y \backslash 1$ & ro,rrr & $\cdot, \Lambda I \vee$ & Yo,TTV & جماعى إرثـاد \\
\hline غير دالة & $1, \varepsilon 1\}-$ & صفر & صفر & $r, \cdot \cdot$ & $1,0$. & $\cdot, \varepsilon \cdot \wedge$ & YI,1TV & $\cdot, \wedge r v$ & YI,O. & إرثـاد فردي \\
\hline
\end{tabular}




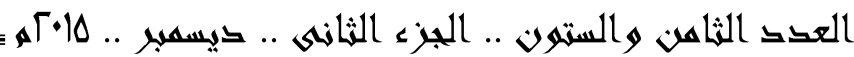

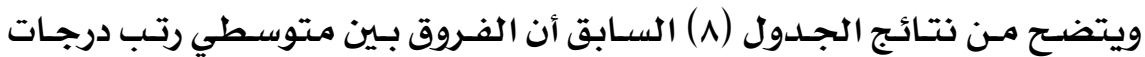

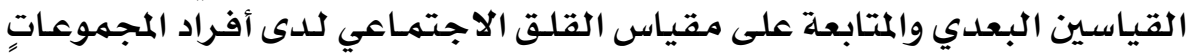

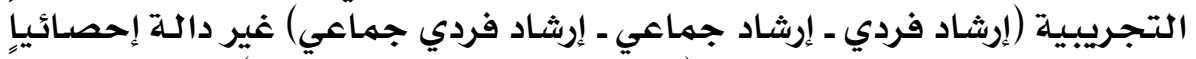

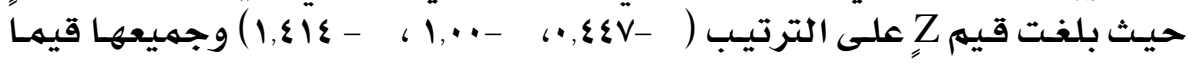

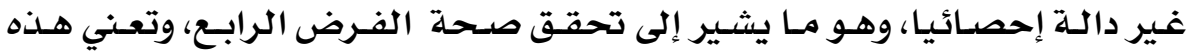

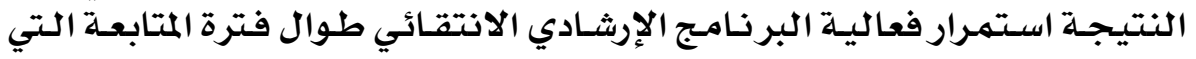

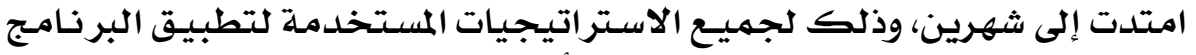

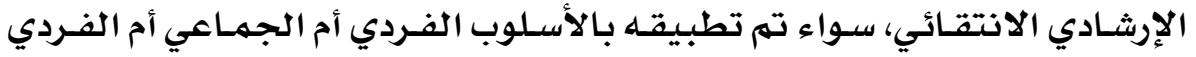
الجماعي.

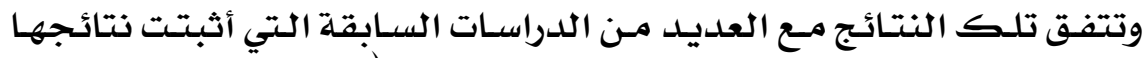

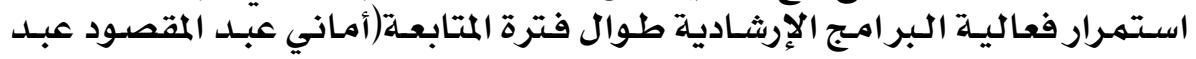

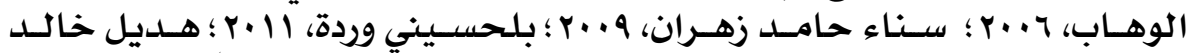

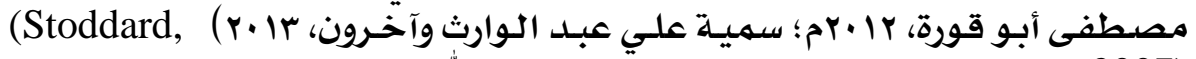

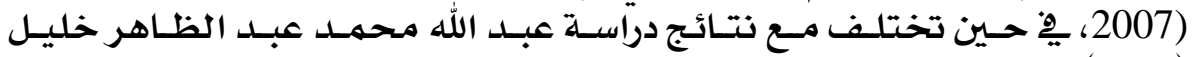

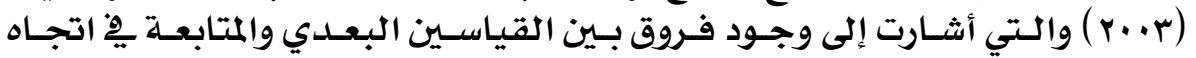

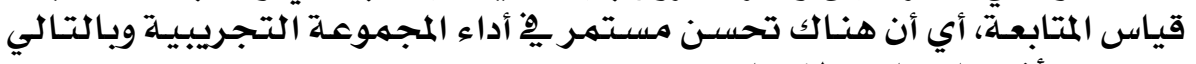

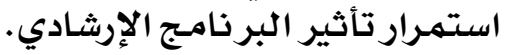

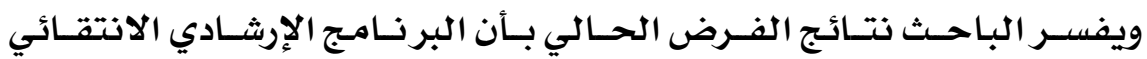

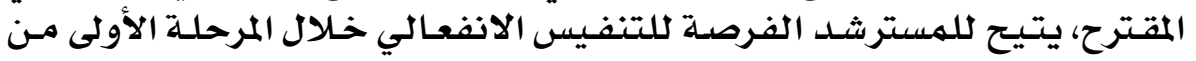

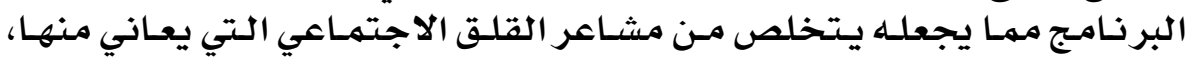

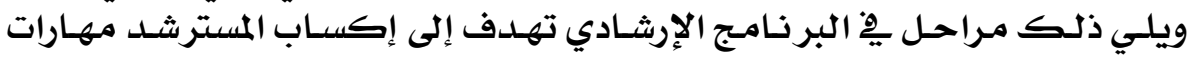

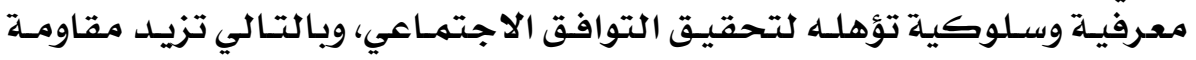

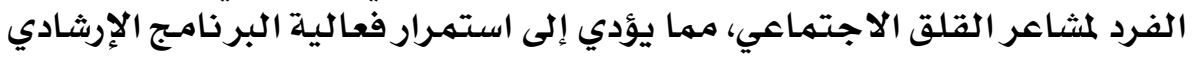

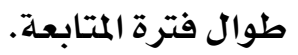

\section{• نتائج اختبار الفرض الخاهس وتفسيرها:}

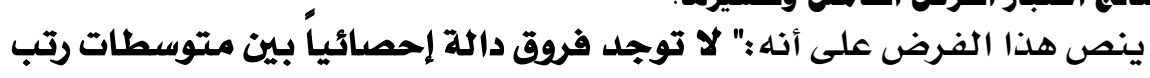

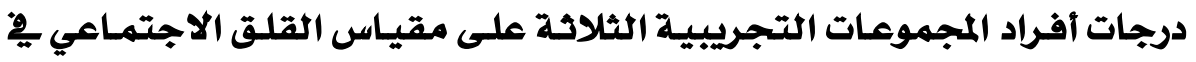

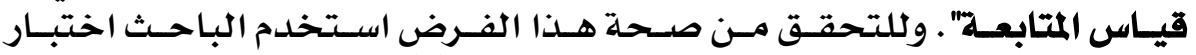

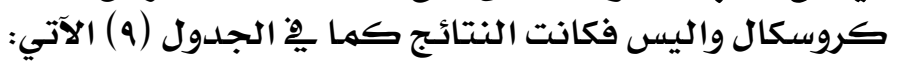

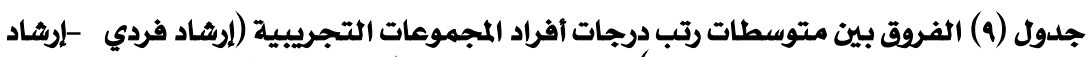

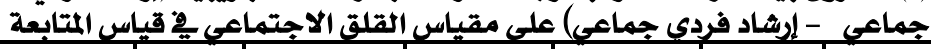

\begin{tabular}{|c|c|c|c|c|c|c|c|}
\hline مستوى & الحرجية & كاי & متوسط & الانحياريى & المتوسط & العدد & الإجشمودية \\
\hline \multirow{3}{*}{$\cdot,+1$} & \multirow{3}{*}{ r } & \multirow{3}{*}{$11,99 \varepsilon$} & $1,, \cdot \cdot$ & $1, .97$ & ro & 7 & إرثاد فردي \\
\hline & & & $1 \mathrm{Ir}, \cdot \cdot$ & $1, Y \backslash 1$ & ro,rrr & 1 & إرشاد جماعي \\
\hline & & & r.o. & $\cdot, \varepsilon \cdot \wedge$ & $r 1,17 \mathrm{~V}$ & 7 & إرشاد فردي جماعي \\
\hline
\end{tabular}

\section{$11 \varepsilon$}




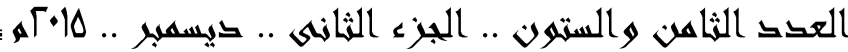

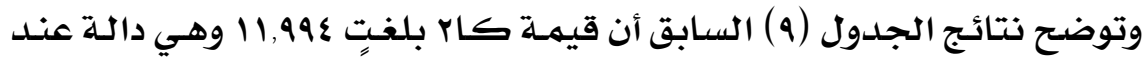

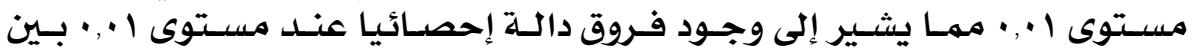

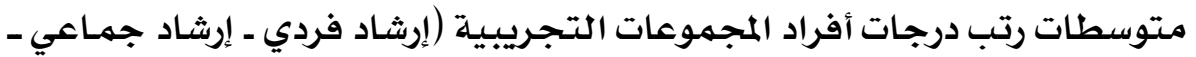

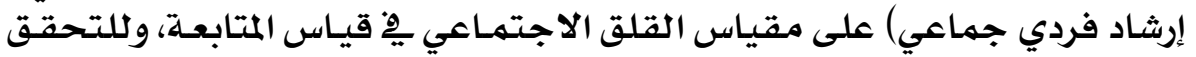

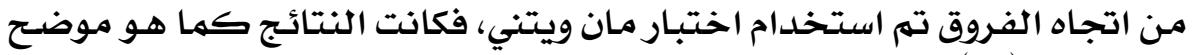

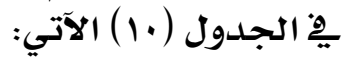

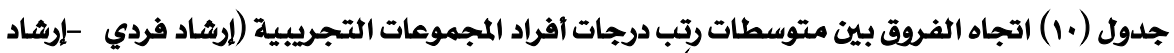

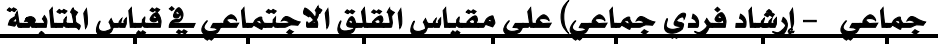

\begin{tabular}{|c|c|c|c|c|c|c|c|c|}
\hline مستولى & قيمة Z & قيمة & قيمة & مجمبوع & متروسط & الانحراف & المتوسط & التجريبية \\
\hline \multirow{2}{*}{ غير } & \multirow{2}{*}{$\cdot, 0 \cdot-$} & \multirow{2}{*}{ rq } & \multirow{2}{*}{10} & rq,.. & $7, \cdot$, & $1, .97$ & ro & إرشاد فردى \\
\hline & & & & $\{r, \cdot \cdot$ & $v, \cdots$ & $1, r \| 1$ & ro,rrr & إرشاد جماعي \\
\hline \multirow[b]{2}{*}{$\cdot, \cdot 1$} & \multirow[b]{2}{*}{$\cdot, r, \cdot \mid V_{-}$} & \multirow[b]{2}{*}{ YI } & \multirow[b]{2}{*}{ صفر } & ov,,$\cdot$ & $9,0$. & $1, .97$ & ro & إرشاد فردي \\
\hline & & & & $r 1, \cdot \cdot$ & r.o. & $\cdot, \varepsilon \cdot \wedge$ & YI,1TV & إرثماد فردي \\
\hline \multirow[b]{2}{*}{$\cdot, \cdot 1$} & \multirow[b]{2}{*}{$r, \cdot \cdot-$} & \multirow[b]{2}{*}{ rI } & \multirow[b]{2}{*}{ صفر } & ov,,$\cdot$ & $9,0$. & $1, Y M 11$ & ro,rrr & إرشاد جماعي \\
\hline & & & & $r 1, \cdot \cdot$ & r,o. & $\cdot, \varepsilon \cdot \Lambda$ & Y $1,17 \mathrm{~V}$ & إرشماد فردي \\
\hline
\end{tabular}

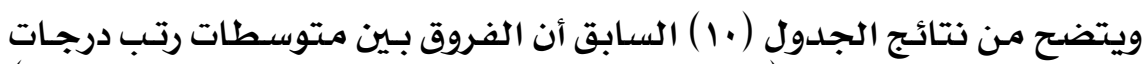

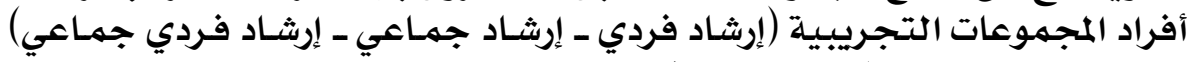

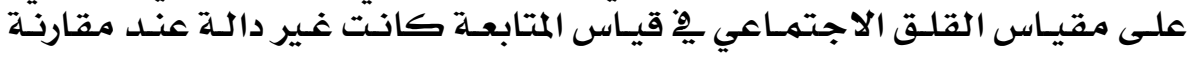

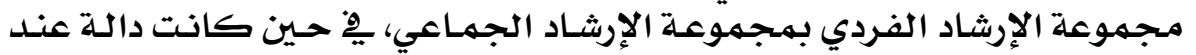

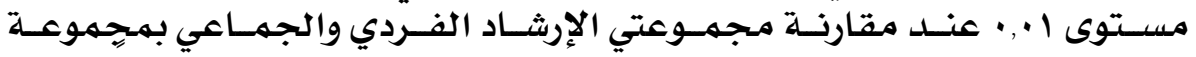

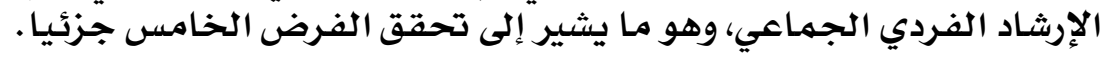

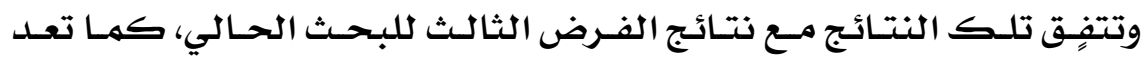

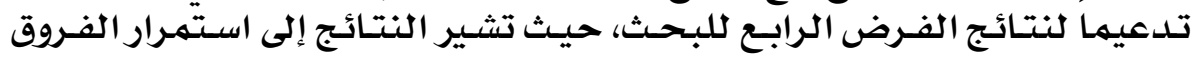

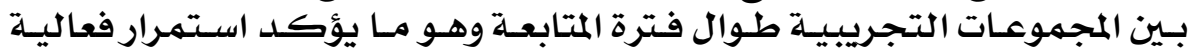

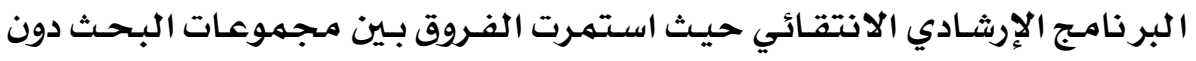
تغيير.

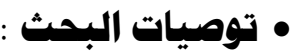

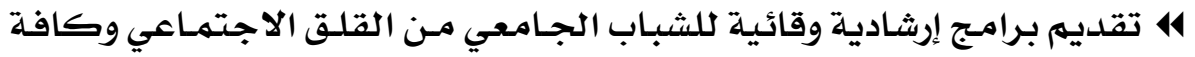

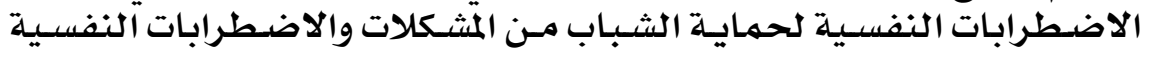

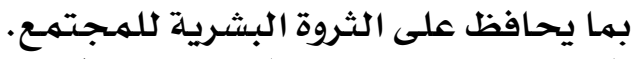

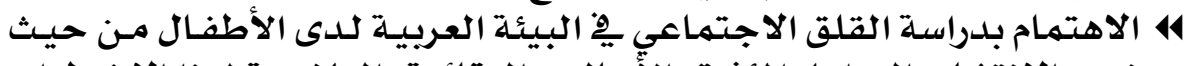

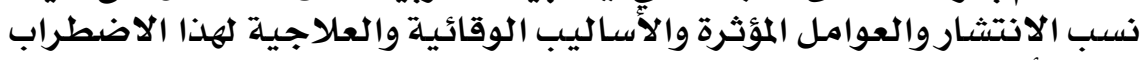

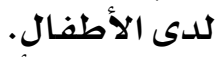

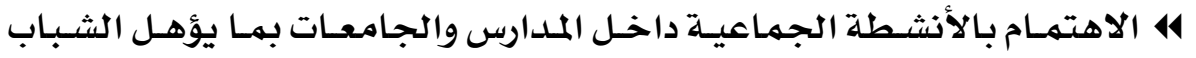

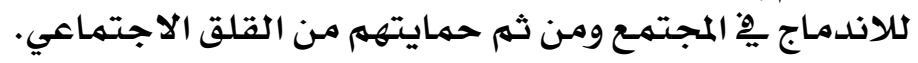

\section{0}




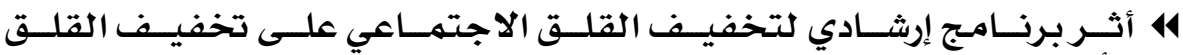

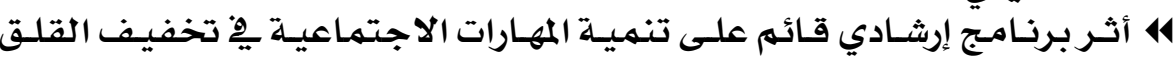

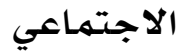

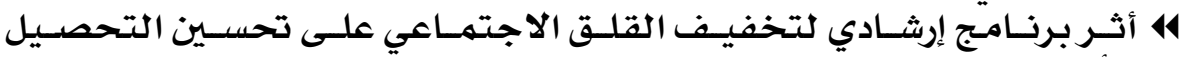

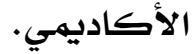

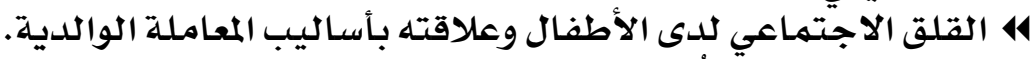

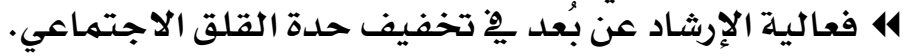

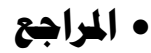

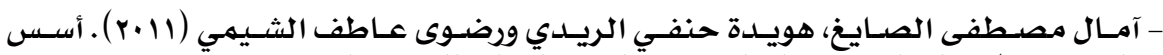

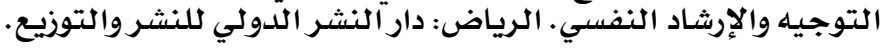

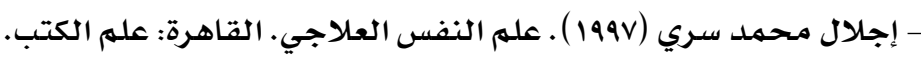

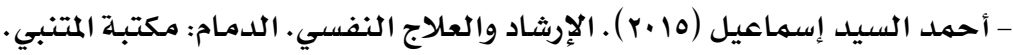

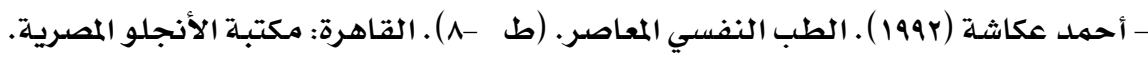

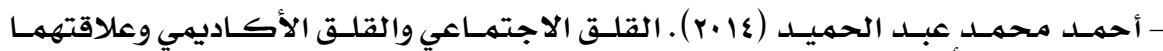

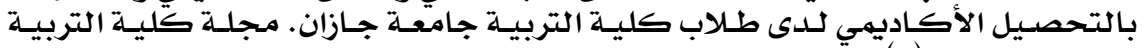

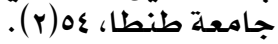

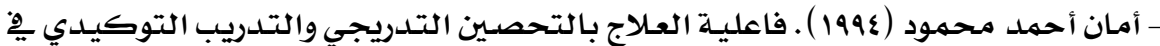

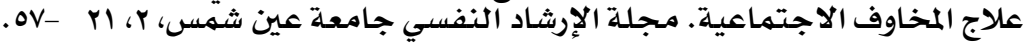

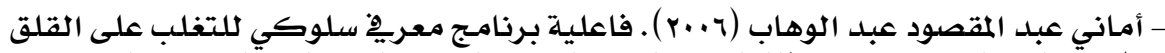

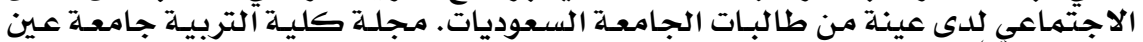

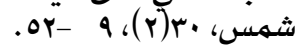

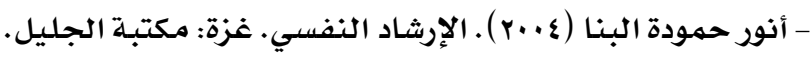

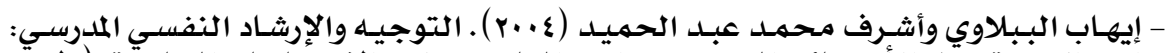

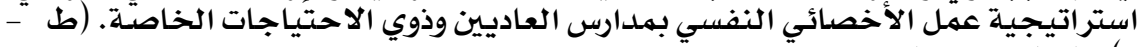

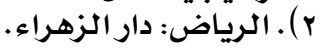

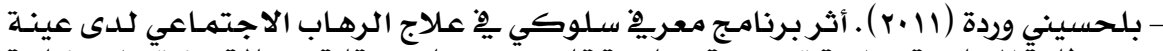

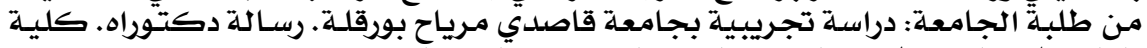

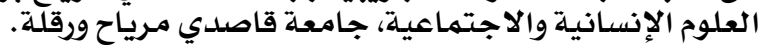

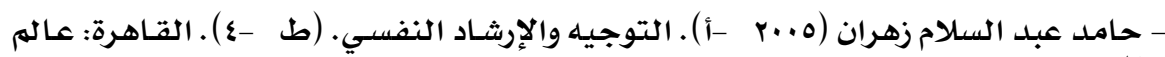

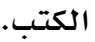

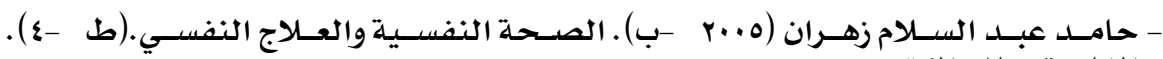

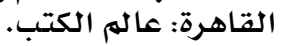

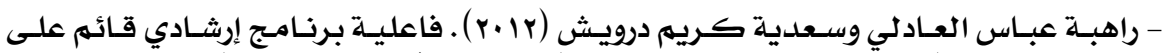

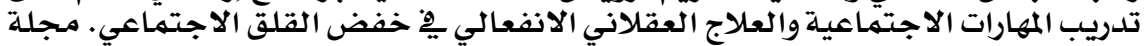

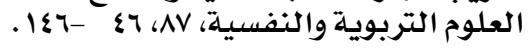

\section{7}




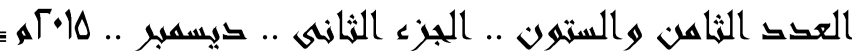

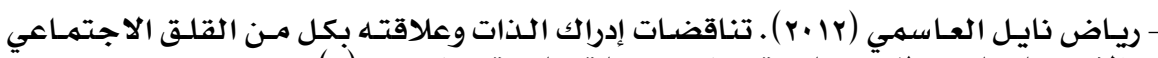

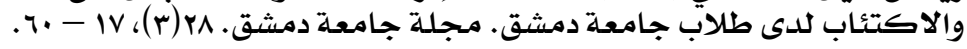

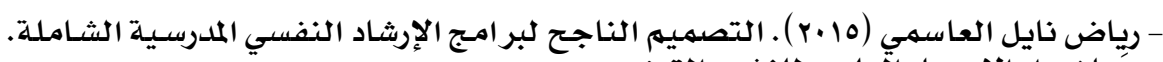

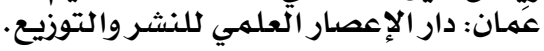

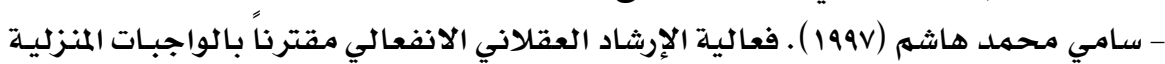

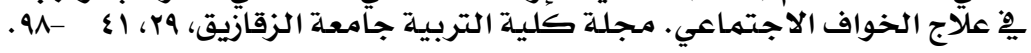

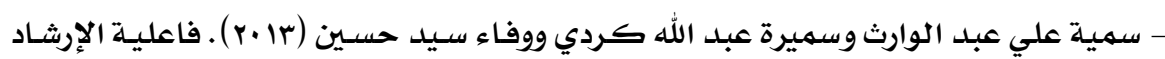

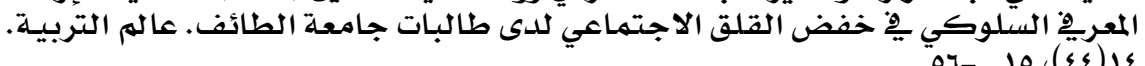

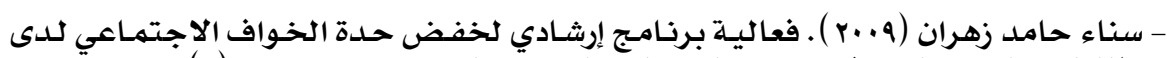

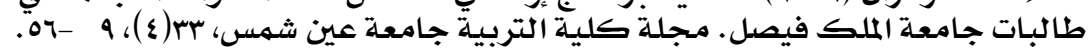

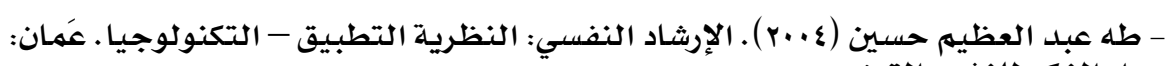
دار الفكر للنشر العظيمالتوزيع.

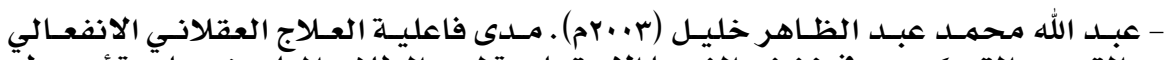

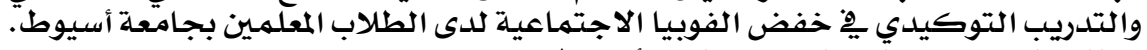

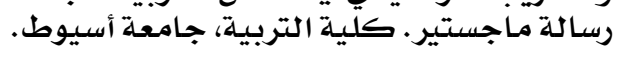

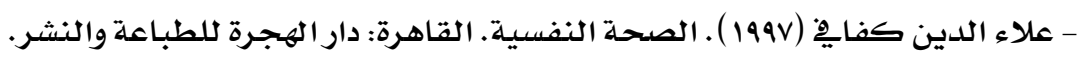

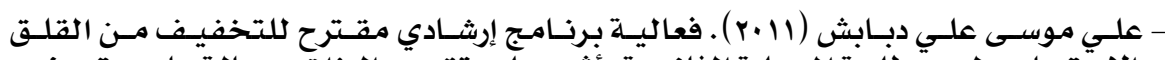

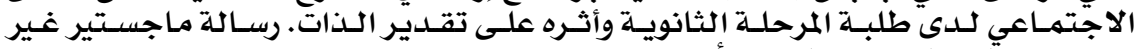

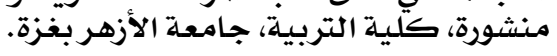

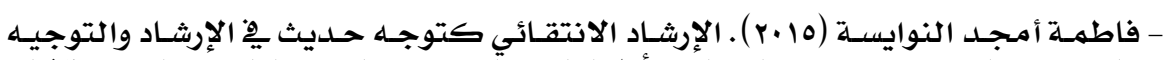

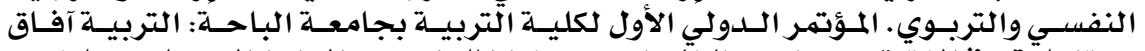

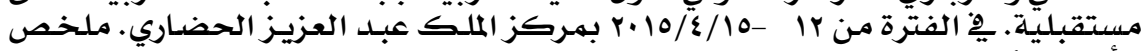
الأبحاث وأوراق العمل.

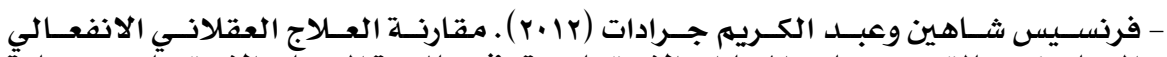

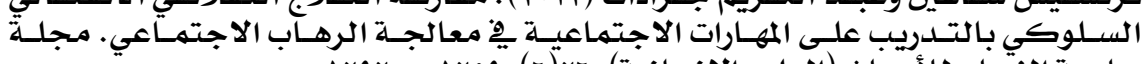

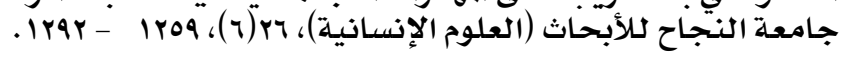

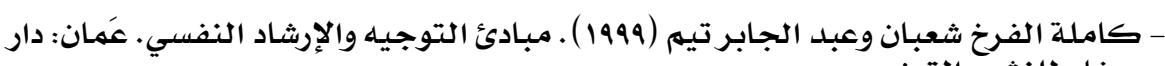
صفاء للنشروالتوزيـع.

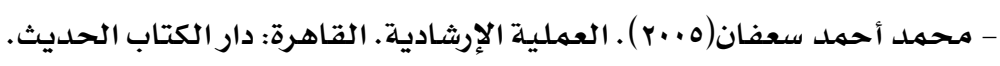

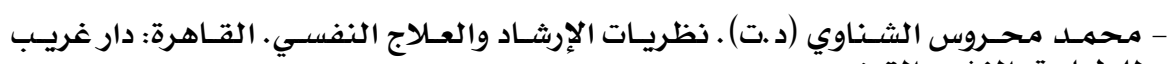
للطباعة والنشروالتوزيـع.

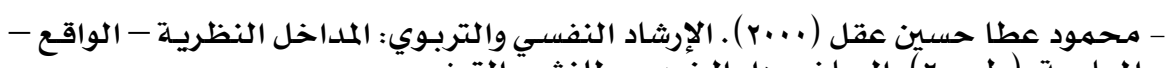

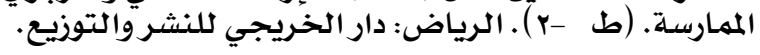

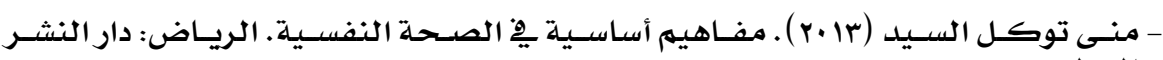

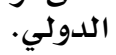

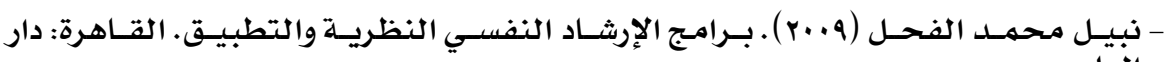
العلوم. 


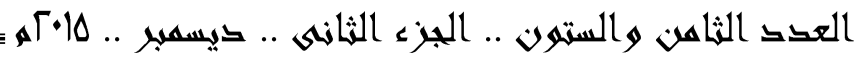

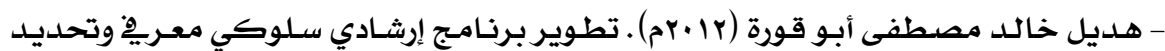

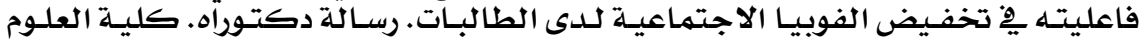

التربوية والنفسية، جامعة عمانية العفيان العربية.

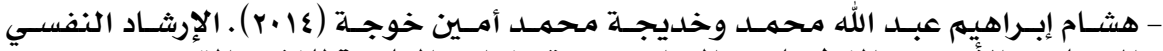

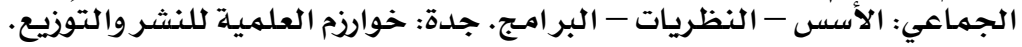

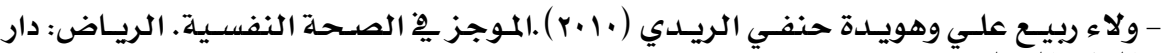

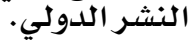

- American Psychiatric Association (1994).Diagnostic and Statistical Manual of Mental Disorders. (4th Ed.).DSM-IV. Washington, Dc: American Psychiatric Association.

- American Psychiatric Association (2013).Diagnostic and Statistical Manual of Mental Disorders. (5th Ed.).DSM-5. Washington, Dc: American Psychiatric Association.

- Asnaani, A.; Rinck, M.; Becker, E. \& Hofmann, S. (2014). The effects of approach- avoidance modification on social anxiety disorder: A pilot study. Cogn Ther Res. 38, 226-238.(Published online: 7 December 2013)

- Baggen, D. \& Kraaimaat, F. (2000). Group social skills training or cognitive group therapy as the clinical treatment of choice for generalized social phobia. Journal of Anxiety Disorders. 14(5), 437-451.

- Beck, A.; Wright, F.; Newman, C. \& Liese, B. (1993). Cognitive Therapy of Substance Abuse. New York: The Guilford Press. Bruch, M. ; Heimberg, R. \& Hope, D. (1991). States of mind model \& cognitive change in treated social phobias. Journal of Cognitive Therapy and Research.15 (6), 429-441.

- Castella, K., Goldin, P. , Jazaieri, H. , Ziv, M. , Heimberg , R. \& Gross, J. (2014).Emotion beliefs in social anxiety disorder: Associations with stress, anxiety, and well-being. Australian Journal of Psychology. 66, 139-148.

- Corey, G.(2009). Theory and Practice of Counseling and Psychotherapy. (8th Ed.). United States: Thomson Brooks/Cole.

- El Alaoui, S, Ljótsson B, Hedman E, KaldoV, Andersson E, Rück C, Andersson, G. \& Lindefors, N. (2015). Predictors of symptomatic change and adherence in internet-based cognitive behaviour therapy for social anxiety disorder in routine psychiatric care. PLoS ONE. 10(4):e0124258.doi:10.1371/journal.

- Fisher, P. ; Masia_Warne, C. \& Klein, R. (2004). Skills for social and academic success: A school_based intervention for social 
anxiety disorder in adolescents. Clinical Child and Family Psychology Review. 7(4), 241-249.

- Geangu, E. \& Reid, V. (2006). What can early social cognition teach us about the development of social anxieties? . Cognition, Brain, Behavior. 10 (4), 543-557.

- Herbert, J.; Rheingold, A. \& Brandsma, L. (2010). Assessment of social anxiety and social phobia. (In). Hofmann, S. \& Dibartolo, P. (Eds.). Social Anxiety: Clinical, Developmental, and Social Perspectives. (2nd Ed.). London: Elsevier. 23-64.

- Huang, X.; Li, C.; Li; W.; Luo, Y.; Wang, B.; Zhang, W.; Gan, J. \& Ji, J. (2013). Clinical evaluation of the efficacy and safety of tandospirone versus sertraline monotherapy for social anxiety disorder: A randomized open-label trial. Human Psychopharmacology Clin. Exp., 28(6), 594-599.

- Kashdan, T. \& Herbert, J. (2001). Social anxiety disorder in childhood and adolescence: Current status and future direction. Clinical Child and Family Psychology Review. 4, 37-61.

- McNeil, D. (2010). Evolution of terminology and constructs in social anxiety and its disorders. (In). Hofmann, S. \& Dibartolo, P. (Eds.). Social Anxiety: Clinical, Developmental, and Social Perspectives. (2nd Ed.). London: Elsevier, 3-21.

- Rachman, S. (1998). Anxiety Psychology. London: Press Ltd.

- Rogers, C. (1976). Client-centered Therapy: Its Current Practice, Implicatons and Theory. London: Contable.

- Sharf, R. (2012). Theories of Psychotherapy and Counseling: Concepts and Cases. (5th Ed.). U.S.A.: Brooks/ Cole, Cengage Learning.

- Stoddard, J. (2007). Development And Single Case Evaluation Of Intensive Cognitive Behavioral Treatment For Social Phobia. Dissertation of Ph. D. Boston University.

- Vassilopoulos, S., Brouzos \& Moberly, N. (2015).The relationships between metacognition, anticipatory processing, and social anxiety. Behaviour Change. 32(2) , 114-126.

- Wersebe, H. ; Sijbrandij, M. \& Cuijpers, P. (2013).Psychological group-treatments of social anxiety disorder: A meta-analysis. PLoS ONE. 8(11). E 79034, doi: 10.1371/ Journal.Pone.0079034. 


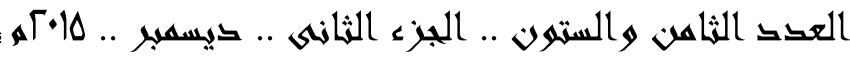

- World Health Organization (2003). The ICD-10 Classification of Mental and Behavioural Disorders: Diagnostic Criteria For Research. Geneva: World Health Organization. (Reprinted in Malta).

- Yalom, I. \& Leszcz, M. (2005). The Theory and Practice of Group Psychtherapy. (5th Ed.). New York: Basic Books.

溇潾溇潾溇 